\title{
The Effects of Age and Sex on Mental Rotation Performance, Verbal Performance, and Brain Electrical Activity
}

\author{
Jonathan E. Roberts
}

Dissertation submitted to the faculty of Virginia Polytechnic Institute and State

\author{
University \\ in partial fulfillment of the requirements for the degree of \\ Doctor of Philosophy \\ in \\ Psychology
}

\author{
Martha Ann Bell, Ph.D., Chair \\ Robin Panneton Cooper, Ph.D. \\ Bruce H. Friedman, Ph.D. \\ Joseph J. Franchina, Ph.D. \\ Neil M. A. Hauenstein, Ph.D.
}

March, 2001

Blacksburg, VA

Key Words: Sex Differences, EEG, Mental Rotation, Verbal Fluency 


\section{THE EFFECTS OF AGE AND SEX ON MENTAL ROTATION PERFORMANCE, VERBAL PERFORMANCE, AND BRAIN ELECTRICAL ACTIVITY}

By Jonathan E. Roberts

Martha Ann Bell, Ph.D., Chair

Psychology

(ABSTRACT)

In adult populations, it is generally accepted there is an overall male advantage on spatial tasks and an overall female advantage on verbal tasks. These differences are inconsistent in children. The present study examined relations among age, sex, EEG hemispheric activation, and performance on spatial and verbal tasks. Thirty-two eight-year-olds (16 boys) and 32 college students (16 men) had EEG recorded at baseline and while performing a computerized 2-dimensional Gingerbread Man mental rotation task, a computerized 2-dimensional Alphanumeric mental rotation task, a computerized 3dimensional Basketball Player mental rotation task, and a computerized Lexical Decision-Making task. Additionally, participants completed a paper-and-pencil Water Level task and an oral Verbal Fluency task. On the 2-dimensional Alphanumeric and 3dimensional Basketball Player mental rotation tasks men performed better than boys, but the performance of women and girls did not differ. On the Lexical Decision-Making and Water level tasks, men performed better than women, while there was no difference between boys and girls. No sex differences were found on the 2-dimensional Gingerbread Man mental rotation task or Verbal Fluency task. Analyses of task-related data also indicate that computer familiarization or computer related task demands might contribute to sex differences on computerized tasks. EEG analyses indicated that, on the 2-dimensional Alphanumeric mental rotation task, men exhibited more left posterior temporal activation than women, while there were no differences between boys and girls. Additionally, there was evidence that simple, or 2-dimensional, mental rotation tasks are associated with left posterior brain activation, while 3-dimensional mental rotation tasks are associated with right posterior brain activation. On the 2-dimensional Gingerbread Man mental rotation task, males exhibited more activation of the left parietal area than females, while on the 2-dimensional Alphanumeric mental rotation task, men exhibited more activation of the left posterior temporal area than women. On the 3-dimensional Basketball player mental rotation task, all participants exhibited greater activation of the right parietal area than the left parietal area. 


\section{ACKNOWLEDGEMENTS}

As my graduate career comes to a close I have many people to thank. First and foremost, I would like to thank my advisor, Dr. Martha Ann Bell. Her continued support and advice as I made my way through the program were most helpful and greatly appreciated. Additionally, I would like to thank my committee members: Dr. Robin Panneton Cooper, Dr. Bruce H. Friedman, Dr. Joseph J. Franchina, and Dr. Neil M. A. Hauenstein. Their support, insight, and suggestions have made for a more polished product and I have appreciated their interest in my professional development.

I also don't want to forget the numerous undergraduate researchers who helped me by giving me their time and effort. Specifically, I appreciated the help of Ian Reed and Ian Ehrhart, who contributed to my efforts by assisting me in developing the computer programs, data collection, and data entry. Finally, I wish to thank my family and friends, who have always continued to support me in my endeavors. 


\section{TABLE OF CONTENTS}

Abstract $\quad$ i

Acknowledgements $\quad$ ii

Table of Contents iii

Introduction and Literature Review 1

Introduction to EEG 6

Mental Rotation: Brain Localization 6

Verbal Fluency and Lexical Decision-Making: Brain Localization 8

EEG Age and Sex Interactions 9

$\begin{array}{ll}\text { Purpose and Hypotheses } & 10\end{array}$

Behavior 11

Baseline EEG $\quad 11$

Task EEG 12

$\begin{array}{ll}\text { Method } & 13\end{array}$

$\begin{array}{ll}\text { Participants } & 13\end{array}$

8-year-olds. 13

College students $\quad 13$

$\begin{array}{ll}\text { Procedure } & 13\end{array}$

EEG Recording 14

EEG Analysis $\quad 15$

Computerized Tasks $\quad 16$

2-dimensional “Gingerbread Man” Mental Rotation Task 16

2-dimensional Alphanumeric Mental Rotation Task 17

3-dimensional "Basketball Player" Mental Rotation Task 18

Lexical Decision-Making Task 19

Reading Task 20

Non Computerized Tasks $\quad 20$

Water Level Task 20

Verbal Fluency Task $\quad 21$

Results 21

Behavior 21

2-Dimensional "Gingerbread Man” Mental Rotation, $\quad 21$

2-Dimensional Alphanumeric Mental Rotation,

3-Dimensional "Basketball Player" Mental Rotation, and Water Level Tasks

Lexical Decision-Making and Verbal Fluency Tasks 24

EEG Activity 26

Baseline EEG 26

Task EEG Covaried for Baseline EEG 28

2-Dimensional “Gingerbread Man” Mental Rotation 30

and 2-Dimensional Alphanumeric Mental Rotation Tasks

3-Dimensional "Basketball Player" Mental Rotation 31

Lexical Decision-Making Task 32

Reading Task 33 
$\begin{array}{ll}\text { Discussion } & 33\end{array}$

$\begin{array}{ll}\text { Behavior } & 33\end{array}$

Mental Rotation and Water Level Tasks $\quad 34$

Lexical Decision-Making and Verbal Fluency Tasks $\quad 35$

$\begin{array}{ll}\text { Baseline EEG } & 36\end{array}$

$\begin{array}{ll}\text { Task EEG } & 37\end{array}$

2-Dimensional Gingerbread Man Task $\quad 37$

2-Dimensional Alphanumeric Task $\quad 37$

3-Dimensional Basketball Player Task $\quad 38$

Lexical Decision-Making Task 38

$\begin{array}{ll}\text { General Conclusions } & 39\end{array}$

Computer Familiarization Effects $\quad 39$

Overall Findings $\quad 39$

2-Dimensional vs. 3-Dimensional Rotations $\quad 41$

Future Research 41

References $\quad 43$

Tables $\quad 51$

$\begin{array}{ll}\text { Figures } & 61\end{array}$

$\begin{array}{ll}\text { Appendices } & 93\end{array}$

$\begin{array}{ll}\text { Vita } & 140\end{array}$ 


\section{The Effects of Age and Sex on Mental Rotation Performance, Verbal Performance, and Brain Electrical Activity}

Since the seminal publication The Psychology of Sex Differences by Maccoby and Jacklin (1974), the existence of sex differences on cognitive tasks has been staunchly debated. These authors stated that there are sex differences on spatial and verbal tasks. In the case of spatial differences, Maccoby and Jacklin suggested that there were no sex differences until adolescence, whereupon boys gained an advantage that continued through adulthood. In the case of verbal differences, Maccoby and Jacklin suggested that before approximately three years of age girls developed more quickly than boys and had superior verbal skills. From three years until adolescence, boys caught up and there were no sex differences, and then from adolescence into adulthood females again were superior to males. Soon after the Maccoby and Jacklin publication, many studies were published both supporting and rejecting the existence of these differences. However, the results of recent meta-analyses have documented that, in adult populations, there is an overall male advantage on spatial tasks and an overall female advantage on verbal tasks (Hyde \& Linn, 1988; Linn \& Petersen, 1985; Voyer, Voyer, \& Bryden, 1995). Research using mental rotation tasks and electrophysiological measures have reported that there are brain activation differences between men and women, but not boys and girls, during task performance (Roberts \& Bell, 2000b). The purpose of this study was to examine the relations among spatial ability, verbal ability, and EEG activity in children and college students. This study was conducted from an information processing perspective, which assumes that differences in cognition between children and adults are quantitative in nature.

Spatial ability can be generally defined as the skills of generating, transforming, representing, and recalling symbolic, nonlinguistic information (Linn \& Petersen, 1985). Although there are numerous individual tasks used to test spatial ability, meta-analyses have concluded that two types of spatial tasks show the most reliable male advantage: mental rotation tasks and spatial perception tasks (Linn \& 
Petersen, 1985; Voyer et al., 1995). Mental rotation tasks are broadly characterized as exercises that require the mental repositioning of a 2- or 3-dimensional object. Specifically, participants are typically presented with an object that is to be turned in the imagination and matched with one of two or more choices. Spatial Perception tasks require participants to determine spatial relationships despite distracting information. The classic example of a spatial perception task is Piaget and Inhelder's (1956) Water Level Task (WLT), which requires participants to draw a water line in a glass that is tilted to various degrees. In adult populations (over the age of 18), the effect sizes for sex differences on tasks of mental rotation (d $=0.66$; Voyer et al., 1995) and spatial perception $(\mathrm{d}=0.48$; Voyer et al., 1995) are considered the most robust and consistent. According to Cohen's (1977) guidelines, these effect sizes are considered to be medium.

Among boys and girls, however, sex differences on such tasks have been less consistently found (Voyer et al., 1995). In the Voyer et al. study, the effect size was calculated for children under the age of 13 (mental rotation, $\mathrm{d}=0.33$; spatial perception, $\mathrm{d}=0.33$ ). According to Cohen's (1977) guidelines, these effects are small. Because children's effect sizes are considerably smaller than those of adults, these data suggest that sex differences on spatial tasks are more reliable in adults.

At least two recent studies in the area of mental rotation support the notion that sex differences are present in adults but not present in children. In a study using the hand mental rotation task with 9year-olds and college age students, sex differences were found in the college age students but not in the 9year-olds (Karaldi, Szabo, Szepesi, Kallai, \& Kovacs, 1999). Roberts and Bell (2000b) found a sex difference in college students, but not 8-year-olds, using a 2-dimensional mental rotation task. In contrast, a recent study measuring children's Water Level task performance longitudinally from 8 to 16 years of age found no sex differences in performance (Thomas, Lohaus, \& Kessler, 1999). In view of the sample size of over 400 participants, the lack of a sex difference in the older age groups is surprising, and does not support previous literature. 
In terms of its effect on future research, one possible effect of the meta-analyses on spatial ability has been to greatly reduce the number of behavioral studies examining sex differences on spatial tasks (Linn \& Petersen, 1985; Voyer et al., 1995). In contrast, much of the current research examining mental rotation and spatial perception assumes a sex difference in adults, and follows along two lines. First, some researchers are interested in determining ways to "tweak" the tasks to either eradicate or amplify the sex differences (e.g., Levin, Huttenlocher, Taylor, \& Langrock, 1999; Roberts \& Bell, 2000a; Saccuzzo, Craig, Johnson, \& Larson, 1996, Schaeffer \& Thomas, 1998). A second line of research is concerned with determining brain or hormonal differences that may accompany the sex differences (e.g., Cohen et al., 1996; Roberts \& Bell, 2000b; Slabbekoorn, Van Goozen, Megens, Gooren, \& Cohen-Kettenis, 1999; Van Tagaris et al., 1998; Van Goozen, Cohen-Kettenis, Gooren, Fridja, \& Van de Poll, 1994,1995; Wegesin, 1998a).

Verbal ability has also been studied using many different types of tasks. Meta-analyses have concluded that the area of verbal ability with the greatest female advantage is that of speech production (Hyde \& Linn, 1988). One specific task in the speech production category is the verbal fluency task, in which participants are required to produce words that belong to a specific category in a specific time period. For example, participants may be asked to produce as many words as possible starting with the letter " $\mathrm{S}$ " in a 60-second time period. Another method to assess speech production is the Lexical Decision-Making task, in which participants are asked to look at a group of letters and determine if the group is a word. For example, "roop" and "room" may be presented, and the participant is required to determine which of the two is actually a word. Sex differences in speech production are the most documented female advantage sex difference, and Hyde and Linn (1988) concluded that the effects sizes were larger for adults over 19 years of age $(d=0.45)$ than when children and adults were combined $(d=$ 0.33). Again, this suggests that the sex difference is more reliable in adult populations.

In one of the only studies measuring the development of verbal fluency longitudinally, Hassler (1991) followed a group of students from roughly 11 to 17 years of age. In the first six time measures 
(ages 11-16) there were no statistical differences between girls and boys on a test of verbal fluency, although the girls' mean was greater than the boys' mean from ages 12 to 16 . However, in the last age tested (17 years of age), the differences reached significance and females outperformed males on the verbal fluency task. In a recent study investigating adult sex differences on a lexical decision-making task, Wegesin (1998a) found that heterosexual females outperformed heterosexual males. Similar to the study of sex differences on spatial tasks, one possible effect of the meta-analysis on verbal ability (Hyde \& Linn, 1988) has been to greatly reduce the number of behavioral studies examining sex differences on verbal tasks. In contrast, much of the current research investigating verbal fluency and lexical decisionmaking either examines ways to "tweak" the tasks to explode or eliminate differences (e.g., Capitani, Laiacona, \& Barbarotto, 1999; Laws, 1999), or is concerned with determining brain or hormonal differences that may accompany the sex differences (e.g., Cardebat et al., 1996; Hoptman \& Davidson, 1998; Phelps, Hyder, Blamire, \& Shulman, 1997; Rumsey, et al., 1997; Schlosser et al., 1998; Wegesin, 1998b).

It may be that performance on tasks of spatial ability and verbal fluency is influenced by hormonal influx. In a compelling series of studies by Van Goozen and colleagues (Slabbekoorn et al., 1999; Van Goozen et al, 1994,1995) groups of male-to-female and female-to-male transsexuals were studied before and after hormone therapy. The male-to-female group showed enhanced performance on verbal fluency and deteriorated performance on spatial tasks after treatment, while the female-to-male group's performance showed deteriorated performance on tasks of verbal fluency and enhanced performance on spatial tasks after treatment. This line of research is particularly compelling in a developmental sense, because it may be that the hormonal influx of puberty is associated with sex differences on these types of tasks, and this could play into the explanation of why sex differences are more reliable in adults than in children. However, in order to test this hypothesis experimentally, the measurement of hormones would be necessary. (For a more detailed discussion of hormonal influences on spatial ability see Appendix A.) 
Newcombe and her colleagues, who argue that these differences are driven by an individual's experience within the environment, have proposed another explanation of the sex differences found on spatial tasks. A spatial experience questionnaire found that male college students participated in more spatially related tasks than did the female college students (Newcombe, Bandura, \& Taylor, 1983). Furthermore, a meta-analysis found a reliable relation between spatial activity participation and spatial ability, such that participation in spatial activities was positively correlated with spatial ability among both males and females (Baenninger \& Newcombe, 1989). However, Baenninger and Newcombe (1989) conceded that, for both sexes, all of the effect sizes were small, with spatial experience only accounting for about a $9 \%$ improvement rate on test scores.

For both verbal and spatial abilities, it is probably the case that both biological and experiential factors contribute to the sex differences. However, it is interesting to note that in a recent review of sex differences in the non-human primate literature, sex differences in human spatial ability were paralleled in non-human primates, suggesting that underlying biological mechanisms may play a critical role in the development of sex differences (Kimura, 1999).

Because sex differences on mental rotation and verbal fluency appear to develop between childhood and adulthood, an interesting avenue of exploration is to examine possible differences in brain activity that may accompany the sex differences in behavior. For instance, if we know that adults exhibit a sex difference on a specific task, and also have accompanying differences in brain activity during task performance, while children exhibit neither the sex difference nor the brain activity difference, then an interesting line of research would be to see at what point the sex difference and the accompanying brain differences emerge. However, there are no studies in the literature examining sex differences and accompanying differences in brain activity using both children and adults and both spatial and verbal tasks. 
Introduction to EEG

A non-invasive way of localizing brain function is with the use of the electroencephalogram (EEG). Typically, adult EEG recordings made in a state of cognitive functioning exhibit reduced alpha power values at the scalp recording site associated with the area of the brain most involved in the task. This is sometimes referred to as alpha suppression, and is considered to exemplify activation of that particular brain area. When recording EEG data, alpha is EEG activity between $8-13 \mathrm{~Hz}$ and is the classic band associated with cognitive functioning in adults (Hugdahl, 1995). For instance, if alpha suppression were seen in the scalp electrodes associated with the right parietal cortex during mental rotation tasks, researchers would interpret the data to indicate right parietal activation (alpha suppression), meaning that the right parietal area is involved in mental rotation performance.

\section{Mental Rotation: Brain Localization}

Researchers using EEG procedures, as well as other brain measures have found activation of the right parietal lobe during complex spatial tasks. In a study by Davidson, Chapman, Chapman, and Henriques (1990), psychometrically matched verbal and spatial cognitive tasks were compared. In a group of college students, the verbal task produced relatively more left central 8-13 Hz EEG alpha suppression (indicating more left central activation) than right central suppression, while the spatial task produced relatively more right parietal 8-13 Hz EEG suppression (indicating more right parietal activation) than left parietal suppression. In a study using the dual measures of EEG evoked potentials (EPs) and regional cerebral blood flow $(\mathrm{rCBF})$, mental rotation task performance was associated with greater activation in the right parietal than the left parietal regions (Papanicolaou, et al., 1987). Michel, Kaufman, and Williamson (1994) found that alpha suppression increased with angle in a mental rotation task. In this task, subjects were asked if an abstract probe figure was the same as a memory figure that was presented earlier at a different orientation. As the angle of the figure rotated further from the original position, there was an increase in alpha suppression, as well as an increase in reaction time. In a study using a functional magnetic resonance imaging procedure (fMRI), brain functioning was compared while 
participants were determining if two figures were the same (Cohen et al., 1996). The figures were in either a rotation or a non-rotation condition, allowing for the use of a subtraction technique. Using this procedure, it was concluded that the areas most activated during the rotation condition (as compared to the non-rotation condition) were the superior parietal and frontal eye field areas. Likewise, a different fMRI study found that both the left and right precentral gyrus, as well as the right superior parietal lobule, were the areas most activated in a mental rotation task (Tagaris et al., 1998).

However, there is in the literature a suggestion that rotation of simple stimuli can lead to activation of the left parietal area. In a PET study performed by Alivisatos and Petrides (1997), participants were required to discriminate whether alphanumeric stimuli were "normal" or "mirror image" at various angles. While the task required mental rotation, the stimuli were simple alphanumeric stimuli, resulting in a "simpler" 2-dimensional rotation task. The task elicited activation of the left parietal and right frontal areas. Likewise, a left hemisphere advantage for the rotation of both alphanumeric characters and figures from the Primary Mental Abilities test has been found (Fischer \& Pellegrino, 1988). Finally, Roberts and Bell (2000b) found left parietal and posterior temporal activation in adult males, but not adult females, using a 2-dimensional rotation task. Because adult males also performed better on the 2-dimensional task, it was hypothesized that the task was more difficult for the females because of their greater relative right activation, which may be indicative of a more difficult rotation. The rotations in each of these studies (Alivisatos \& Petrides, 1997; Fischer \& Pellegrino, 1988; Roberts \& Bell, 2000b) are considered "simple" because they consisted of simple figures (alphanumeric characters or line drawings) rotated 2-dimensionally (only on one axis). In contrast, most of the literature using 3dimensional rotations has consisted of more complicated 3-dimensional block drawings rotated 3dimensionally (on more than one axis). Therefore, it could be the case that simple rotations lead to activation of the left parietal area, while more complex rotations lead to activation of the right parietal area. In the literature, however, there are currently no studies that have tested this hypothesis. 
Despite these general findings of activation of the parietal area during spatial tasks, there is some evidence that EEG activation may also be moderated by sex. Ray, Newcombe, Semon, and Cole (1981) reported that high spatial ability among males was associated with greater relative right parietal alpha suppression during a spatial task than during baseline. Ray et al. also reported that among low spatial ability males there was greater left parietal alpha suppression, while there was no systematic suppression patterns among either high or low spatial ability females during spatial tasks. This suggested that mastery of the task is associated with right parietal alpha suppression, but only in males. Results of greater right parietal alpha suppression by high ability males during spatial tasks were replicated by Berfield, Ray, and Newcombe (1986), who likewise found no consistent relations among either high or low ability females and right or left alpha suppression during the spatial tasks. In another study, Corsi-Cabrera, Ramos, Guevara, Arce, \& Gutierrez, (1993) found alpha suppression for males, but not for females, during a spatial task. These EEG data suggest that males and females have electrophysiological differences in their processing of spatial material.

Verbal Fluency and Lexical Decision-Making: Brain Localization

While there is a great deal of literature relating performance on mental rotation tasks to brain areas using EEG measures, the literature relating verbal fluency and lexical decision-making to brain areas using EEG measures is sparse. Hoptman and Davidson (1998) conducted a study relating baseline EEG asymmetries to performance on a verbal fluency. In this study, EEG was recorded in a baseline state, and then participants completed a word fluency task. Participants who exhibited greater left central activation at a baseline state performed at a higher level on the word fluency task. Using a PET procedure, Boivin et al. (1992) found that higher performance on a verbal fluency task was related to higher baseline metabolic activity in left temporal region, and lower baseline metabolic activity in both right and left frontal regions. Boivin et al. suggested that lower baseline metabolic activity may be related to cognitive efficiency, allowing those participants with more efficient frontal areas to perform at a higher level on the verbal fluency task. Finally, using an fMRI procedure, Schlosser et al. (1998) found that 
participants demonstrated an increase of activation in the left prefrontal cortex during a verbal fluency task. Taken together, the literature suggests that the left frontal and central regions are involved in verbal fluency.

It also appears that lexical decision-making may also be largely lateralized to the left side of the brain. Using a PET procedure, Rumsey et al. (1997) found that during a lexical decision-making task participants had increased activation of the left frontal region, the left cingulate, as well as bilateral activation of the parietal region. In a different study, Wegesin (1998a) examined sex differences in cognitive processing using a lexical decision-making and semantic monitoring (LD/SM) task while recording ERP's. During LD/SM task participants watched a computer screen as different words were presented, and the participants were required to detect the presence of pseudowords among the "real" words. In this task, females performed better than males, and there were also sex differences in the N400 component, with men exhibiting greater asymmetry when the target was presented in the left visual field. Finally, reading (which is an important component of lexical decision-making) is generally considered to be a left hemisphere task, a finding that has also been substantiated in the literature (e.g., Kraft, Mitchell, Lagguis, \& Wheatley, 1980; Mattson, Sheer, \& Fletcher, 1992).

\section{$\underline{\text { EEG Age and Sex Interactions }}$}

Longitudinal and cross-sectional studies examining the relationship between age, sex, and EEG power values indicate several types of findings. First, there is a general finding that interindividual variability in EEG recordings is much greater in children than in adults (Benninger, Matthis, \& Scheffner, 1984; Gasser, Verleger, Bacher, \& Sroka, 1988; Matsuura et al., 1985). This is probably due to individual differences in maturation rates. Next, women tend to exhibit greater overall EEG alpha power than men both during baseline measures and during performance of different types of tasks (Benninger et al., 1984; Gasser et al., 1988; Matsuura et al., 1985). Such findings have been replicated in studies dealing with mental rotation task, where patterns of greater EEG alpha power among women have been reported both during a baseline condition and while performing mental rotation tasks (Arce, Ramos, 
Guevara, \& Corsi-Cabrera, 1995; Corsi-Cabrera et al., 1993; Roberts \& Bell, 2000b). Finally, there is no indication of a sex difference in the alpha band in children between 6 years of age and 11-12 years of age (Benninger et al., 1984; Matsuura et al., 1985; Roberts \& Bell, 200b). In light of these data, it will be important to account for any baseline EEG sex differences when examining EEG sex differences during any type of task performance.

\section{Purpose and Hypotheses}

The purpose of this study was to twofold: 1) to examine the effects of age and sex on mental rotation performance, verbal performance, and brain wave activity (specific hypotheses are detailed below), and 2) to test the hypothesis that simple rotation tasks are associated with left parietal activation while more complex rotation tasks are associated with right parietal activation. To accomplish this, tasks that met several criteria were used. First, the tasks previously exhibited a sex difference in performance. Next, the tasks were appropriate for both the 8-year-old children and the college-age adults. Furthermore, tasks that could be performed while having EEG recorded were used. The tasks that were used included three computerized mental rotation tasks (a 2-dimensional Gingerbread Man mental rotation task, a 2dimensional Alphanumeric mental rotation task, and a 3-dimensional Basketball Player mental rotation task), a computerized Lexical Decision-Making task, a oral Verbal Fluency task, and a paper-and-pencil Water Level task. Additionally, EEG was recorded during a reading task to further assure that activation during each of the rotation tasks was the result of the rotation component of the tasks, rather than general cognition. Reading was used as a task of general cognition because there are no reported sex differences in tasks of reading or reading comprehension.

This study measured baseline EEG and EEG during task performance in males and females in two age groups: 8-year olds and college students. This study is important because it is the first study to have measured mental rotation and verbal sex differences and corresponding EEG differences in both children and adults using a within-subjects design. In light of the different processing speed between children and adults, it was expected that children would perform all tasks at a slower rate than the adults. 
Finally, this is the first study to test the hypothesis that simple rotation tasks are associated with left parietal activation while more complex rotation tasks are associated with right parietal activation.

Recent studies have indicated that the standard 8-13 Hz alpha band may actually may be comprised of two distinct (high and low) bands (Crawford, Clarke, \& Kitner-Triolo, 1996; Crawford \& Vasilescu, 1995; Klimesch, 1996). Particularly, studies have found that the lower (7.5-10.5 Hz) and higher (10.5-13.5 Hz) alpha bands may be differentially associated with different types of cognitive workloads (Crawford et al., 1996; Klimesch, Schimke, Ladurner, \& Pfurtscheller, 1990). In light of this research, the low $(7.5-10.5 \mathrm{~Hz})$, high $(10.5-13.5 \mathrm{~Hz})$, and complete $(7.5-13.5 \mathrm{~Hz})$ alpha bands were analyzed.

Three groups of hypotheses were addressed in this study:

\section{1) Behavior}

Mental Rotation Tasks and Water Level Task. Consistent with previous literature, it was hypothesized that there would be an age by sex interaction on task performance such that male college students would perform at a higher level than female college students, but that there would be no sex difference between the 8-year-old boys and girls.

Lexical Decision-Making Task and Verbal Fluency Task. It was hypothesized that there would be an age by sex interaction on the Lexical Decision-Making and Verbal Fluency tasks such that female college students would perform at a higher level than male college students, but that there would be no sex difference between the 8-year-old boys and girls. These hypotheses were consistent with previous literature.

\section{2) Baseline EEG}

It was hypothesized that there would be an age by sex interaction such that men would exhibit generally lower EEG alpha power values than women throughout all scalp locations, while there would be no baseline EEG alpha power value differences between the 8-year-old boys and girls at any recording 
site. This hypothesis was consistent with the literature on developmental sex differences in EEG power values in the alpha band.

\section{3) Task EEG}

Four tasks were designed so that EEG recordings could be accomplished during task performance. These tasks were the 2-dimensional "Gingerbread Man" mental rotation, the 2-dimensional Alphanumeric mental rotation, the 3-dimensional "Basketball Man" mental rotation, and the Lexical Decision-Making tasks. The other two tasks (Water Level and Verbal Fluency) were performed without the EEG recording due to task demands that would introduce excessive gross motor artifact in the EEG recording. While assessing the task EEG, baseline EEG measures were covaried for during all tasks.

Overall, it was hypothesized that there would be an age by sex by task type interaction. Within each task, additional hypotheses were made. With a more recent focus on the brain as a system, as opposed to a collection of independent lobes, it is important to acknowledge that brain areas are interconnected. Because the brain is rich with interconnections among many of the different areas, it would not have been surprising to see activation in areas other than those where the hypotheses are made. For example, there are many interconnections between prefrontal and parietal cortices. Because of these interconnections, parietal activation during the mental rotation task performance may be associated with some level of frontal activation, relative to baseline values.

2-dimensional "Gingerbread Man" and Alphanumeric Mental Rotation Tasks. It was hypothesized that there would be an age by sex interaction in the task EEG data at the parietal scalp locations. Within the college students, it was hypothesized that there would be task EEG differences between men and women, with men exhibiting more left parietal activation (lower EEG power values) than women during the mental rotation task. Within the 8-year-old group, it was hypothesized that there would be no task EEG alpha power differences between boys or girls at any recording site.

3-dimensional "Basketball Man" Rotation Task. It was hypothesized that there would be an age by sex interaction in the task EEG data at the parietal scalp locations. Within the college students, it was 
hypothesized that there would be task EEG differences between men and women, with men exhibiting more right parietal activation (lower EEG power values) than women during the mental rotation task. Within the 8-year-old group, it was hypothesized that there would be no task EEG alpha power differences between boys or girls at any recording site.

Lexical Decision-Making Task. It was hypothesized that there would be an age by sex interaction in the task EEG data at the left central and left frontal locations. Within the college students, it was hypothesized that there would be task EEG differences between men and women, with women exhibiting more left central and left frontal activation (lower EEG power values) than men during the Lexical Decision-Making task. Within the 8-year-old group, it was hypothesized that there would be no task EEG alpha power differences between boys or girls at any recording site.

\section{Method}

\section{$\underline{\text { Participants }}$}

$\underline{8 \text {-year-olds. }}$ Thirty-two right-handed 8-year-old participants (16 boys, mean age $=8.31 ; 16$ girls, mean age $=8.18)$ from the community were recruited for this study. During the recruitment procedure parents were told that we were looking for participants who were free of medications and neurological diagnoses. After scheduling their appointment, parents were asked to reschedule if their child became sick and needed to take medications. For their participation, the children were rewarded with a single trip to a "treasure chest" of small toys at the end of the session.

College students. Thirty-two right-handed college students $(16$ men, mean age $=19.86 ; 16$ women, mean age $=19.82$ ) who were free of medications and neurological diagnosis were recruited through the Introductory Psychology extra credit pool to participate in this study. Participants were compensated for their participation with extra credit in their Introductory Psychology class.

\section{Procedure}

Upon entering the lab, both age groups were given an informed consent form to read and sign (see Appendices B \& C). In addition, parents of the 8-year-olds also signed a consent form (see 
Appendix D). Both age groups completed questionnaires to assess handedness (Oldfield, 1971; see Appendix E) and neurological issues (see Appendix F). Potential participants were dismissed there if there were more than $20 \%$ "left" answers to the handedness questionnaire, if there were any "yes" answers to the neurological questionnaire, or if they had consumed more than two caffeinated beverages on the day of testing.

Testing was counterbalanced within and between Computerized and Non-Computerized tasks. The Computerized tasks were always performed with the EEG cap applied and included the 2dimensional "Gingerbread Man" mental rotation task, the 2-dimensional Alphanumeric mental rotation task, the 3-dimensional "Basketball Man" mental rotation task, and the Lexical Decision-Making task. The Non-Computerized tasks were always performed without the EEG cap applied and included the Water Level and Verbal Fluency tasks.

\section{EEG Recording}

Participants had the Electro-Cap EEG recording device, as well as EOG electrodes, applied. After the cap was in place, Omni-Prep abrasive gel and Electro-Gel conductive gel was inserted in 16 electrodes associated with the international 10/20 system (Jasper, 1958): Fp1, Fp2 (frontal pole), F3, F4 (medial frontal), F7, F8 (lateral frontal), C3, C4 (central), T3, T4 (anterior temporal), T5, T6 (posterior temporal), P3, P4 (parietal), and O1, O2 (occipital). Odd numbers represent the left hemisphere and even numbers represent the right hemisphere. Electrodes were referenced to $\mathrm{Cz}$ and grounded anterior to $\mathrm{Fz}$ electrode on the Electro-Cap. Lead-Lok solid gel electrodes were applied to the supra orbit and outer canthus of the right eye after the skin had been wiped with an alcohol pad. This allowed monitoring of the EOG and eyeblinks for later artifact scoring of the EEG data. For all electrodes (EEG, EOG), impedances were less than $5 \mathrm{~K}$ ohms and less than 500 ohms separated homologous electrode pairs. EEG recordings were made with SA Instrumentation Bio-Amps at a sampling rate of $512 \mathrm{~Hz}$ to prevent aliasing. The high pass filter setting was set at $1 \mathrm{~Hz}$ and the low pass filter setting was at $100 \mathrm{~Hz}$, with a gain of 20K. Data were collected on a Pentium computer using Snap/Shot acquisition software. 
Baseline EEG consisted of one minute with eyes open, during which participants were instructed to look at a blank computer screen and think about a "walk in the woods". Participants were instructed to sit quietly without motor movements. After baseline EEG was recorded, the computer-based tasks began. All computer-based tasks were counter-balanced within sex and age groups, and performance of the computer-based block of tasks and non computer-based block of tasks were also counter-balanced.

\section{EEG Analysis}

Using software developed by the James Long Company, the EEG data were re-referenced via software to an average reference configuration. Average referencing, in effect, weighted all the electrode sites equally and eliminated the need for a non-cephalic reference. Active to reference electrode distances vary across the scalp, and without re-referencing, power values at each active site may reflect interelectrode distance as much as they reflect electrical potential. Data were artifact scored using EOG as a guide, with gross motor and muscle movements removed through artifact scoring. The visual representation of gross motor and muscle artifact was obvious because artifact occurs at frequencies greater than $90 \mathrm{~Hz}$. Artifact free EEG data were analyzed with a discrete Fourier transform (DFT) using a Hanning window of one-second width and 50\% overlap. Fourier transform has traditionally been used to study laterality effects. Mean voltage was subtracted from each data point prior to analysis to eliminate any power results due to DC offset. Consistent with much of the adult literature using spatial tasks (e.g. Davidson et al, 1990), power values for alpha (8-13 Hz) were computed. However, recent research has indicated that that traditional alpha $(8-13 \mathrm{~Hz})$ may be divided into high and low rhythmic components that may differentially be associated with memory, attention, and emotional state (Crawford, Clark, \& KitnerTriolo, 1996; Klimisch, 1996). All hypotheses were analyzed using alpha power values measured at low rhythmic $(7.5-10.5 \mathrm{~Hz})$ and high rhythmic $(10.5-13.5 \mathrm{~Hz})$ frequencies. These analyses were accomplished separately. In a review of the ontogeny of EEG during childhood, Bell (1998) has noted that EEG power values of 8-year-old children are within the adult-like 8-13 $\mathrm{Hz}$ range. 
Computerized Tasks

2-dimensional "Gingerbread Man” Mental Rotation Task. Participants were seated in front of a computer and shown the Overman Mental Rotation Task (Epting, Barbour, \& Overman, 1996; Epting \& Overman, 1998). This mental rotation task consists of a "Gingerbread Man" (later referred to as "figure") presented at the top of the computer screen, with two choices, one of which matches the original, presented at the bottom of the screen. Figures, original and choices, are computer-generated in such a manner so that each has the same amount of area within its borders. The figure has four possible positions. While either the left or right arm is extended straight out, the opposite arm is either in an "up" or "down" position. During task performance, the participant is asked to match the original figure at the top to one of two figures at the bottom. The original figure is always in an upright position, while the subsequent "choice" figures at the bottom are rotated $90^{\circ}, 180^{\circ}$, or $270^{\circ}$ (see Figure 1). Participants were asked to choose which "choice" figure was the same as the "original" figure. The entire keyboard was covered except for two keys, one on the right side of the keyboard and one on the left side of the keyboard, which the participants used to choose the figure which correctly matched the original. Additionally, the space bar was used to let participants self-pace time between trials. In order to minimize motor movements, hands were rested in such a manner that only finger movements were required. All trials were randomized in such a manner that correct responses were equally divided between the right and left choices, and that the choice figures were turned equally to each side.

In order to control for general attentional and/or reaction time differences, a match-to-sample task utilizing the same stimuli was randomly mixed within the testing session. These trials were the same as above except that the figures at the bottom of the page were not rotated, but remained in a $0^{\circ}$ rotation condition. This match-to-sample task assured that differences in rotation ability were due specifically to the ability to mentally rotate objects. Likewise, if there were general or reaction time differences in the match-to-sample task, the $0^{\circ}$ latency data would allow transformation of the trial latency values. For 
example, latency to respond during the match to sample could be considered baseline response for reaction time.

After two familiarization pre-trials the testing phase began. Participants were given two blocks of 16 trials. Only 32 total trials were given because pilot data have shown that after $30-40$ trials, the task becomes one of memory, rather than rotation (W.H. Overman, personal communication, September, 1998). Performance was measured by number of correct trials, as well as mean latency to respond. Participants' responses were recorded automatically by the computer and saved for later analysis. The computer program was set up in such a manner that the participant could respond any time after the "choice" figures were displayed on the screen. After making a choice, the computer screen displayed feedback to the participant to inform if the response was correct or incorrect. The participant then started the next trial by pressing the space bar.

2-dimensional Alphanumeric Mental Rotation Task. Participants were seated in front of a computer and shown the Alphanumeric rotation task. This task is similar to the task used by Alivisotos and Petrides (1997) and consists of a single alphanumeric stimuli presented at the top of the computer screen, with two choices, one of which matches the original and one of which was a mirror image of the original, presented at the bottom of the screen. The stimuli are the upper case letters G, F, R, and the Arabic numerals 2, 5, 7. During task performance, the participant was asked to match the original stimuli at the top to one of two stimuli at the bottom. The original stimulus was always in an upright position, while the subsequent "choice" figures at the bottom were rotated $60^{\circ}, 120^{\circ}, 180^{\circ}, 240^{\circ}$, or $300^{\circ}$ (see Figure 2). Participants were asked to choose which "choice" stimuli was the same as the "original" stimuli. In all cases, the "choice" stimuli were either identical to the original stimuli or a mirror image of the original stimuli, and both choices were rotated to the same degree. The entire keyboard was covered except for two keys, one on the right side of the keyboard and one on the left side of the keyboard, which the participants used to choose the figure which correctly matched the original. Additionally, the space bar was used to let the participants self-pace time between trials. In order to minimize motor movements, 
hands were rested in such a manner that only finger movements were required. All trials were randomized in such a manner that correct responses were equally divided between the right and left choices, and that the choice figures were turned equally to each side.

In order to control for general attentional and/or reaction time differences, a match-to-sample task utilizing the same stimuli was randomly mixed within the testing session. These trials were the same as above except that the stimuli at the bottom of the page were not rotated, but remained in a $0^{\circ}$ rotation condition. Similar to the condition in the "Gingerbread Man" task, this match-to-sample task assured that differences in rotation ability were due specifically to the ability to mentally rotate objects. Likewise, if there were general or reaction time differences in the match-to-sample task, the $0^{\circ}$ latency data would allow transformation of the trial latency values.

After two familiarization pre-trials the testing phase began. Participants were given one block of 36 trials. This allowed for each stimulus to be tested once in each of the six rotation conditions. Performance was measured by percentage of correct trials, as well as mean latency to respond. Participants' responses were recorded automatically by the computer and saved for later analysis. The computer program was set up in such a manner that the participant could respond any time after the "choice" figures were displayed on the screen. After making a choice, the computer screen displayed feedback to the participant to inform if the response was correct or incorrect. The participant then started the next trial by pressing the space bar.

3-dimensional "Basketball Player" Mental Rotation Task. Similar to the methods used in the 2dimensional rotation tasks described above, participants were seated in front of the computer and shown the 3-dimensional task. This task utilizes a "Basketball Player" presented at the top of the computer screen. The "Basketball Player" consists of a silhouette image of a person holding a basketball in either the right or left hand. The original figure is always in an upright position and facing the participant, while the subsequent "choice" figures at the bottom are rotated $60^{\circ}, 120^{\circ}, 180^{\circ}, 240^{\circ}$, or $300^{\circ}$. Also, in half of the trials the "choice" figures are also rotated so that they are facing away from the participant, resulting 
in a three dimensional rotation (see Figure 3). Participants were asked to choose which "choice" figure was the same as the "original" figure. The entire keyboard was covered except for two keys, one on the right side of the keyboard and one on the left side of the keyboard, which the participants used to choose the figure which correctly matched the original. Additionally, the space bar was used to let participants self-pace time between trials. In order to minimize motor movements, hands were rested in such a manner that only finger movements were required. All trials were randomized in such a manner that correct responses were equally divided between the right and left choices, and that the choice figures were turned equally to each side.

In order to control for general attentional and/or reaction time differences, a match-to-sample task utilizing the same stimuli was randomly mixed within the testing session. These trials were the same as above except that the stimuli at the bottom of the page were not rotated, but remained in a $0^{\circ}$ rotation condition. Similar to the condition in the "Gingerbread Man" task, this match-to-sample task assured that differences in rotation ability were due specifically to the ability to mentally rotate objects. Likewise, if there were general or reaction time differences in the match-to-sample task, the $0^{\circ}$ latency data would allow transformation of the trial latency values.

After two familiarization pre-trials the testing phase began. Participants were given two blocks of 36 trials. This allowed for each stimulus to be tested six times in each of the twelve rotation conditions. Performance was measured by percentage of correct trials, as well as mean latency to respond. Participants' responses were recorded automatically by the computer and saved for later analysis. The computer program was set up in such a manner that the participant could respond any time after the "choice" figures were displayed on the screen. After making a choice, the computer screen displayed feedback to the participant to inform if the response was correct or incorrect. The participant then started the next trial by pressing the space bar.

Lexical Decision-Making Task. Participants completed a Lexical Decision-Making task that is similar to the task used by Wegesin (1998a, 1998b). In this task, word stimulus pairs are presented on the 
computer screen, one word on each side of screen. Each pair included one "pseudoword" and one "real word." The pseudowords were created by combining two real English words (e.g. book + lick = blick), and were matched to the real words in length. All of the real words were at a $2^{\text {nd }}$ grade or lower reading level, as verified by two local $2^{\text {nd }}$ grade teachers (see Appendix $G$ for a list of the word pairs). The word pairs were comprised of word pairs used by Wegesin (1998a, 1998b), as well as from words suggested by the $2^{\text {nd }}$ grade teachers.

After the word pair was flashed on the screen, participants were asked to decide which word was a real word. Participants pressed the button (right or left) corresponding to the real word. Performance was measured by percentage of correct trials, as well as mean latency to respond. Participants' responses were recorded automatically by the computer and saved for later analysis. After making a choice, the computer screen displayed feedback to the participant to inform if the response was correct or incorrect. The participant then started the next trial by pressing the space bar. Participants were given 2 blocks of 20 trials. All trials were randomized in such a manner that correct responses were equally divided between the right and left choices.

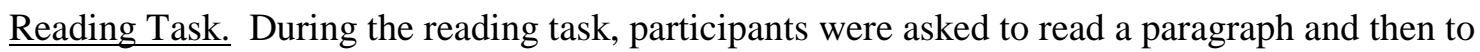
answer questions regarding this paragraph (as consistent with Kraft et al., 1980; Roberts \& Bell, 2000b). The material was at the second grade reading level and taken from a reading textbook. The participants were asked a total of four questions about the reading. Two questions were factual and two were inferential (see Appendix H). The main purpose of the reading task was to have an additional cognitive task that was dissociated with each of the mental rotation tasks. Because the EEG patterns during the reading, and not necessarily performance on the questions, were of greatest interest, performance on the questions was not analyzed.

\section{$\underline{\text { Non Computerized Tasks }}$}

Water Level Task. Participants were given a single sheet of paper with a line drawing of a bottle sitting just above a table. On the first sheet, the experimenter explained that the top figure represented a 
vertical bottle and the bottom figure represented a table upon which the bottle rests. Then, the experimenter drew a horizontal line representing that the bottle was half full of water. Then the experimenter explained that "On the following pages the jar will be shown tilted to various angles. You are to use the straight-edge to draw the water-line as it should appear at the various angles." Subsequently, seven different pages were given to the participants, one at a time (see Figure 4). Performance was measured by total number of degrees the "water line" was drawn from horizontal. Verbal Fluency Task. A standard Verbal Fluency task was used, giving the participants 60 seconds to produce as many words as possible. The Verbal Fluency task was explained, and the participants were given the opportunity to "practice" with the letter "B". The experimenter explained that the participant "should try to come up with as many words as possible that start with the letter B," and offered the words "big" and "bright". After the short practice session, the participants were tested on the letters "S" and "T". Responses were videotaped for later analyses. Performance was measured by the total number of different words produced in the 60 -second period.

\section{Results}

For a summary of all of the task-related data, see Figures 5-18. Details of all analyses and effects testing can be found in Tables 1-6. Although values of $\mathrm{p} \leq .10$ are presented in these tables, only values of $\mathrm{p} \leq .05$ are discussed in this results section.

\section{$\underline{\text { Behavior }}$}

2-Dimensional “Gingerbread Man” Mental Rotation, 2-Dimensional Alphanumeric Mental Rotation, 3$\underline{\text { Dimensional "Basketball Player" Mental Rotation, and Water Level Tasks }}$

Consistent with previous literature, it was hypothesized that there would be an age by sex interaction on task performance such that male college students would perform at a higher level than female college students on the mental rotation and Water Level tasks, but there would be no sex difference between the 8-year-old boys and girls. 
Non-Rotation $\left(0^{\circ}\right)$ Conditions

Reaction Time. In order to assess the effects of age and sex on the reaction time, an ANOVA was performed using age and sex as the independent variables and reaction time on correct trials of the non-rotation $\left(0^{\circ}\right)$ conditions as the dependent variable. Because each task was independently performed and represented different abilities, each task was analyzed separately. Analyses indicated a main effect of age with the adults having faster reaction times than children on the Gingerbread Man, Alphanumeric, and Basketball Player tasks. There were no main effects for sex or age by sex interactions on the Gingerbread Man, Alphanumeric, or Basketball Player tasks (see Table 1 and Figures 5, 7, \& 9).

Total Number Correct. In order to assess the effects of age and sex on the total number correct, an ANOVA was performed using age and sex as the independent variables and number of correct trials of the non-rotation $\left(0^{\circ}\right)$ conditions as the dependent variable. Because each task was independently performed and represented different abilities, each task was analyzed separately. Analyses revealed a main effect of age on the alphanumeric and Basketball Player tasks, with the adults producing more correct responses than children (see Table 2 and Figures $6,8, \& 10$ ). There were no other main effects or interactions in these data.

Mental Rotation Conditions

Because each task had a different number of rotation conditions, analyses were accomplished independently for each individual task. In order to simultaneously examine the effects of 1) reaction time on correct trials corrected for reaction time on the non-rotation conditions, and 2) number of correct trials, a separate variable was created. This was particularly important because the participants were told to choose "as quickly and accurately as possible." Therefore, by taking into account both reaction time and number of correct trials, a better overall picture of the data was created. The first part of this variable was created by subtracting the mean reaction time on the correct trials on the non-rotation condition of each task from the mean reaction time on the correct trials on each of the rotation conditions of each task. For example, if a participant had a mean of one second on the non-rotation condition of the Alphanumeric 
task, and a mean of two seconds on the $180^{\circ}$ condition of the Alphanumeric task, then the one second difference was considered the amount of time unique to the rotating the Alphanumeric character $180^{\circ}$, hence called the difference score. Then, the number of incorrect trials on each rotation condition was computed. Next, the difference scores and the data concerning the number of incorrect trials were Zscored separately. Finally, the two Z-scores were added together to create one variable (hereafter called the Total Score) that encompassed both aspects of the task at each angle (number of correct responses, reaction time on correct "rotation" trials corrected for reaction time on correct "non-rotation" trials). Because the two variables that comprised the score were reaction time (lower reaction time is better) and number of incorrect trials (fewer incorrect trials is better), a lower Total Score represents better performance on the task. Therefore, the terms "lower score" and "better score" are used interchangeably. For each task, a repeated measures ANOVA was performed. The between subjects independent variables were age and sex, and the dependent variable was Total Score. In the case of age by sex interactions, the Tukey's LSD post-hoc test was performed because it is the test of choice when examining all pairwise comparisons that were not hypothesized a priori.

In three cases, participants had no correct trials in $180^{\circ}$ rotation conditions (two in the Basketball Player and one in the Alphanumeric). Therefore, these participants had no reaction time data that could be used in the analyses, and the conservative approach of dropping their data from analysis on the task affected was taken.

2-Dimensional "Gingerbread Man” Mental Rotation. Analyses revealed a main effect of age, with adults achieving a better Total Score than children on all of the rotation conditions of the Gingerbread Man rotation task. There were no sex main effects of sex or age by sex interactions (see Table 3 and Figure 11).

2-Dimensional Alphanumeric Mental Rotation. One participant, a boy, had no correct trials at the $180^{\circ}$ rotation condition. Therefore, these results include a total of 31 children (15 boys) and 32 adults (16 men). Analyses revealed a main effect of age, with adults achieving better Total Scores than children on 
the rotation conditions of the Alphanumeric rotation task. There was no main effect for sex, however, there was an age by sex interaction such that men performed better than boys, but there was no difference between women and girls (see Table 3).

3-Dimensional "Basketball Player" Mental Rotation. Two participants, a girl and a woman, had no correct trials at the $180^{\circ}$ rotation condition. Therefore, these results include a total of 31 children (16 boys) and 31 adults (16 men). Analyses revealed a main effect of age, with adults scoring generally higher than children on all of the rotation conditions of the Basketball Player rotation task. There was no main effect for sex, however, there was an age by sex interaction such that men performed better than boys, but there was no difference between women and girls (see Table 3).

Water Level Task.

Number of Correct Trials. In order to assess the effects of age and sex on the Water Level task, an ANOVA was performed. Correct trials were defined as any trial that was within $10^{\circ}$ of horizontal. The independent variables were age and sex, and the dependent variable was the total number of correct trials. Analyses revealed a main effect of age, $\underline{\mathrm{F}}(1,60)=11.60, \mathrm{p} \leq .001$, with adults performing better than children. Likewise, analyses yielded a main effect of sex, $\underline{F}(1,60)=5.84, \underline{p} \leq .02$, with males performing better than females. However, there was no interaction between age and sex, $\underline{F}(1,60)=1.74$, $\mathrm{p}=.19$. While there was no interaction between age and sex, post hoc analyses indicated that men performed better than women, $\mathrm{t}(30)=2.05, \mathrm{p} \leq .05$, while there was no difference between boys and girls, $\mathrm{t}(30)=1.33, \mathrm{p}=.19($ see figure 14$)$.

\section{$\underline{\text { Lexical Decision-Making and Verbal Fluency Tasks. }}$}

Consistent with previous literature, it was hypothesized that there would be an age by sex interaction on the Lexical Decision-Making and Verbal Fluency tasks such that female college students would perform at a higher level than male college students, but that there would be no sex difference between the 8-year-old boys and girls. 
Lexical Decision-Making Task. In order to assess the effects of age and sex on the reaction time on the Lexical Decison-Making task, an ANOVA was performed. The independent variables were sex and age, and the dependent variable was reaction time on the correct trials (see Figure 15). Analyses revealed a main effect of age such that adults performed faster than children. There was no main effect of sex or age by sex interaction (see Table 4).

In order to assess the effects of age and sex on the total number of correct responses on the Lexical Decision-Making task, an ANOVA was performed. The independent variables were age and sex, and the dependent variable was the total number of correct responses (see Figure 16). Analyses revealed a main effect of age, with adults having more correct responses than children. However, analyses yielded no main effect of sex or age by sex interaction (see Table 4).

In order to examine the effects of both reaction time and number of correct trials the $\underline{\text { Total Score }}$ (similar to the formula described above, reaction time data from the correct trials and data concerning the total number of incorrect trials were Z-scored separately and then added together) was computed. The independent variables were age and sex, and the dependent variable was overall score (see Table 4).

These analyses revealed a main effect of age with adults performing better than children. These analyses did not yield main effect of sex; however, there was an interaction between age and sex. Post hoc analyses indicated that men achieved a better Total Score than women, $\mathrm{t}(30)=2.78, \mathrm{p} \leq .01$, while there was no difference between boys and girls, $\mathrm{t}(30)=1.51, \mathrm{p}=.14$ (see figure 17 ).

Verbal Fluency Task. In order to assess the effects of age and sex on the total number of words produced on the Verbal Fluency task, an ANOVA was performed. The independent variables were age and sex, and the dependent variable was the total number of words produced (see Figure 18). Analyses revealed a main effect of age, $\underline{\mathrm{F}}(1,60)=66.38, \underline{\mathrm{p}} \leq .001$, with adults performing better than children. There was no main effect for sex, $\underline{\mathrm{F}}(1,60)=.10, \underline{\mathrm{p}}=.74$, and no age by sex interaction, $\underline{\mathrm{F}}(1,60)=2.22$, $\underline{\mathrm{p}}$ $=.14$. 
EEG Activity

Analyses were accomplished on baseline EEG and task EEG controlling for baseline EEG. Within each one of these analyses, the overall MANOVA (or MANCOVA) was not interpreted independently, but rather was used for justification for separate MANOVAs (or MANCOVAs) performed on the EEG for each individual region (i.e., each homologous pair of recording sites).

Recent research has indicated that that traditional alpha $(8-13 \mathrm{~Hz})$ may be divided into high and low rhythmic components that may differentially be associated with memory, attention, and emotional state (Crawford, Clark, \& Kitner-Triolo, 1996; Klimisch, 1996). For this reason, all hypotheses were analyzed using alpha power values measured at low rhythmic frequencies $(7.5-10.5 \mathrm{~Hz})$, high rhythmic frequencies, $(10.5-13.5 \mathrm{~Hz})$, and as a total band $(7.5-13.5 \mathrm{~Hz})$. These analyses were accomplished separately and can be found in Appendix I.

Previous research using some of these same tasks has indicated that the high rhythmic band is of particular interest (Roberts \& Bell, 2000b). Additionally, other studies have shown that the high alpha band may be associated with cognitive workload, while the lower alpha band may be associated with states of alertness and emotions (Burgesss \& Gruzelier, 2000; Crawford et al., 1996; Klimesch, Schimke, Ladurner, \& Pfurtscheller, 1990). Because this study was interested in the cognitive demands of the tasks, only the high frequency band will be discussed from this point forward.

In the case of significant interactions, EEG data are graphed in Figures 19-30. In all cases the three-way data is presented (age, sex, and hemisphere) in the region of interest. In cases of two-way interactions, representations of the significant interaction using only the two variables included in the interaction can be found in Appendix J.

\section{$\underline{\text { Baseline EEG }}$}

It was hypothesized that there would be an age by sex interaction such that men would exhibit generally lower EEG alpha power values than women throughout all scalp locations, while there would be 
no baseline EEG alpha power value differences between the 8-year-old boys and girls at any recording site.

A repeated measures MANOVA was used to assess the effects of age and sex on region/hemispheric activation at baseline. The within groups independent variables were region (frontal pole, medial frontal, lateral frontal, central, anterior temporal, posterior temporal, parietal, occipital) and hemisphere (right, left) and the between groups independent variables were sex and age. The dependent variable was baseline EEG ln power values at $10.5-13.5 \mathrm{~Hz}$. There were main effects for age, $\underline{\mathrm{F}}(1,60)=$ $5.73, \mathrm{p} \leq .02$, and region [Wilks $=.22$, approximate $\underline{\mathrm{F}}(7,54)=27.49, \mathrm{p} \leq .001]$. Interactions included region by age $[$ Wilks $=.73$, approximate $\underline{F}(7,54)=2.83, \mathrm{p} \leq .01]$, region by hemisphere [Wilks $=.78$, approximate $\underline{\mathrm{F}}(7,54)=2.23, \mathrm{p} \leq .05]$, region by hemisphere by age $[$ Wilks $=.77$, approximate $\underline{\mathrm{F}}(7,54)=$ $2.29, \mathrm{p} \leq .05]$, and region by hemisphere by sex [Wilks $=.69$, approximate $\underline{\mathrm{F}}(7,54)=3.52, \mathrm{p} \leq .01]$.

To examine these interactions, separate MANOVAs were performed on the EEG power values for each region. This also allowed for interpretation of the main effects of age, sex, and region that were reported in the overall MANOVA analysis noted above. For the MANOVAs done for each region, age and sex were the between subjects factors and hemisphere was the within subjects factor. The dependent variable was EEG power at $10.5-13.5 \mathrm{~Hz}$.

The $\mathrm{F}$ values for these MANOVAs are summarized in Table 5. Although values of $\mathrm{p} \leq .10$ are presented in the table, only values of $\mathrm{p} \leq .05$ are discussed in this results section. In the frontal pole, lateral frontal, medial frontal, central, and anterior regions college students exhibited lower EEG power values than children. All participants exhibited more activation of the left anterior temporal region than the right anterior temporal region.

Post-hoc testing of the higher order hemisphere by age by sex interaction in the lateral frontal region revealed that girls exhibited greater relative activation of the left lateral frontal region, $\mathrm{t}(15)=$ $3.46, \mathrm{p} \leq .01$, while there were no differences between left and right lateral frontal activation in boys, $\mathrm{t}$ $(15)=.75, \mathrm{p}=.46$, men, $\mathrm{t}(15)=1.41, \mathrm{p}=.16$, or women, $\mathrm{t}(15)=1.26, \mathrm{p}=.22$ (see Figure 19). Testing 
of the hemisphere by age interaction in the central region revealed that children exhibited more relative activation of the left central region, $\mathrm{t}(31)=2.63, \mathrm{p} \leq .01$, while there were no differences between left and right central activation in adults, $\mathrm{t}(31)=.38, \mathrm{p}=.71$ (see Figure 20 and Appendix J, Figure 20j). Additionally, testing of the hemisphere by sex interaction in the parietal region revealed a non-significant trend of males exhibiting more relative activation of the right parietal area, $\mathrm{t}(31)=1.65, \mathrm{p}=.11$ and females exhibiting more activation of the left parietal area, $\mathrm{t}(31)=1.43, \mathrm{p}=.16$ (see Figure 21 Appendix J, Figure 21j).

\section{$\underline{\text { Task EEG Covaried for Baseline EEG }}$}

In order to assure that the age and sex effects found during task performance were specific to task performance, and not due to the influence of the sex difference in the baseline EEG measures, a MANCOVA was used to control for baseline EEG power values. Likewise, in order to ensure that the effects found during each of the tasks were specific to particular task type, and not due to the generalized effects of cognition, EEG data were collected during several different types of tasks thought to elicit activation in different areas of the brain. The use of covariates in our analyses was particularly important in order to assure any effects found in the EEG were due to the specific task being performed, and not due to baseline EEG power values differences. Whenever covariates are used there is a potential for factorcovariate interactions. Because there was no theoretical reason to believe that factor-covariate interactions would appear in the current data, all of the interpretations of the task-related EEG data are based on the assumption that factor-covariate interactions were not a problem.

The within groups independent variables were region (frontal pole, medial frontal, lateral frontal, central, anterior temporal, posterior temporal, parietal, occipital), hemisphere (right, left), and task (2dimensional "Gingerbread Man" mental rotation, 2-dimensional Alphanumeric mental rotation, 3dimensional "Basketball Player" mental rotation, Lexical Decision-Making, and reading), and the between groups independent variables were age and sex. The dependent variable was task performance EEG $\ln$ power values at $10.5-13.5 \mathrm{~Hz}$, and the covariate was baseline EEG $\ln$ power values at 10.5-13.5 
Hz. There were main effects for age, $\underline{\mathrm{F}}(1,44)=3.91, \mathrm{p} \leq .05$, task [Wilks $=.72$, approximate $\underline{\mathrm{F}}(4,41)=$ $3.94, \mathrm{p} \leq .01$ ], and region [Wilks $=.26$, approximate $\underline{\mathrm{F}}(4,41)=15.33, \mathrm{p} \leq .001]$. Interactions included task by age $[$ Wilks $=.69$, approximate $\underline{\mathrm{F}}(4,41)=4.57, \mathrm{p} \leq .01]$, region by age [Wilks $=.61$, approximate $\mathrm{F}(4,41)=3.39, \mathrm{p} \leq .01$ ], task by region [Wilks $=.09$, approximate $\underline{\mathrm{F}}(4,41)=6.14, \mathrm{p} \leq$ $.001]$, task by hemisphere by age [Wilks $=.79$, approximate $\underline{\mathrm{F}}(4,41)=2.81, \mathrm{p} \leq .04]$, and region by hemisphere by age [Wilks $=.70$, approximate $\underline{\mathrm{F}}(4,41)=2.24, \mathrm{p} \leq .05]$.

To examine the interactions among age, sex, region, hemisphere, and task type while controlling for baseline activation, separate MANCOVAs were performed on the EEG power values for each region. For the MANCOVAs done for each region, age and sex were the between subjects factors. Hemisphere and task type were the within subjects factors. The dependent variable was EEG In power values at 10.513.5 $\mathrm{Hz}$ and the covariate was baseline EEG ln power values at $10.5-13.5 \mathrm{~Hz}$.

The F values for these MANCOVAs are summarized in Table 6. In all regions except frontal pole and lateral frontal, the college students exhibited more activation (lower EEG power values) than the children. In medial frontal, central, parietal, and occipital regions, male participants exhibited more activation than female participants. The right hemisphere was more activated than the left hemisphere in the lateral frontal region. In all regions except the medial frontal and posterior temporal there was a main effect of task type. There were interactions involving task type at the posterior temporal, parietal, and occipital areas.

\section{$\underline{\text { Post-Hoc Analyses on Task EEG Covaried for Baseline EEG }}$}

To examine these main effects and interactions involving task type, separate post-hoc MANCOVA analyses using the EEG associated with each individual task covaried with baseline EEG were accomplished. The main goal of the reading task was to further ensure that the age and sex effects found during the rotation tasks were specific to rotation, and not due to the influence of general cognition. While the interactions involving task type denoted that the tasks were associated with differential electrical patterns at the scalp locations, performing separate MANCOVAs on the EEG from each of the 
different tasks allowed for assessment of these interactions. In each of these task-separated MANCOVAs, age and sex were the between subjects factors and hemisphere was the within subjects factor. The dependent variable was EEG $\ln$ power values at $10.5-13.5 \mathrm{~Hz}$, and the covariate was baseline EEG $\ln$ power values at $10.5-13.5 \mathrm{~Hz}$.

\section{2-Dimensional "Gingerbread Man" Mental Rotation and 2-Dimensional Alphanumeric Mental Rotation}

Tasks.

It was hypothesized that there would be an age by sex interaction in the task EEG data at the parietal scalp locations. Within the college students, it was hypothesized that there would be task EEG differences between men and women, with men exhibiting more left parietal activation (lower EEG power values) than women during the mental rotation task. Within the 8-year-old group, it was hypothesized that there would be no task EEG alpha power differences between boys or girls at any recording site.

2-Dimensional "Gingerbread Man" Mental Rotation. The F values for the MANCOVAs on the 2Dimensional "Gingerbread Man" mental rotation EEG are summarized in Table 7. During this task adults exhibited more activation than children in all areas except the frontal pole, lateral frontal, and anterior temporal regions. Likewise, males exhibited more activation than females at the medial frontal, parietal, and occipital regions. Simple effects testing of the hemisphere by age interaction in the lateral frontal region revealed a non-significant trend such that adult participants exhibited greater right lateral frontal activation, $\mathrm{t}(31)=1.50, \mathrm{p}=.14$, than children, while there were no left lateral frontal differences between adults and children, $\mathrm{t}(31)=.01, \mathrm{p}=.99$ (see Figure 22 Appendix J, Figure 22j). Testing of the hemisphere by sex interaction at the parietal area revealed that males exhibited more activation of the left hemisphere than females, $\mathrm{t}(31)=3.28, \mathrm{p} \leq .001$, while there were no right parietal differences between males and females, t $(31)=1.55, \mathrm{p}=.12$ (see Figure 23 Appendix J, Figure 23j).

Simple effects testing of the higher order hemisphere by age by sex interaction at the occipital area revealed that men exhibited more activation of the left occipital area than women, $\mathrm{t}(15)=2.83, \mathrm{p} \leq$ 
.01 . There were no differences between men and women in the right occipital area, $\mathrm{t}(15)=1.47, \mathrm{p}=.15$, and there were no differences between boys and girls in either the left, $\mathrm{t}(15)=.95, \mathrm{p}=.35$, or right, $\mathrm{t}(15)$ $=1.88, \mathrm{p}=.06$ occipital areas (see Figure 24).

2-Dimensional Alphanumeric Mental Rotation. The F values for the MANCOVAs on the 2Dimensional Alphanumeric mental rotation EEG are summarized in Table 8. During this task adults exhibited more activation than children did at the medial frontal, central, posterior temporal, parietal, and occipital regions. Likewise, men exhibited more activation than women did at the frontal pole and medial frontal regions. Furthermore, the right medial frontal area was more activated (had lower power values) than the left medial frontal area in all participants.

Simple effects testing of the age by sex interaction at the lateral frontal and parietal region revealed that men exhibited more activation than women $[\mathrm{t}(31)=3.02, \mathrm{p} \leq .01 ; \mathrm{t}(31)=2.53, \mathrm{p} \leq .02$, respectively], while there were no differences between boys and girls $[\mathrm{t}(31)=.33, \mathrm{p}=.97 ; \mathrm{t}(31)=.45, \mathrm{p}$ $=.65$, respectively]. Effects testing of the hemisphere by sex interactions at the central and occipital areas revealed that males exhibited greater left central, $\mathrm{t}(31)=2.43, \mathrm{p} \leq .02$, and left occipital, $\mathrm{t}(15)=2.43, \mathrm{p}$ $\leq .02$, activation than females. There were no differences between the males and females in right central, $\mathrm{t}(15)=.78, \mathrm{p}=.43$, or right occipital activation, $\mathrm{t}(15)=1.01, \mathrm{p}=.31$ (see Figures 25 and 26; Appendix J, Figures $25 \mathrm{j}$ and $26 \mathrm{j}$ ).

Testing of the higher order hemisphere by age by sex interaction at the posterior temporal area revealed that men exhibited more activation of the left posterior temporal area than women, $\mathrm{t}(15)=2.83$, $\mathrm{p} \leq .01$. There were no differences between men and women in the right posterior area, $\mathrm{t}(15)=1.42, \mathrm{p}=$ .16 , and there were no differences between boys and girls in either the left, $\mathrm{t}(15)=.83, \mathrm{p}=.41$, or right, $\mathrm{t}$ $(15)=.31, \mathrm{p}=.73$, posterior temporal areas (see Figure 27).

3-Dimensional "Basketball Player" Mental Rotation. It was hypothesized that there would be an age by sex interaction in the task EEG data at the parietal scalp locations. Within the college students, it was hypothesized that there would be task EEG differences between men and women, with men 
exhibiting more right parietal activation (lower EEG power values) than women during the mental rotation task. Within the 8-year-old group, it was hypothesized that there would be no task EEG alpha power differences between boys or girls at any recording site.

The F values for the MANCOVAs on the 3-Dimensional "Basketball Player" mental rotation EEG are summarized in Table 9. During this task adults exhibited more activation than children did in all areas except the frontal pole, lateral frontal, and anterior temporal regions. Likewise, men exhibited more activation than women did at the medial frontal, parietal, and occipital regions. Additionally, all participants exhibited activation of the right lateral frontal and right anterior temporal regions. Simple effects testing of the hemisphere by age interaction at lateral frontal area revealed a non-significant trend such that adult participants exhibited greater right lateral frontal activation, $\mathrm{t}(31)=1.50, \mathrm{p}=.14$, while there was no differences between left and right frontal activation in children, $\mathrm{t}(31)=.15, \mathrm{p}=.88$ (see Figure 28 Appendix J, Figure 28j). Testing of the hemisphere by sex interaction at the central area revealed that males exhibited more activation of the left hemisphere than females, $\mathrm{t}(31)=2.73, \mathrm{p} \leq .01$, while there were no right central activation differences between males and females, $\mathrm{t}(31)=.63, \mathrm{p}=.53$ (see Figure 29 Appendix J, Figure 29j).

Lexical Decision-Making Task. It was hypothesized that there would be an age by sex interaction in the task EEG data at the left central and left frontal locations. Within the college students, it was hypothesized that there would be task EEG differences between men and women, with women exhibiting more left central and left frontal activation (lower EEG power values) than men during the mental rotation task. Within the 8-year-old group, it was hypothesized that there would be no task EEG alpha power differences between boys or girls at any recording site.

The F values for the MANCOVAs on the Lexical Decision-Making task are summarized in Table 10. During this task adults exhibited more activation than children at all areas except the lateral frontal region. Likewise, men exhibited more activation than women at the frontal pole, lateral frontal, and occipital regions. All participants exhibited more activation of the left lateral frontal area. 
Simple effects testing of the age by sex interactions revealed that men exhibited greater medial frontal, $\mathrm{t}(15)=2.55, \mathrm{p} \leq .02$, lateral frontal, $\mathrm{t}(15)=3.06, \mathrm{p} \leq .01$, and posterior temporal, $\mathrm{t}(15)=2.27, \mathrm{p}$ $\leq .03$ activation than women. There were no differences between boys and girls in medial frontal, $\mathrm{t}(15)=$ $.20, \mathrm{p}=.84$, lateral frontal, $\mathrm{t}(15)=.08, \mathrm{p}=.94$, and posterior temporal activation, $\mathrm{t}(15)=1.17, \mathrm{p}=.25$

Reading Task. The F values for the MANCOVAs on the Reading task are summarized in Table 11. During this task adults exhibited more activation than children at all areas except the lateral frontal and anterior temporal regions. Likewise, men exhibited more activation than women did at all areas except the frontal pole, lateral frontal, and anterior temporal regions. All participants exhibited more activation of left occipital area than the right occipital area.

Simple effects testing of the age by sex interaction at medial frontal area revealed that men exhibited greater activation than women, $\mathrm{t}(31)=3.65, \mathrm{p} \leq .001$, while there were no medial frontal differences between boys and girls, $\mathrm{t}(31)=.08, \mathrm{p}=.93$. Testing of the hemisphere by age interaction at lateral frontal area revealed that children exhibited greater left lateral frontal activation, $\mathrm{t}(31)=2.44, \mathrm{p} \leq$ .02 , than adults, while there were no right lateral frontal differences between children and adults, $\mathrm{t}(31)=$ $.03, \mathrm{p}=.98$ (see Figure 30 Appendix J, Figure 30j).

\section{Discussion}

The purpose of this study was twofold. The first purpose was to examine the effects of age and sex on 2-dimensional mental rotation performance, 3-dimensional mental rotation performance, verbal performance, sex, and EEG activation. The second purpose was to test the hypothesis that simple rotation tasks are associated with left parietal activation while more complex rotation tasks are associated with right parietal activation.

\section{$\underline{\text { Behavior }}$}

Past research indicated that the male advantage on mental rotation tasks and the female advantage on verbal tasks is most robust in adults (Hyde \& Linn, 1988; Linn \& Petersen, 1985; Voyer et al., 1995). The hypothesis for this study was an age by sex interaction such that, among college students, men would 
outperform women on mental rotation and Water Level tasks, and women would outperform men on the Lexical Decision-Making and Verbal Fluency tasks. Among 8-year-olds, no sex differences were hypothesized.

Mental Rotation and Water Level Tasks. An age by sex interaction was found on the Water Level task, with men out-performing women, and no difference between boys' and girls' performance. This finding supported the hypothesis on the Water Level task. On the rotation trials of the 2-dimensional Alphanumeric task and the 3-dimensional Basketball Player task, there was an age by sex interaction, with men performing better than boys, and no differences between girls and women.

There was no age by sex interaction on the 2-dimensional Gingerbread Man mental rotation task. These data did not support the hypothesis that men would outperform women and there would be no differences between boys and girls. At least three other studies using this same task have found an adult sex difference on this task, even with a smaller sample size (Epting, Barbour, \& Overman, 1996; Epting \& Overman, 1998; Roberts \& Bell, 2000b). However, a recent study using this same task found that familiarization with the computer demands of the task may alleviate sex differences on the 2-dimensional Gingerbread Man mental rotation task (Roberts \& Bell, 2000a). In that study, college students who performed only the 2-dimensional Gingerbread Man mental rotation task exhibited the traditional sex differences. In college students who were allowed to practice the computer demands of the task by performing a similar non-rotation task before the 2-dimensional Gingerbread Man mental rotation task, there were no sex differences.

Previous literature indicates that women have less experience performing computer games than men (Dominick, 1984; Phillips, Rolls, Rouse, \& Griffiths, 1995). Likewise, data indicate that men perform at a higher level than women on new computer games (Brown, Hall, Holtzer, Brown, \& Brown, 1997; Greenfield, et al., 1994). In light of this literature, the results of the computerized rotation tasks in this study could be explained in the following way. During the first task or two, men may have "automatized" quickly and, thus, were only performing one challenging task (the rotation task). On the 
other hand, the women may not have been as experienced with computer games and were performing the rotation task plus the computer manipulation task. As the women began to familiarize themselves with the demands of the computer task, the computer task became "automatic" for the women also. After this, the women were also performing only one cognitively challenging task, the mental rotation task. Because the current study counter-balanced all of the tasks, most participants had completed 100 or more trials of similar computerized tasks before completing the Gingerbread Man task. This familiarization may have alleviated the adult sex difference.

The proposal that the overall adult sex difference on the 2-dimensional Gingerbread Man mental rotation task was alleviated through computer familiarization brings up another question - why does the overall sex difference still exist on the 2-dimensional Alphanumeric task and the 3-dimensional Basketball player task? A male advantage on 3-dimensional mental rotation tasks has always been the most robust sex difference (Voyer et al., 1995). Therefore, it would be expected that the sex difference on the 3-dimensional task would remain even after computer familiarization. However, this does not explain why the 2-dimensional Alphanumeric task exhibited a sex difference while the 2-dimensional Gingerbread man task did not. Unfortunately, the only answer to this is anecdotal, with many of the participants expressing that the Alphanumeric task was the most difficult task, despite the fact that it required only a 2-dimensional rotation. It may be that participants had difficulty ignoring the properties of the letters and numbers and focusing on the rotation task at hand. Therefore, it may be that the sex differences on the computerized 2-dimensional Alphanumeric rotation task and 3-dimensional Basketball Player rotation task are robust enough to withstand the removal of the initial sex difference in computer game skills. This hypothesis warrants further exploration with larger sample sizes.

Lexical Decision-Making and Verbal Fluency Tasks. There was an age by sex interaction on the Lexical Decision-Making task such that men outperformed women, but there were no differences between boys and girls. This was opposite of the hypothesized difference. Particularly among adults, there was a ceiling effect on the number of correct choices (both men and women averaged over 39 out of 40), so this 
sex difference is largely due to reaction time differences. Because there was no "non-rotation" condition of the Lexical Decision-Making task, generalized reaction time was not accounted for, and the results of this task are likely due to men having generally faster reaction times than women. The hypothesized sex difference on the Verbal Fluency task was also not found. This was surprising, but there is no indication of a confound to explain these results. Meta-analyses examining adult sex differences have found that the female advantage on tasks of speech production reach a medium $(d=0.45)$ effect size, while the male advantage on mental rotation tasks reaches a somewhat larger $(\mathrm{d}=0.66)$ effect size $($ Hyde and Linn, 1988; Voyer, et al., 1995). In the case of the present study, it may be that our sample was large enough to detect sex differences in mental rotation tasks (with their larger effect sizes), but not large enough to detect differences in verbal fluency.

\section{$\underline{\text { Baseline EEG }}$}

EEG was recorded during a baseline condition and during the computerized tasks. Consistent with previous literature, it was hypothesized that there would be an age by sex interaction such that men would exhibit generally lower EEG alpha power values than women, while there would be no baseline EEG alpha power value differences between the 8-year-old boys and girls. In the baseline condition, there was a main effect for age in all areas except the occipital area, with adults exhibiting lower alpha power values than children. The age by sex interaction was not present in any location during baseline recordings. However the age by sex interaction was present in many of the task conditions (see below), suggesting that cognitive demands may enhance the adult sex differences not always apparent in baseline EEG.

There are three different explanations for the main effect of age. First, because the eight-yearolds have not finished growing, it may be that their skulls are much thinner than the adults' skulls, resulting in higher power values being transmitted to the recording sites. Secondly, the brain of an eightyear-old may still be "pruning" toward adult-like levels. In this case, the children's brains would have more connections that would lead to higher power values. Finally, it may be that generally higher power 
values are seen throughout the entire scalp of the eight-year-old because the brain is not as specialized as the adult brain, and the higher power values are the result of a generally less specialized, less efficient brain (Thatcher, 1997).

\section{$\underline{\text { Task EEG }}$}

Overall, it was hypothesized that there would be an age by sex by task type interaction.

Specifically, it was hypothesized that on the 2-dimensional Gingerbread Man and Alphanumeric tasks, there would be an age by sex interaction, with men exhibiting more activation of the left parietal area. On the 3-dimensional Basketball Player task, an interaction was hypothesized such that men would exhibit more activation of the right parietal area. On the Lexical Decision-Making task, an interaction was hypothesized such that women would exhibit more activation of the left central and left frontal activation.

2-Dimensional Gingerbread Man Task. Although the proposed hemisphere by age by sex interaction was not found, a hemisphere by sex effect was found. Examination of this interaction revealed that males exhibited more left parietal activation than females during the Gingerbread Man task. The finding of males exhibiting more left parietal activation during the 2-dimensional task was expected, and is similar to other studies that have found activation of the left parietal area during a simple rotation task (Alivisatos \& Petrides, 1997; Roberts \& Bell, 2000b).

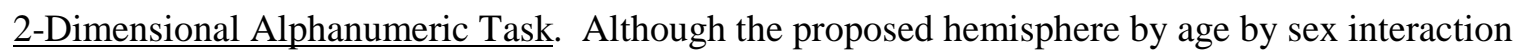
was not found at the parietal area, it was found at the posterior temporal area. Examination of this interaction revealed that men exhibited more left posterior temporal activation than women during the Alphanumeric task. While mental rotation tasks are traditionally though to be localized to the parietal area, EEG is a gross measure of brain electrical activity, and not a measure that allows for source localization. Thus, finding the effect in the posterior temporal, an area that is adjacent to the parietal area, is not unusual in the EEG literature. In fact, Roberts \& Bell (2000b), also found the same hemisphere by age by sex interaction in both the posterior temporal and parietal areas on a 2-dimensional mental rotation task. 
3-Dimensional Basketball Player Task. The proposed hemisphere by age by sex interaction was not found at the parietal area. However, a main effect of hemisphere at the posterior temporal area was found, such that all participants had more right posterior temporal activation. This effect was similar to the one expected, as research had indicated that complex rotations led to activation of the right parietal areas (e.g., Berfield et al., 1986; Michel et al., 1994; Papanicolaou et al., 1987). While the current effect was not in specifically in the parietal area, it was in the posterior temporal area, which is adjacent to the parietal area. In retrospect, the proposed hypothesis may have been incorrect, and a better hypothesis may have been for a main effect of hemisphere such that all participants exhibit more activation of the right posterior brain area. Because it was also hypothesized that more difficult tasks lead to activation of the right parietal area, this should have been the case for all participants, not just the men.

Lexical Decision-Making Task. The proposed age by sex by hemisphere interaction of women exhibiting more activation of the left central and left frontal areas was not found. Conversely, all participants exhibited more activation of the right lateral frontal area. Lexical decision making tasks are traditionally thought to lead to activation of the left frontal and left central areas (Rumsey et al., 1997; Wegesin, 1998a). Traditionally, participants in Lexical Decision-Making tasks are presented one word at a time, and are asked to make a single decision (Rumsey et al., 1997; Wegesin, 1998a). In order to make the task demands of the Lexical Decision-Making task in the present study more like the task demands of the mental rotation tasks, the Lexical Decision-Making task was modified to make the decision a "choice" between a word and a non-word, rather than a yes/no decision. Additionally, because the words were at a second grade level and "easy" for the majority of the subjects, it may be that processing was automatic, and the "choice" of comparing and contrasting became the real task for the participants. A recent analysis examining EEG alpha power values during comparison and contrast of figures found that during the comparison process there was activation of the right frontal lobe (Gill, O’Boyle, \& Hathaway, 1998). Because the processing of words in the current task may have been automatized because of the (lack of) 
task difficulty, it is very possible that the EEG effects were due to comparison, rather than Lexical Decision-Making, per se.

\section{General Conclusions}

\section{Computer Familiarization Effects}

Sex differences on the mental rotation tasks used in this study appear to have been affected by the order in which the tasks were presented. Thus, computer familiarization and computer task demands are variables that should be accounted for in future studies of sex differences on computerized tasks. The current study supports the proposal that sex differences on some computer-based tasks may be eliminated through computer familiarization or practice (Roberts \& Bell, 2000a). However, the data from the current study can also be used to demonstrate that the sex differences on some computer-based tasks are robust enough to withstand the removal of computer familiarization differences (or practice effects) between males and females. It is concluded that adult sex differences on mental rotation tasks are present, but the robustness of these sex differences warrants further research.

Overall Findings

The behavioral and EEG results, taken together, suggest that changes which affect both mental rotation task performance and EEG high alpha power values occur sometime between eight years of age and college age. During the 2-dimensional Alphanumeric and 3-dimensional Basketball Player tasks, there was an age by sex interaction in the posterior temporal regions such that men exhibited more activation than women, while there were no differences between boys and girls. The EEG effects are similar to (but not the same as) the behavioral data from the 2-dimensional Alphanumeric and 3dimensional Basketball Player tasks. In these tasks, there was as an age by sex interaction such that men were better than boys, while there were no differences between women and girls. During these tasks on behavioral and EEG measures, the mean values on each of the dependent measures presented themselves in a similar order: 1) men, 2) women, 3) girls, and 4) boys. This held true both for EEG measures (power values representing activation) and performance on the task (measured via Total Score). When there were 
significant differences among the means, there were three different patterns. First, there sometimes was a main effect of age, with adults performing better than children. Second, in some cases there was an age by sex interaction driven by men performing better than women, while boys and girls performed equally. Third, other times there was an age by sex interaction driven by men performing better than boys, while women and girls performed equally. Behaviorally, it is particularly interesting to note that on the 2dimensional Alphanumeric and 3-dimensional Basketball Player tasks, female performance did not improve from childhood to adulthood. In contrast, male performance improved dramatically from childhood to adulthood.

Clearly, something happens between 8 years of age and college age to affect performance on these tasks as well as EEG alpha power. One possible explanation of these differences could be brain plasticity, with a malleable brain forming to the needs of the body. It may be that male children differentially participate in activities that require the use of spatial skills, their brains become adapted to the tasks, and specialization to spatial tasks occurs within the brain (Baenninger \& Newcombe, 1989; Newcombe, Bandura, \& Taylor, 1983). Another explanation for the differences in rotation task ability and EEG could be the onset of puberty and the resulting hormonal changes. The body of evidence to suggest that hormonal factors influence spatial abilities is growing (Hampson, 1990a, 1990b; Hampson \& Kimura, 1988; Silverman \& Phillips, 1993; Van Goozen, Cohen-Kettenis, Gooren, Fridja, \& Van de Poll, 1994,1995). Additionally, recent experimental research has indicated that hormones may also have a direct effect on EEG (Corsi-Cabrera, Ugalde, Del-Rio-Portilla, \& Fernandez-Guasti, 2000). These different lines of research could all be used to explain the results of the current study. While the results of the current study add to the sex difference literature, they cannot be used to comment on why these sex differences in mental rotation performance and EEG activation occur.

In the case of the 2-dimensional Gingerbread Man task, there were sex differences in the EEG patterns, but no sex differences in performance. While this may appear troublesome on the surface, it may also be one of the more interesting findings in this study. Despite the EEG data to suggest that men 
and women processed the Gingerbread Man task differently, they performed at the same level. This suggests that there may be two different means to the same end. That is, even though the material is processed in different ways, the outcomes are the same.

\section{2-Dimensional vs. 3-Dimensional Rotations}

In the current study, the two simple rotation tasks were associated with activation of the left posterior brain areas, while the more complex rotation task was associated with activation of the right posterior brain areas. Although spatial tasks, and particularly mental rotation tasks, have traditionally been regarded as right hemisphere tasks (e.g., Berfield et al., 1986; Michel et al., 1994; Papanicolaou et al., 1987), the current study adds to the literature which indicates that simple, or 2-dimensional, rotation tasks lead to left hemisphere activation (Alivisatos \& Petrides, 1997; Roberts \& Bell, 2000b). It should be noted that the left hemisphere activation was not the result of cognition in general, because the current study also found that that a more complex, 3-dimensional, rotation task exhibited the traditional activation of the right posterior areas. Because the task demands of the 2-dimensional and 3-dimensional tasks were identical, there can be no argument that there was something particular about the task demands in the current study that lead to left activation on the 2-dimensional tasks.

\section{$\underline{\text { Future Research }}$}

Generally, this study has two major implications on future research. First, more research needs to be conducted examining the effects of computer familiarization (and computer tasks demands) on sex differences on computerized mental rotation tasks. This research would help discover which tasks have sex differences that are robust enough to withstand the alleviation of sex differences in computer familiarization. Second, while this study supported the hypothesis that 2-dimensional rotation tasks lead to left posterior activation and 3-dimensional rotation tasks lead to right posterior activation, more research is also needed in this area. It could be that 2-dimensional tasks are specific to the left posterior area (as found with the men in the current study), or it could be that task difficulty is the key component. 
Sex Differences

This hypothesis could be directly tested using a relatively "difficult" 2-dimensional rotation task and a relatively "easy" 3-dimensional rotation task. 


\section{References}

Alivisatos, B., \& Petrides, M. (1997). Functional activation of the human brain during mental rotation. Neuropsychologia, 35, 111-118.

Arce, C. Ramos, J., Guevara, M.A., \& Corsi-Cabrera, M. (1995). Effect of spatial ability and sex on EEG power in high school students. International Journal of Psychophysiology, 20, 11-20.

Baenninger, M., \& Newcombe, N. (1989). The role of experience in spatial test performance: A meta-analysis. Sex Roles, 20, 327-344.

Bell, M.A. (1998). The ontogeny of the EEG during infancy and childhood: Implications for cognitive development. In B. Gaineau (ed.) Neuroimaging in childhood psychiatric disorders (pp. 97 111). Berlin: Springer-Verlag.

Benninger, C., Matthis, P., \& Scheffner, D. (1984), EEG development of healthy boys and girls: Results of a longitudinal study. Electroencephalography and Clinical Neurophysiology, 57, 1-12.

Berfield, K.A., Ray, W.J., \& Newcombe, N. (1986). Sex role and spatial ability: An EEG study. Neuropsycholgia, 24, 731-735.

Boivin, M.J., Giordoni, B., Bernet, S., Amato, D.A., Lehtin, S., Koeppe, R.A., Buchtel, H.A., Foster, N.I., \& Kuhl, D.E. (1992). Verbal fluency and positron emission tomographic mapping of regional cerebral glucose metabolism. Cortex, 28, 231-239.

Brown, R. M., Hall, L. R., Holtzer, R., Brown, S. L., \& Brown, N. L. (1997) Gender and video game performance. Sex Roles, 36, 793-812.

Burgess, A.P., \& Gruzelier, J.H. (2000). Short duration power changes in the EEG during recognition memory for words and faces. Psychophysiology, 37, 596-606.

Cardebat, D., Demonet, J.F., Viallard, G., Faure, S., Puel, M., \& Celsis, P. (1996). Brain functional profiles in formal and semantic fluency tasks: A SPECT study in normals. $\underline{\text { Brain and }}$ Language, 52, 305-313. 
Capitani, E., Laiacona, M., \& Barbarotto, R. (1999). Gender affects word retrieval of certain categories in semantic fluency tasks. Cortex, 35, 273-278.

Cohen, J. (1977). Statistical power analyses for the behavioral sciences. Hillsdale, NJ: Erlbaum Cohen, M.S., Kosslyn, S.M., Bretier, H.C., DiGirolamo, G.L., Thompson, W.L., Anderson, A.K., Bookheimer, S.Y., Rosen, B.R., \& Belliveau, J.W. (1996). Changes in cortical activity during mental rotation: a mapping study using functional MRI. Brain, 119, 89-100.

Corsi-Cabrera, M., Ramos, J., Guevara, M., Arce, C., \& Gutierrez, S. (1993). Gender differences in the EEG during cognitive activity. International Journal of Neuroscience, 72, 257-264.

Corsi-Cabrera, M., Ugalde, E., Del-Rio-Portilla, Y., \& Fernandez-Guasti, A. (2000). Organizational and activational effects of gonadal steroid hormones on the EEG of male and female rats. Developmental Psychobiology, 37, 194-207.

Crawford, H.J., Clarke, S.W., \& Kitner-Triolo, M. (1996). Self-generated happy and sad emotions in low and highly hypnotizable persons during waking and hypnosis: laterality and regional EEG activity differences. International Journal of Psychophysiology, 34, 239-266.

Crawford, H.J., \& Vasilescu, P. (1995). Differential EEG pattern activity of low and high sustained attention adults during decision-making tasks. Psychophysiology, 32 (Supplement 1): S26.

Davidson, R.J., Chapman, J.P., Chapman, L.J., \& Henriques, J.B. (1990). Asymmetrical brain electrical activity discriminates between psychometrically-matched verbal and spatial cognitive tasks. Psychophysiology, 27, 528-543.

Dominick, J. R. (1984) Videogames, television violence, and aggression in teenagers. Communication, 34, 179-184.

Epting, K., Barbour, K., \& Overman, W. (1996). Failure to find variations in performance on gender-specific cognitive tasks as a function of menstrual cycle phase. Abstracts of the Society for Neuroscience, 22, p.1594. 
Epting, K., \& Overman, W. (1998). Sex sensitive tasks in men and women: A search for performance fluctuations across the menstrual cycle. Behavioral Neuroscience, 112, 304-317.

Fischer, S.C., \& Pellegrino, J.W. (1988). Hemispheric differences for components of mental rotation. Brain and Cognition, 7, 1-15.

Gasser, T., Verleger, R., Bacher, P, \& Sroka, L. (1988). Development of school age children and adolescents. I. Analysis of band power. Electroencephalography and Clinical Neurophysiology, 69, 9199.

Gill, H.S., O’Boyle, M.W., \& Hathaway, J. (1998). Cortical distribution of EEG activity for component processes during mental rotation. Cortex, 34, 707-718.

Greenfield, P. M., Camaioni, L. Ercolani, P, Weiss, L., Lauber, B. A., \& Perrucchini, P. (1994) Cognitive socialization by computer games in two cultures: inductive discovery or mastery of an iconic code? Journal of Applied Developmental Psychology, 15, 59-85.

Hassler, M. (1991). Maturational rate and spatial, verbal, and musical abilities: A seven year longitudinal study. International Journal of Neuroscience, 58, 183-198.

Hoptman, M.J., \& Davidson, R.J. (1998). Baseline EEG asymmetries and performance on neuropsychological tasks. Neuropsychologia, 36, 1343-1353.

Hugdahl, K. (1995). Psychophysiology: The mind body perspective. Harvard University Press: Cambridge, Massachusetts.

Hyde, J.S., \& Linn, M.C. (1988). Gender differences in verbal ability: A meta-analysis. Psychological Bulletin, 104, 53-69.

Janowsky, J.S., Oviatt, S.K., \& Orwoll, E.S. (1994). Testosterone influences spatial cognition in older men. Behavioral Neuroscience, 108, 225-232.

Jasper, J.J. (1958). The 10/20 international electrode system. EEG and Clinical Neurophysiology, 10, 371-375. 
Karaldi, K., Szabo, I., Szepesi, T., Kallai, J., \& Kovacs, B. (1999). Sex differences on the hand mental rotation task for 9-year-old children and young adults. Perceptual and Motor Skills, 89, 969-972.

Kimura, D. (1999). Sex and Cognition. MIT Press: Cambridge, Massachusetts.

Klimesch, W. (1996). Memory processes, brain oscillations and EEG synchronization. International Journal of Psychophysiology, 24, 61-100.

Klimesch, W., Schimke, H., Ladurner, G., \& Pfurtscheller, G. (1990). Alpha frequency and memory performance. Journal of Psychophysiology, 4, 381-390.

Kraft, R.H., Mitchell, O.R., \& Languis, M.L. (1980). Hemispheric asymmetries during six- to 8year olds performance of Piagetian conservation and reading tasks. Neuropsychologia, 18, 637-643.

Laws, K.R. (1999). Gender affects naming latencies for living and non-living things: Implications for familiarity. Cortex, 99, 729-733.

Levin, S.C., Huttenlocher, J., Taylor, A., \& Langrock, A. (1999). Early sex differences in spatial skill. Developmental Psychology, 35, 940-949.

Linn, M.C., \& Petersen, A.C. (1985). Emergence and characterization of sex differences in spatial ability: A meta-analysis. Child Development, 56, 1479-1498.

Maccoby, E.E., \& Jacklin, C.N. (1974). The Psychology of Sex Differences. Stanford, CA: Stanford University Press.

Matsuura, M., Yamototo, K., Fukasawa, H., Okubu, Y., Uesugi, H., Moriiwa, M., Kojima, T., \& Shimazono, Y. (1985). Age development and sex differences of various EEG elements in healthy children and adults -- quantification by a computerized wave form recognition method. Electroencephalography and Clinical Neurophysiology, 60, 394-406.

Mattson, A.J., Sheer, D.E., \& Fletcher, J.M. (1992). Electrophysiological evidence of lateralized disturbances in children with learning disabilities. Journal of Clinical and Experimental Neuropsychology, 14, 707-716. 
Michel, C.M., Kaufman, L., \& Williamson, S.J. (1994). Duration of EEG and MEG alpha suppression increases with angle in mental rotation task. Journal of Cognitive Neuroscience, 6, 139-150.

Newcombe, N., Bandura, M.M., \& Taylor, D. (1983). Sex differences in spatial ability and spatial activities. Sex Roles, 9, 377-386.

Oldfield, R.C. (1971). The assessment and analysis of handedness: Edinburgh Inventory. Neuropsychologia, 9, 97-113.

Papanicolaou, A.C., Deutsch, G., Bourbon, W.T., Will, K.W., Loring, D.W., \& Eisenberg, H.M. (1987). Convergent evoked potential and cerebral blood flow evidence of task-specific hemispheric differences. Electroencephalography and Clinical Neuropsychology, 66, 515-520.

Phillips, C. A., Rolls, S., Rouse, A., \& Griffiths, M. D. (1995) Home video game playing in schoolchildren: a study of incidence and patterns of play. Journal of Adolescence, 18, 687-691.

Phelps, E.A., Hyder, F., Blamire, A.M. \& Shulman, R.G. (1997). FMRI of the prefrontal cortex during overt verbal fluency. Neuroreport, 8, 561-565.

Piaget, J., \& Inhelder, B. (1956). The child's conception of space. New York: Humanities Press.

Ray, W.J., Newcombe, N., Semon, J., \& Cole, P.M. (1981). Spatial abilities, sex differences, and EEG functioning. Neuropsychologia, 19, 719-722.

Roberts, J.E, Bell, M.A. (2000). Sex differences on a computerized mental rotation task disappear with computer familiarization. Perceptual and Motor Skills, 91, 1027-1034.

Roberts, J.E., \& Bell, M.A. (2000). Sex differences on a mental rotation task: Variations in EEG hemispheric activation between children and college students. Developmental Neuropsychology, 17, 199-224.

Rumsey, J.M., Horwitz, B.C., Donohue, B.C., Nace, K., Maisog, J.M., \& Andreason, P. (1997). Phonological and orthographic components of word recognition: A PET-rCBF study. Brain, 120, 739759. 
Saccuzzo, D.P, Craig, A.S., Johnson, N.E., \& Larson, G.E. (1996). Gender differences in dynamic spatial abilities. Personality and Individual Differences, 21, 599-607.

Schaeffer, P.D., \& Thomas, J. (1998). Difficulty of spatial task and sex difference gains from practice. Perceptual and Motor Skills, 87, 56-58.

Schlosser, R., Hutchinson, M., Joseffer, S., Rusinek, H., Saarimaki, A., Stevenson, J., Dewey, S.L., \& Brodie, J.D. (1998). Functional magnetic resonance imaging of human brain activity in a verbal fluency task. Journal of Neurology, Neurosurgery, and Psychiatry, 64, 492-498.

Slabbekoorn, D., Van Goozen, S.H.M., Megens, J., Gooren, L.J.G., \& Cohen-Kettenis, P.T. (1999). Activating effects of cross-sex hormones on cognitive functioning: a study of short-term and long-term hormone effects in transsexuals. Psychoneuroendocrinology, 24, 423-447.

Tagaris, G.A., Richter, W., Seong-Gi, K., Pellizzer, G., Andersen, P., Ugurbil, K., \& Georgopoulos, A.P. (1998). Functional magnetic resonance imaging of mental rotation and memory scanning: a multidimensional scaling analysis of brain activation patterns. Brain Research Reviews, 26, 106-112.

Thatcher, R.W., (1997). Human frontal lobe development: A theory of cyclical cortical reorganization. In N. Krasneger, G. Lyon, \& P. Goldman-Rakic. Development of the prefrontal cortex: Evolution, neurobiology and behavior (pp. 85 - 113). Baltimore: Paul H. Brooks.

Van Goozen, S.H.M., Cohen-Kettenis, P.T., Gooren, L.J.G., Fridja, N.H., \& Van de Poll, N.E. (1995). Gender differences in behaviour: Activating effects of cross-sex hormones. Psychoneuroendocrinology, 20, 343-363.

Van Goozen, S.H.M., Cohen-Kettenis, P.T., Gooren, L.J.G., Fridja, N.H., \& Van de Poll, N.E. (1994). Activating effects of androgens on cognitive performance: Causal evidence in a group of femaleto-male transsexuals. Neuropsychologia, 32, 1153-1157.

Voyer, D., Voyer, S., \& Bryden, M.P. (1995). Magnitude of sex differences in spatial abilities: A meta-analysis and consideration of critical variables. Psychological Bulletin, 117, 250-270. 
Sex Differences

Wegesin, D.J. (1998a). Event-related potentials in homosexual and heterosexual men and women: Sex dimorphic patterns in verbal asymmetries and mental rotation. Brain and Cognition, 36, 7392.

Wegesin, D.J. (1998b). A neuropsychologic profile of homosexual and heterosexual men and women. Archives of Sexual Behavior, 27, 91-108. 
Table 1

$\underline{\text { Summary of F Values for Reaction Time on Non-Rotation Trials of 2-D Gingerbread Man, 2-D Alphanumeric, and 3-D Basketball Player Tasks }}$

\begin{tabular}{llll}
\hline & Gingerbread Man & Alphanumeric & Basketball Player \\
\hline$d f$ & 1,60 & 1,60 & 1,60 \\
& & & \\
Age & $38.56^{* * *}$ & $80.99^{* * *}$ & $37.49^{* * *}$ \\
& A $<$ C & A $<$ C & A $<$ C
\end{tabular}

Sex

Age X Sex

$\begin{array}{ll}\mathrm{b}=\text { boys } & \mathrm{A}=\text { Adults } \\ \mathrm{g}=\text { girls } & \mathrm{C}=\text { Children } \\ \mathrm{m}=\text { men } & \mathrm{M}=\text { Males } \\ \mathrm{w}=\text { women } & \mathrm{F}=\text { Females }\end{array}$

Note. Only numbers that were significant at the $\mathrm{p} \leq .10$ level are presented.

$* \mathrm{p} \leq .05 . * * \mathrm{p} \leq .01 . * * * \mathrm{p} \leq .001 .+\mathrm{p} \leq .10$. 
Table 2

$\underline{\text { Summary of F Values for Number Correct on Non-Rotation Trials of 2-D Gingerbread Man, 2-D Alphanumeric, and 3-D Basketball Player Tasks }}$

\begin{tabular}{llll}
\hline & Gingerbread Man & Alphanumeric & Basketball Player \\
\hline$d f$ & 1,60 & 1,60 & 1,60 \\
& & $7.12^{* *}$ & 4.55 \\
Age & A $>$ C & A $>$ C
\end{tabular}

Sex

Age X Sex

$\begin{array}{ll}\mathrm{b}=\text { boys } & \mathrm{A}=\text { Adults } \\ \mathrm{g}=\text { girls } & \mathrm{C}=\text { Children } \\ \mathrm{m}=\text { men } & \mathrm{M}=\text { Males } \\ \mathrm{w}=\text { women } & \mathrm{F}=\text { Females }\end{array}$

Note. Only numbers that were significant at the $\mathrm{p} \leq .10$ level are presented.

$* \mathrm{p} \leq .05 . * * \mathrm{p} \leq .01 . * * * \mathrm{p} \leq .001 .+\mathrm{p} \leq .10$. 
Table 3

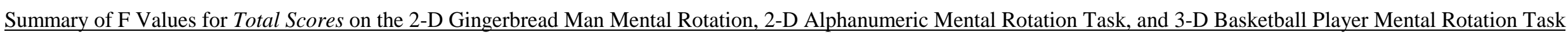

\begin{tabular}{|c|c|c|c|}
\hline & Gingerbread Man & Alphanumeric & Basketball Playes \\
\hline$d f$ & 1,60 & 1,59 & 1,60 \\
\hline Age & $\begin{array}{l}32.47 * * * \\
\mathrm{~A}<\mathrm{C}\end{array}$ & $\begin{array}{l}17.10^{* * *} \\
\mathrm{~A}<\mathrm{C}\end{array}$ & $\begin{array}{l}8.63^{* *} \\
\mathrm{~A}<\mathrm{C}\end{array}$ \\
\hline Sex & & & \\
\hline Age X Sex & & $\begin{array}{l}7.23^{* *} \\
\mathrm{~m}=\mathrm{w} \\
\mathrm{m}<\mathrm{b} \\
\mathrm{m}<\mathrm{g} \\
\mathrm{w}<\mathrm{b} \\
\mathrm{w}=\mathrm{g} \\
\mathrm{b}>\mathrm{g}\end{array}$ & $\begin{array}{l}4.22 * \\
\mathrm{~m}=\mathrm{w} \\
\mathrm{m}<\mathrm{b} \\
\mathrm{m}=\mathrm{g} \\
\mathrm{w}<\mathrm{b} \\
\mathrm{w}=\mathrm{g} \\
\mathrm{b}=\mathrm{g}\end{array}$ \\
\hline
\end{tabular}

$\begin{array}{ll}\mathrm{b}=\text { boys } & \mathrm{A}=\text { Adults } \\ \mathrm{g}=\text { girls } & \mathrm{C}=\text { Children } \\ \mathrm{m}=\text { men } & \mathrm{M}=\text { Males } \\ \mathrm{w}=\text { women } & \mathrm{F}=\text { Females }\end{array}$

Note. Only numbers that were significant at the $\mathrm{p} \leq .10$ level are presented.

$* \mathrm{p} \leq .05 . * \mathrm{p} \leq .01 . * * * \mathrm{p} \leq .001 .+\mathrm{p} \leq .10$

Note. Overall refers to the overall statistical test that combined all angles of rotation.

Note. Lower Total Scores means lower reaction time and fewer incorrect trials. Therefore, lower numbers indicate better performance. 
Table 4

Summary of F Values for Number Correct, Reaction Time, and Total Score on the Lexical Decision-Making Task

\begin{tabular}{llll}
\hline & Reaction Time & Number Correct & Total Score \\
\hline$d f$ & 1,60 & 1,60 & 1,60 \\
& & & \\
Age & $75.10^{* * *}$ & $10.95^{* * *}$ & $113.09^{* * *}$ \\
& $\mathrm{~A}<\mathrm{C}$ & $\mathrm{A}<\mathrm{C}$ & $\mathrm{A}<\mathrm{C}$ \\
& & \\
Sex & & \\
& & \\
Age X Sex & & $7.19^{* *}$ \\
& & $\mathrm{~m}<\mathrm{w}$ \\
& & $\mathrm{b}=\mathrm{g}$ \\
\hline
\end{tabular}

$\begin{array}{ll}\mathrm{b}=\text { boys } & \mathrm{A}=\text { Adults } \\ \mathrm{g}=\text { girls } & \mathrm{C}=\text { Children } \\ \mathrm{m}=\text { men } & \mathrm{M}=\text { Males } \\ \mathrm{W}=\text { women } & \mathrm{F}=\text { Females }\end{array}$

Note. Only numbers that were significant at the $\mathrm{p} \leq .10$ level are presented.

$* \mathrm{p} \leq .05 . * * \mathrm{p} \leq .01 . * * * \mathrm{p} \leq .001 .+\mathrm{p} \leq .10$. 
Table 5

$\underline{\text { Summary of MANOVA F Values for High Alpha }(10.5-13.5 \mathrm{~Hz}) \text { during the Baseline Condition }}$

\begin{tabular}{|c|c|c|c|c|c|c|c|}
\hline$\underline{\text { Region }}$ & Age & Sex & Age X Sex & Hemi & Hemi X Age & Hemi X Sex & Hemi X Age X Sex \\
\hline$d f$ & 1,60 & 1,60 & 1,60 & 1,60 & 1,60 & 1,60 & 1,60 \\
\hline Fp1, Fp2 & $\begin{array}{l}3.95^{*} \\
\mathrm{~A}<\mathrm{C}\end{array}$ & & & & $3.19+$ & & \\
\hline $\mathrm{F} 3, \mathrm{~F} 4$ & $\begin{array}{l}8.06^{* * *} \\
\mathrm{~A}<\mathrm{C}\end{array}$ & & & & & & \\
\hline F7, F8 & $\begin{array}{l}11.77 * * * \\
\mathrm{~A}<\mathrm{C}\end{array}$ & & & $3.63+$ & $\begin{array}{l}5.63^{*} \\
\mathrm{C}(\mathrm{L}<\mathrm{R}) \\
\mathrm{A}(\mathrm{L}=\mathrm{R})\end{array}$ & & $\begin{array}{l}5.11^{*} \\
\mathrm{~g}(\mathrm{~L}<\mathrm{R}) \\
\mathrm{m}, \mathrm{w}, \mathrm{b}(\mathrm{L}=\mathrm{R})\end{array}$ \\
\hline $\mathrm{C} 3, \mathrm{C} 4$ & $\begin{array}{l}5.91^{*} \\
\mathrm{~A}<\mathrm{C}\end{array}$ & & & & $\begin{array}{l}4.21^{*} \\
\mathrm{~A}(\mathrm{~L}=\mathrm{R}) \\
\mathrm{C}(\mathrm{L}<\mathrm{R})\end{array}$ & & $3.35+$ \\
\hline $\mathrm{T} 3, \mathrm{~T} 4$ & $\begin{array}{l}8.00 * * \\
\mathrm{~A}<\mathrm{C}\end{array}$ & & & $\begin{array}{l}10.14^{* * *} \\
\mathrm{~L}<\mathrm{R}\end{array}$ & & & $3.45+$ \\
\hline T5, T6 & $3.73+$ & & & & & & \\
\hline P3, P4 & $2.85+$ & & & & & $\begin{array}{l}4.55^{*} \\
M(L=R) \\
F(L=R)\end{array}$ & \\
\hline
\end{tabular}

Note. Only numbers that were significant at the $\mathrm{p} \leq .10$ level are presented.

$\begin{array}{lll}\mathrm{b}=\text { boys } & \mathrm{A}=\text { Adults } & \mathrm{L}=\text { left } \\ \mathrm{g}=\text { girls } & \mathrm{C}=\text { Children } & \mathrm{R}=\text { right } \\ \mathrm{m}=\text { men } & \mathrm{M}=\text { Males } & \\ \mathrm{w}=\text { women } & \mathrm{F}=\text { Females } & \end{array}$

Hemi $=$ Left or Right Hemisphere

$* \mathrm{p} \leq .05 . * * \mathrm{p} \leq .01 . * * * \mathrm{p} \leq .001 .+\mathrm{p} \leq .10$. 
Table 6

Summary of MANCOVA F Values for High Alpha Values $(10.5-13.5 \mathrm{~Hz})$ during the Task Conditions Covaried with Baseline

\begin{tabular}{|c|c|c|c|c|c|c|c|c|c|}
\hline Region & Age & Sex & Age X Sex & Task & Hemi & Task X Hemi & Task X Age X Hemi & Task X Sex X Hemi & Task X Age X Sex X Hemi \\
\hline$d f$ & 1,58 & 1,58 & 1,58 & 4,55 & 4,55 & 4,55 & 4,55 & 4,55 & 4,55 \\
\hline $1(\mathrm{Fp} 1, \mathrm{Fp} 2)$ & & $3.27+$ & & $14.44 * * *$ & & & & & \\
\hline $2(\mathrm{~F} 3, \mathrm{~F} 4)$ & $38.56 * * *$ & $6.21 *$ & $5.04 *$ & & & & & & \\
\hline $3(\mathrm{~F} 7, \mathrm{~F} 8)$ & & $2.85+$ & $2.80+$ & $10.58 * * *$ & $8.50^{* *}$ & & & & \\
\hline $4(\mathrm{C} 3, \mathrm{C} 4)$ & $30.77 * * *$ & $6.09 *$ & & $7.47^{* * *}$ & & & & & \\
\hline $5(\mathrm{~T} 3, \mathrm{~T} 4)$ & $5.07 *$ & & & $4.42 * *$ & & & & & \\
\hline $6(\mathrm{~T} 5, \mathrm{~T} 6)$ & $36.91 * * *$ & & $4.27^{*}$ & $2.03+$ & & $3.55^{* *}$ & & & $2.12+$ \\
\hline 7 (P3, P4) & $36.54 * * *$ & $5.07 *$ & $4.08^{*}$ & $5.25^{* * *}$ & & & & $3.50 * *$ & \\
\hline $8(\mathrm{O} 1, \mathrm{O} 2)$ & $16.99 * * *$ & $7.35^{* *}$ & & $6.39 * * *$ & $2.73+$ & $2.99 *$ & & & \\
\hline
\end{tabular}

Note. Only numbers that were significant at the $\mathrm{p} \leq .10$ level are presented.

Task = Gingerbread Man Mental Rotation. Basketball Player Mental Rotation, Alphanumeric Mental Rotation, Lexical Decision-Making, or Reading Hemi $=$ Left or Right Hemisphere

$* \mathrm{p} \leq .05 . * * \mathrm{p} \leq .01 . * * * \mathrm{p} \leq .001 .+\mathrm{p} \leq .10$. 
Table 7

Summary of MANCOVA F Values for Post-Hoc Analyses of High Alpha (10.5 - 13.5 Hz) during Gingerbread Man Mental Rotation Task Covaried with Baseline

\begin{tabular}{lll}
\hline Region & Age & Sex \\
\hline$d f$ & 1,58 & 1,58 \\
Fp1, Fp2 & & $2.75+$ \\
& & \\
F3, F4 & $19.55^{* * * *}$ & $6.06^{*}$ \\
& A $<$ C & M $<$ F
\end{tabular}

F7, F8

$\mathrm{C} 3, \mathrm{C} 4$

$15.22 * * *$

$3.56+$

$4.75^{*}$

$\mathrm{R}(\mathrm{A}=\mathrm{C})$

$\mathrm{L}(\mathrm{A}=\mathrm{C})$

$\mathrm{A}<\mathrm{C}$

Age X Sex

Hemi Hemi X Age

Hemi X Sex

Hemi X Age X Sex

1,58

1,58

T3, T4

T5, T6

$15.38 * * * \quad 2.88+$

A $<$ C

P3, P4

$21.55^{* * *} \quad 6.37 * *$

A $<$ C $\quad$ M $<$ F

6.17*

$\mathrm{L}(\mathrm{M}<\mathrm{F})$

$\mathrm{R}(\mathrm{M}=\mathrm{F})$

$\mathrm{O} 1, \mathrm{O} 2$

$\begin{array}{ll}14.97 * * * & 6.96 * * \\ \text { A }<\text { C } & \mathrm{M}<\mathrm{F}\end{array}$

$5.01 *$

6.91**

$\mathrm{L}(\mathrm{m}<\mathrm{w} ; \mathrm{b}=\mathrm{g})$

$\mathrm{R}(\mathrm{m}=\mathrm{w} ; \mathrm{b}=\mathrm{g})$

Note. Only numbers that were significant at the $\mathrm{p} \leq .10$ level are presented.

$\begin{array}{ll}\mathrm{b}=\text { boys } & \mathrm{A}=\text { Adults } \\ \mathrm{g}=\text { girls } & \mathrm{C}=\text { Children } \\ \mathrm{m}=\text { men } & \mathrm{M}=\text { Males } \\ \mathrm{w}=\text { women } & \mathrm{F}=\text { Females }\end{array}$

Hemi $=$ Left or Right Hemisphere

$* \mathrm{p} \leq .05 . * * \mathrm{p} \leq .01 . * * * \mathrm{p} \leq .001 .+\mathrm{p} \leq .10$. 
Table 8

$\underline{\text { Summary of MANCOVA F Values for Post-Hoc Analyses of High Alpha (10.5 - 13.5 Hz) during Alphanumeric Mental Rotation Task Covaried with Baseline }}$

\begin{tabular}{|c|c|c|c|c|c|c|c|}
\hline Region & Age & Sex & Age X Sex & Hemi & Hemi X Age & Hemi X Sex & Hemi X Age X Sex \\
\hline$d f$ & 1,58 & 1,58 & 1,58 & 1,58 & 1,58 & 1,58 & 1,58 \\
\hline Fp1, Fp2 & & $\begin{array}{l}4.81^{*} \\
\mathrm{M}<\mathrm{F}\end{array}$ & & & & & \\
\hline $\mathrm{F} 3, \mathrm{~F} 4$ & $\begin{array}{l}21.60^{* * *} \\
\mathrm{~A}<\mathrm{C}\end{array}$ & $\begin{array}{l}4.38^{*} \\
\mathrm{M}<\mathrm{F}\end{array}$ & $\begin{array}{l}4.78^{*} \\
\mathrm{~m}<\mathrm{w} \\
\mathrm{b}=\mathrm{g}\end{array}$ & & & & $3.62+$ \\
\hline F7, F8 & $3.04+$ & & & $\begin{array}{l}10.03^{* * *} \\
\mathrm{R}<\mathrm{L}\end{array}$ & & & \\
\hline $\mathrm{C} 3, \mathrm{C} 4$ & $\begin{array}{l}18.95^{* * *} \\
\mathrm{~A}<\mathrm{C}\end{array}$ & $3.05+$ & $2.82+$ & & & $\begin{array}{l}4.08^{*} \\
\mathrm{~L}(\mathrm{M}<\mathrm{F}) \\
\mathrm{R}(\mathrm{M}=\mathrm{F})\end{array}$ & \\
\hline $\mathrm{T} 3, \mathrm{~T} 4$ & $\begin{array}{l}8.27 * * \\
\mathrm{~A}<\mathrm{C}\end{array}$ & & & & & $3.38+$ & \\
\hline T5, T6 & $\begin{array}{l}30.06^{* * * *} \\
\mathrm{~A}<\mathrm{C}\end{array}$ & & $3.40+$ & & & & $\begin{array}{l}6.77 * * \\
\mathrm{~L}(\mathrm{~m}<\mathrm{w} ; \mathrm{b}=\mathrm{g}) \\
\mathrm{R}(\mathrm{m}=\mathrm{w} ; \mathrm{b}=\mathrm{g})\end{array}$ \\
\hline $\mathrm{P} 3, \mathrm{P} 4$ & $\begin{array}{l}24.36^{* * * *} \\
\mathrm{~A}<\mathrm{C}\end{array}$ & & $\begin{array}{l}4.55^{*} \\
\mathrm{~m}<\mathrm{w} \\
\mathrm{b}=\mathrm{g}\end{array}$ & & & & \\
\hline $\mathrm{O} 1, \mathrm{O} 2$ & $\begin{array}{l}12.41^{* * * *} \\
\mathrm{~A}<\mathrm{C}\end{array}$ & $3.45+$ & & & & $\begin{array}{l}3.88^{*} \\
\mathrm{~L}(\mathrm{M}<\mathrm{F}) \\
\mathrm{R}(\mathrm{M}=\mathrm{F})\end{array}$ & \\
\hline
\end{tabular}

Note. Only numbers that were significant at the $\mathrm{p} \leq .10$ level are presented.

$\begin{array}{ll}\mathrm{b}=\text { boys } & \mathrm{A}=\text { Adults } \\ \mathrm{g}=\text { girls } & \mathrm{C}=\text { Children } \\ \mathrm{m}=\text { men } & \mathrm{M}=\text { Males } \\ \mathrm{w}=\text { women } & \mathrm{F}=\text { Females }\end{array}$

Hemi $=$ Left or Right Hemisphere

$* \underline{\mathrm{p}} \leq .05 . * * \mathrm{p} \leq .01 . * * * \mathrm{p} \leq .001 .+\mathrm{p} \leq .10$. 
Table 9

Summary of MANCOVA F Values for Post-Hoc Analyses of High Alpha (10.5 - 13.5 Hz) during Basketball Player Mental Rotation Task Covaried with Baseline

$\frac{\text { Region }}{d f}$

Fp1, Fp2

F3, F4

$\begin{array}{ll}33.91 * * * & 5.18^{*} \\ \mathrm{~A}<\mathrm{C} & \mathrm{M}<\mathrm{F}\end{array}$

F7, F8

C3, C4

$26.51 * * *$

$\mathrm{A}<\mathrm{C}$

$3.19+$

T5, T6

$24.29 * * *$

$\mathrm{A}<\mathrm{C}$

P3, P4

$21.21 * * *$

$\mathrm{A}<\mathrm{C}$

$\mathrm{M}<\mathrm{F}$

$\mathrm{O} 1, \mathrm{O} 2$

$\begin{array}{ll}9.93 * * & 4.32 * \\ \mathrm{~A}<\mathrm{C} & \mathrm{M}<\mathrm{F}\end{array}$

Note. Only numbers that were significant at the $\mathrm{p} \leq .10$ level are presented.

$\begin{array}{ll}\mathrm{b}=\text { boys } & \mathrm{A}=\text { Adults } \\ \mathrm{g}=\text { girls } & \mathrm{C}=\text { Children } \\ \mathrm{m}=\text { men } & \mathrm{M}=\text { Males } \\ \mathrm{w}=\text { women } & \mathrm{F}=\text { Females }\end{array}$

$\mathrm{F}=$ Females

Hemi $=$ Left or Right Hemisphere

$* \underline{\mathrm{p}} \leq .05 . * * \mathrm{p} \leq .01 . * * * \mathrm{p} \leq .001 .+\underline{\mathrm{p}} \leq .10$. 
Table 10

Summary of MANCOVA F Values for Post-Hoc Analyses of High Alpha (10.5 - 13.5 Hz) during Lexical Decision-Making Task Covaried with Baseline

\begin{tabular}{|c|c|c|c|c|c|c|c|}
\hline Region & Age & Sex & Age X Sex & Hemi & Hemi X Age & Hemi X Sex & Hemi X Age X Sex \\
\hline$d f$ & 1,58 & 1,58 & 1,58 & 1,58 & 1,58 & 1,58 & 1,58 \\
\hline Fp1, Fp2 & $\begin{array}{l}11.16^{* * * *} \\
\mathrm{~A}<\mathrm{C}\end{array}$ & $\begin{array}{l}4.45^{*} \\
\mathrm{M}<\mathrm{F}\end{array}$ & & & & & \\
\hline F3, F4 & $\begin{array}{l}43.47 * * * \\
\mathrm{~A}<\mathrm{C}\end{array}$ & $2.73+$ & $\begin{array}{l}3.94^{*} \\
\mathrm{~m}<\mathrm{w} \\
\mathrm{b}=\mathrm{g}\end{array}$ & & & & \\
\hline F7, F8 & & $\begin{array}{l}4.94^{*} \\
\mathrm{M}<\mathrm{F}\end{array}$ & $\begin{array}{l}5.03^{*} \\
\mathrm{~m}<\mathrm{w} \\
\mathrm{b}=\mathrm{g}\end{array}$ & $\begin{array}{l}4.64^{*} \\
\mathrm{~L}<\mathrm{R}\end{array}$ & & & \\
\hline $\mathrm{C} 3, \mathrm{C} 4$ & $\begin{array}{l}41.04 * * * \\
\mathrm{~A}<\mathrm{C}\end{array}$ & $3.63+$ & & & & & \\
\hline $\mathrm{T} 3, \mathrm{~T} 4$ & $\begin{array}{l}8.17 * * \\
\mathrm{~A}<\mathrm{C}\end{array}$ & & & & & & \\
\hline $\mathrm{T} 5, \mathrm{~T} 6$ & $\begin{array}{l}38.49 * * * \\
\mathrm{~A}<\mathrm{C}\end{array}$ & & $\begin{array}{l}5.93^{*} \\
\mathrm{~m}<\mathrm{w} \\
\mathrm{b}=\mathrm{g}\end{array}$ & $3.24+$ & & & \\
\hline P3, P4 & $\begin{array}{l}49.30 * * * \\
\mathrm{~A}<\mathrm{C}\end{array}$ & & $3.32+$ & & & & $3.12+$ \\
\hline $\mathrm{O} 1, \mathrm{O} 2$ & $\begin{array}{l}19.57 * * * \\
\mathrm{~A}<\mathrm{C}\end{array}$ & $\begin{array}{l}6.34 * \\
M<F\end{array}$ & & & & & \\
\hline
\end{tabular}

Note. Only numbers that were significant at the $\mathrm{p} \leq .10$ level are presented.

$\begin{array}{ll}\mathrm{b}=\text { boys } & \mathrm{A}=\text { Adults } \\ \mathrm{g}=\text { girls } & \mathrm{C}=\text { Children } \\ \mathrm{m}=\text { men } & \mathrm{M}=\text { Males } \\ \mathrm{w}=\text { women } & \mathrm{F}=\text { Females }\end{array}$

$\mathrm{F}=$ Females

Hemi $=$ Left or Right Hemisphere

$* \mathrm{p} \leq .05 . * * \mathrm{p} \leq .01 . * * * \mathrm{p} \leq .001 .+\mathrm{p} \leq .10$. 
Table 11

Summary of MANCOVA F Values for Post-Hoc Analyses of High Alpha $(10.5-13.5 \mathrm{~Hz})$ during Reading Task Covaried with Baseline

\begin{tabular}{|c|c|c|c|c|c|c|c|}
\hline$\underline{\text { Region }}$ & Age & Sex & Age X Sex & Hemi & Hemi X Age & Hemi X Sex & Hemi X Age X Sex \\
\hline$d f$ & 1,58 & 1,58 & 1,58 & 1,58 & 1,58 & 1,58 & 1,58 \\
\hline Fp1, Fp2 & $\begin{array}{l}4.40^{*} \\
\mathrm{~A}<\mathrm{C}\end{array}$ & & & & & & \\
\hline $\mathrm{F} 3, \mathrm{~F} 4$ & $\begin{array}{l}36.96^{* * * *} \\
\mathrm{~A}<\mathrm{C}\end{array}$ & $\begin{array}{l}6.54 * * \\
\mathrm{M}<\mathrm{F}\end{array}$ & $\begin{array}{l}7.53 * * \\
\mathrm{~m}<\mathrm{w} \\
\mathrm{b}=\mathrm{g}\end{array}$ & & & & \\
\hline F7, F8 & & $3.60+$ & $3.05+$ & $3.52+$ & $\begin{array}{l}9.66^{* *} \\
\mathrm{~L}(\mathrm{C}<\mathrm{A}) \\
\mathrm{R}(\mathrm{C}=\mathrm{A})\end{array}$ & & \\
\hline $\mathrm{C} 3, \mathrm{C} 4$ & $\begin{array}{l}16.86^{* * * *} \\
\mathrm{~A}<\mathrm{C}\end{array}$ & $\begin{array}{l}10.03^{* *} \\
\mathrm{M}<\mathrm{F}\end{array}$ & & & & & \\
\hline $\mathrm{T} 3, \mathrm{~T} 4$ & $3.50+$ & $\begin{array}{l}4.09 * \\
M<F\end{array}$ & & & $2.96+$ & & \\
\hline T5, T6 & $\begin{array}{l}43.83 * * * \\
\mathrm{~A}<\mathrm{C}\end{array}$ & $2.90+$ & $2.90+$ & & & & \\
\hline $\mathrm{P} 3, \mathrm{P} 4$ & $\begin{array}{l}27.09 * * * \\
\mathrm{~A}<\mathrm{C}\end{array}$ & $\begin{array}{l}5.49^{*} \\
\mathrm{M}<\mathrm{F}\end{array}$ & $3.46+$ & & & & \\
\hline $\mathrm{O} 1, \mathrm{O} 2$ & $\begin{array}{l}12.96 * * * \\
\mathrm{~A}<\mathrm{C}\end{array}$ & $\begin{array}{l}9.67 * * \\
\mathrm{M}<\mathrm{F}\end{array}$ & & $\begin{array}{l}5.93^{*} \\
\mathrm{~L}<\mathrm{R}\end{array}$ & & & $2.94+$ \\
\hline
\end{tabular}

Note. Only numbers that were significant at the $\mathrm{p} \leq .10$ level are presented.

$\begin{array}{ll}\mathrm{b}=\text { boys } & \mathrm{A}=\text { Adults } \\ \mathrm{g}=\text { girls } & \mathrm{C}=\text { Children } \\ \mathrm{m}=\text { men } & \mathrm{M}=\text { Males } \\ \mathrm{w}=\text { women } & \mathrm{F}=\text { Females }\end{array}$

$\mathrm{F}=$ Females

Hemi $=$ Left or Right Hemisphere

$* \underline{\mathrm{p}} \leq .05 . * * \mathrm{p} \leq .01 . * * * \mathrm{p} \leq .001 .+\underline{\mathrm{p}} \leq .10$. 


\section{Figure Captions}

Figure 1. Samples of the 2-Dimensional "Gingerbread Man" Mental Rotation Task

Figure 2. Samples of the 2-Dimensional Alphanumeric Mental Rotation Task

Figure 3. Sample of the 3-Dimensional "Basketball Man" Mental Rotation Task

Figure 4. Samples of the Water Level Task

Figure 5. Average Reaction Time on Correct Trials of the 2-D Gingerbread Man Mental Rotation Task

Figure 6. Total Number of Correct Responses on the 2-D Gingerbread Man Rotation Task

Figure 7. Average Reaction Time on Correct Trials of the 2-D Alphanumeric Mental Rotation Task

Figure 8. Total Number of Correct Responses on the 2-D Alphanumeric Mental Rotation Task

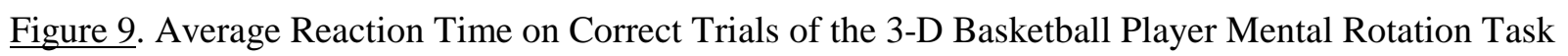

Figure 10. Total Number of Correct Responses on the 3-D Basketball Player Mental Rotation Task

Figure 11. Total Score on the 2-D Gingerbread Man Rotation Task

Figure 12. Total Score on the 2-D Alphanumeric Mental Rotation Task

Figure 13. Total Score on the 3-D Basketball Player Mental Rotation Task

Figure 14. Average Number of Correct Trials on the Water Level Task

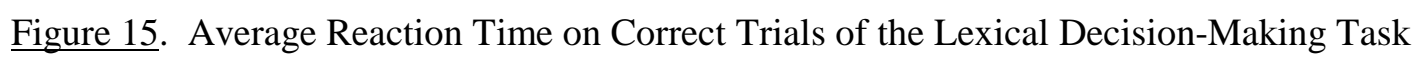

Figure 16. Average Number of Correct Trials on Lexical Decision-Making Task

Figure 17. Total Score on the Lexical Decision-Making Task

Figure 18. Average Number of Words Produced on the Verbal Fluency Task

Figure 19. Baseline EEG at Lateral Frontal Region

Figure 20. Baseline EEG at Central Region

Figure 21. Baseline EEG at Parietal Region

Figure 22. 2-Dimensional "Gingerbread Man" Mental Rotation Task EEG Covaried with Baseline EEG at Lateral Frontal Region 
Figure 23. 2-Dimensional "Gingerbread Man" Mental Rotation Task EEG Covaried with Baseline EEG at Parietal Region

Figure 24. 2-Dimensional "Gingerbread Man" Mental Rotation Task EEG Covaried with Baseline EEG at Occipital Region

Figure 25. 2-Dimensional Alphanumeric Mental Rotation Task EEG Covaried with Baseline EEG at Central Region

Figure 26. 2-Dimensional Alphanumeric Mental Rotation Task EEG Covaried with Baseline EEG at Occipital Region

Figure 27. 2-Dimensional Alphanumeric Task EEG Covaried with Baseline EEG at Posterior Temporal Region

Figure 28. 3-Dimensional "Basketball Player" Mental Rotation Task EEG Covaried with Baseline EEG at Lateral Frontal Region

Figure 29. 3-Dimensional "Basketball Player" Mental Rotation Task EEG Covaried with Baseline EEG at Central Region

Figure 30. Reading Task EEG Covaried with Baseline EEG at Lateral Frontal Region 

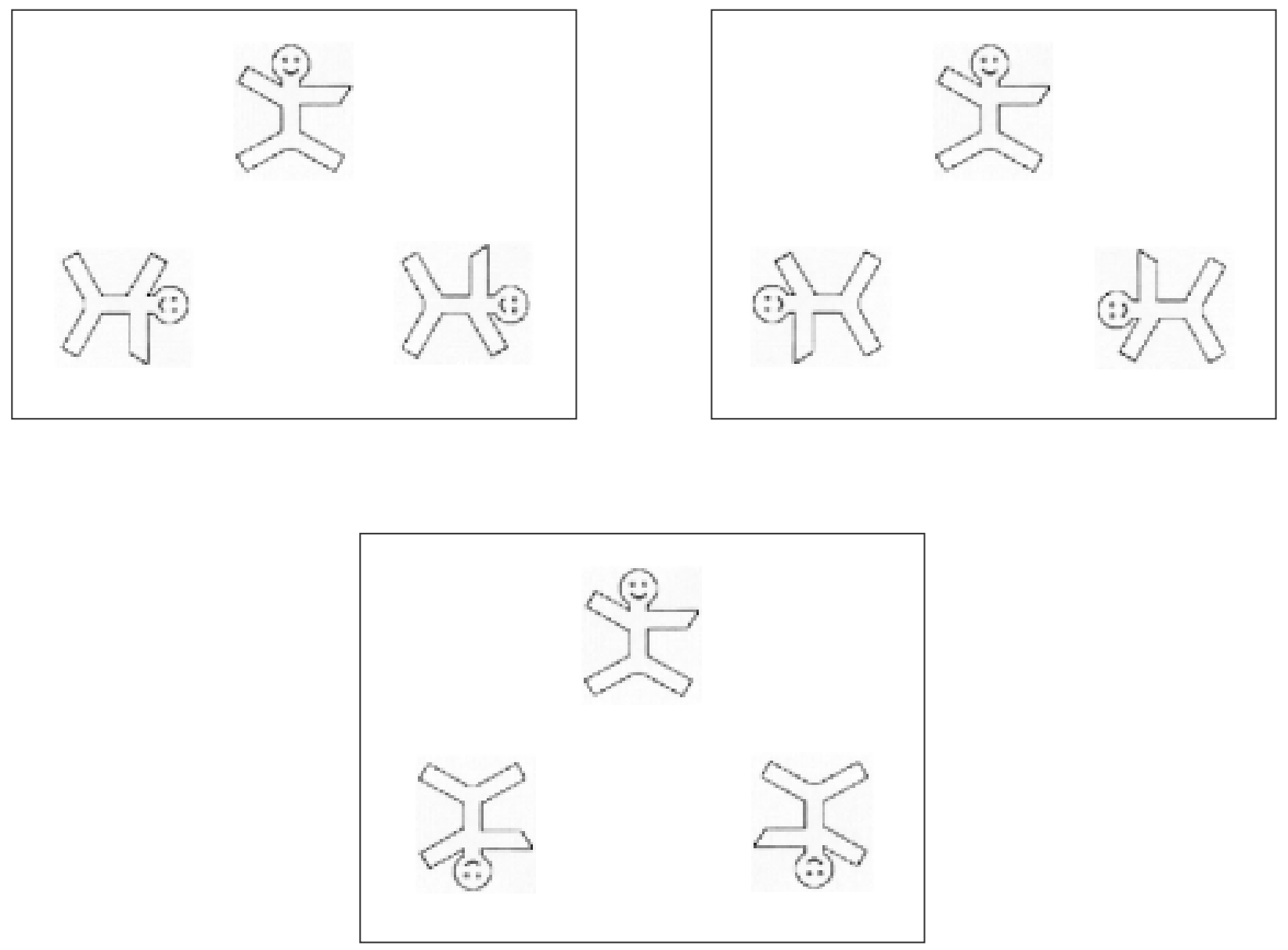

Figure 1

Samples of the 2-Dimensional "Gingerbread Man" Mental Rotation Task 
Sex Differences
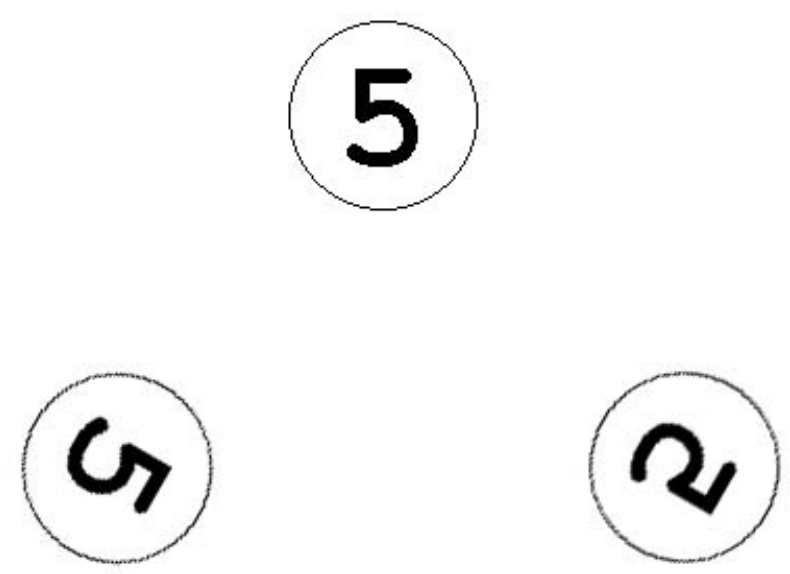

Figure 2

Sample of the 2-Dimensional Alphanumeric Mental Rotation Task 
Sex Differences
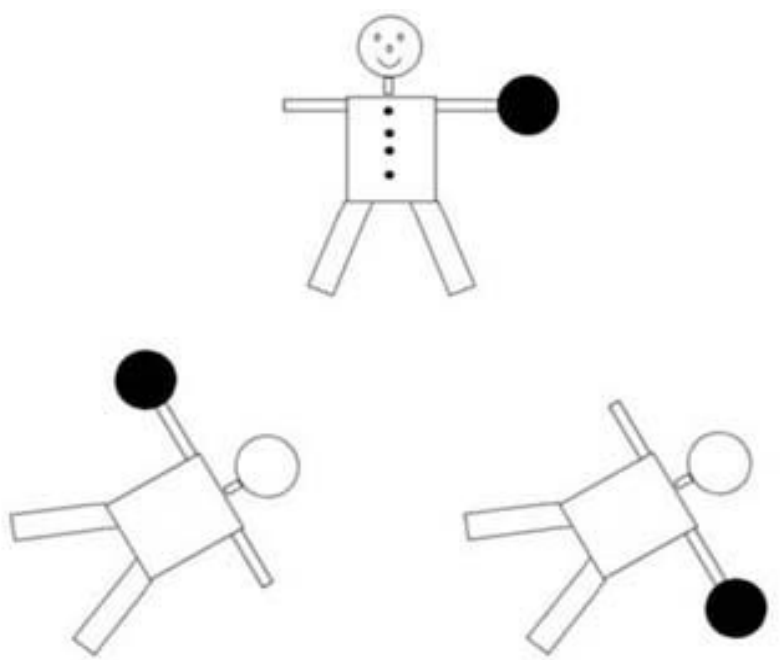

Figure 3

Sample of the 3-Dimensional "Basketball Man” Mental Rotation Task 
Sex Differences
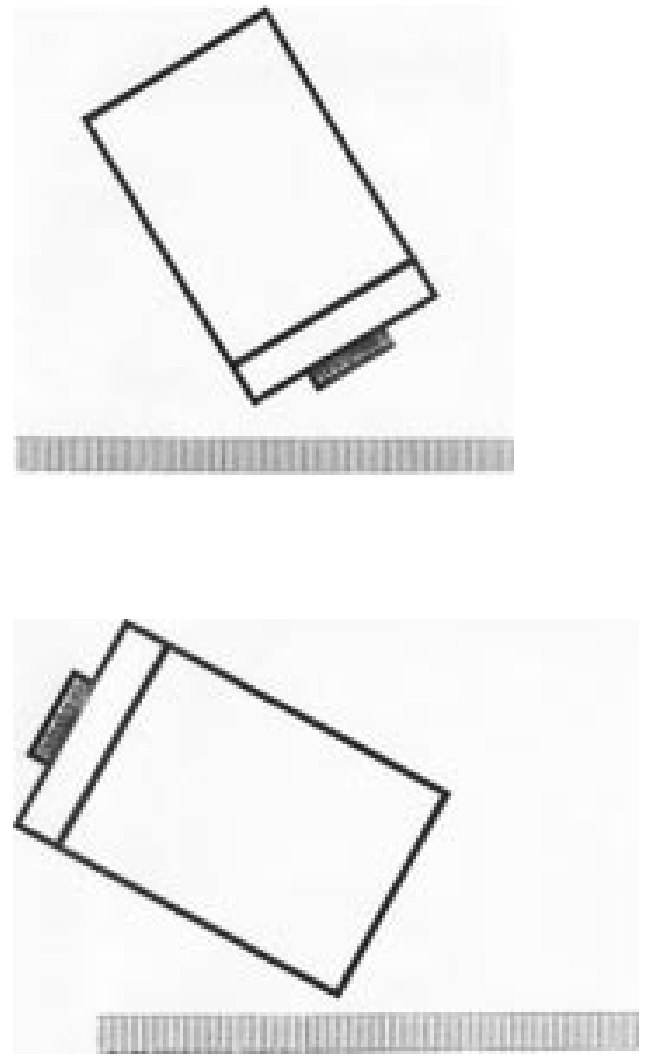

Figure 4

Samples of the Water Level Task 


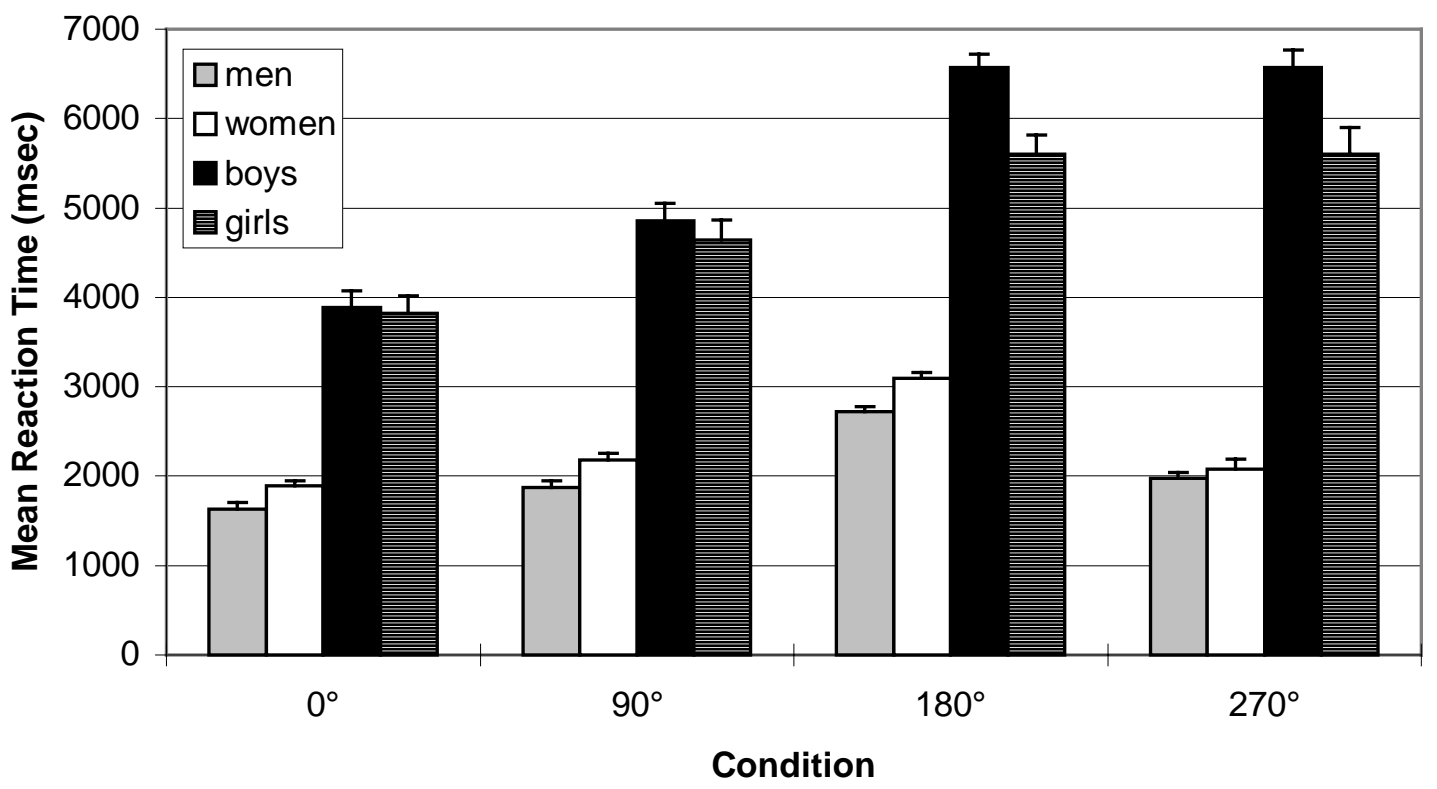

Figure 5

Mean Reaction Time on Correct Trials of the 2-D Gingerbread Man Mental Rotation Task 


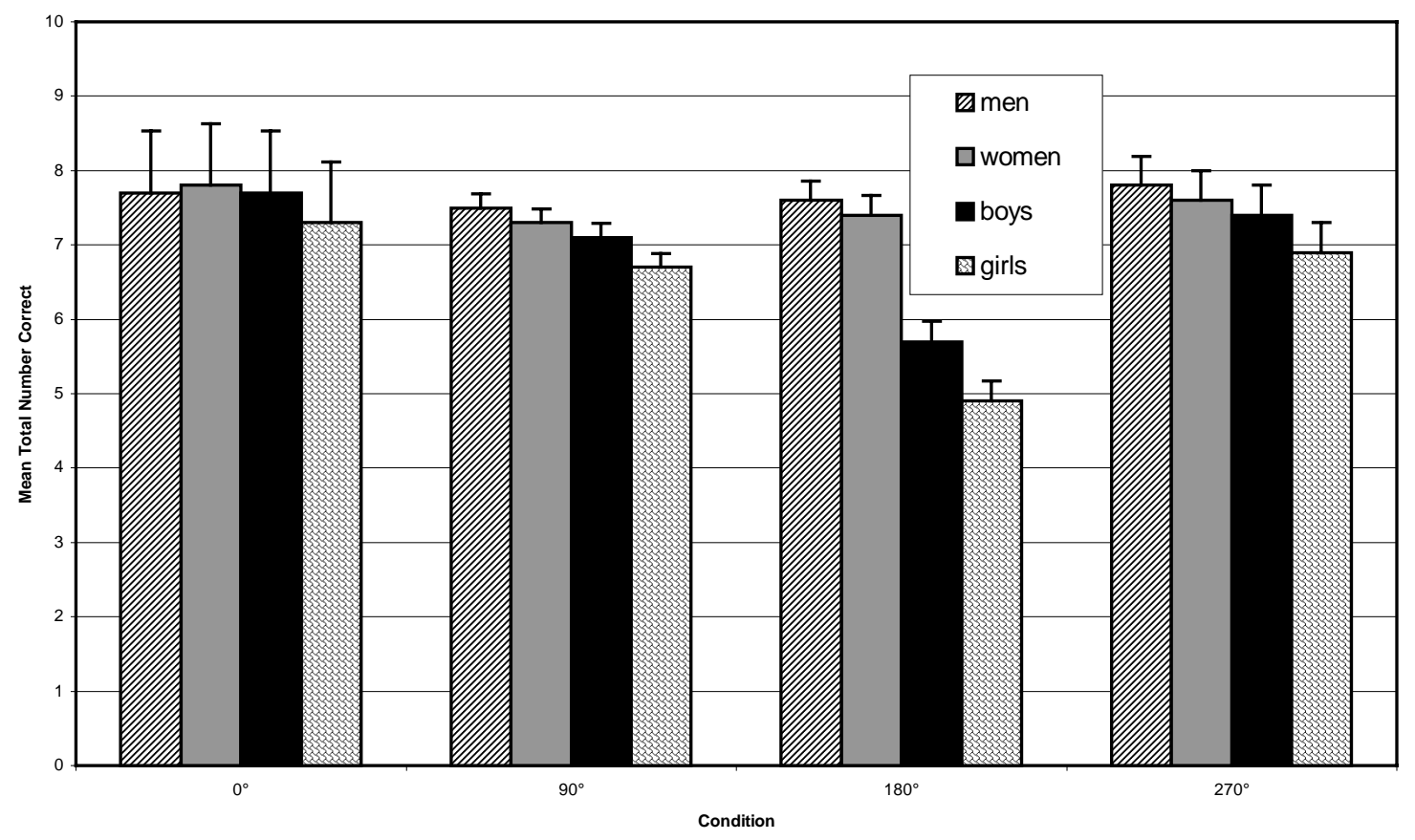

Figure 6

Total Number of Correct Responses on the

2-D Gingerbread Man Rotation Task 


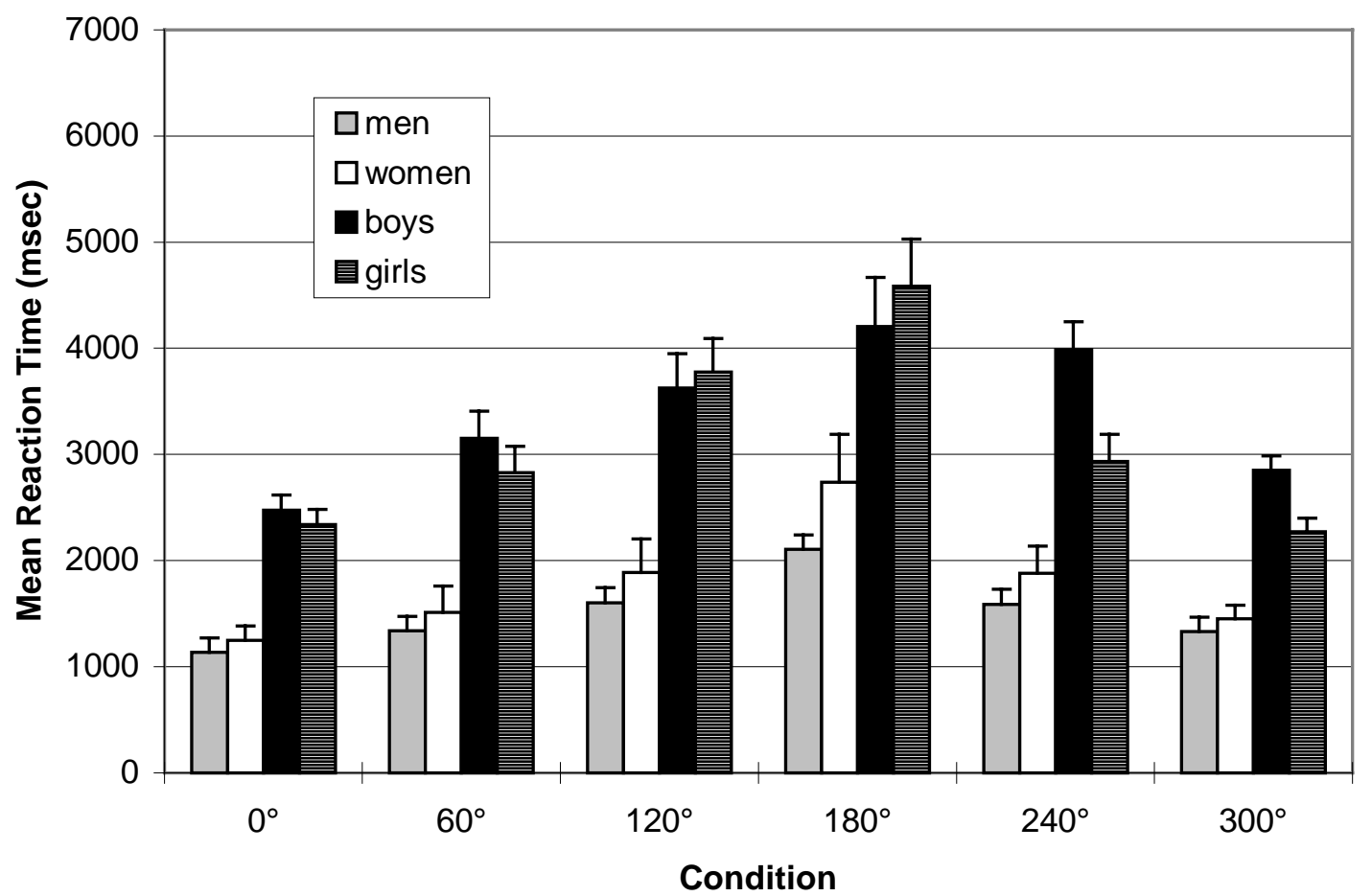

Figure 7

Mean Reaction Time on Correct Trials of the

2-D Alphanumeric Mental Rotation Task 


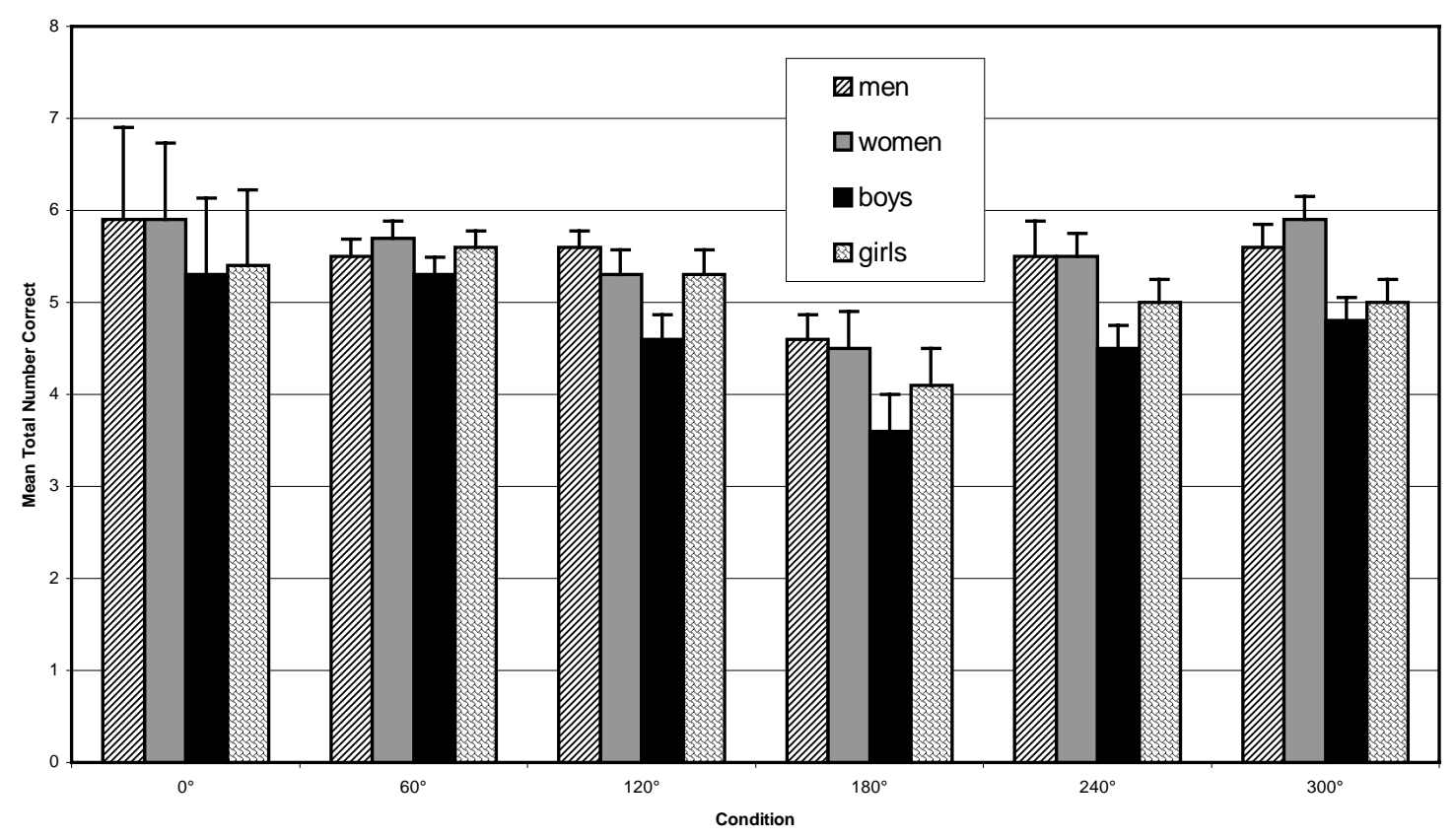

Figure 8

Total Number of Correct Responses on the

2-D Alphanumeric Mental Rotation Task 


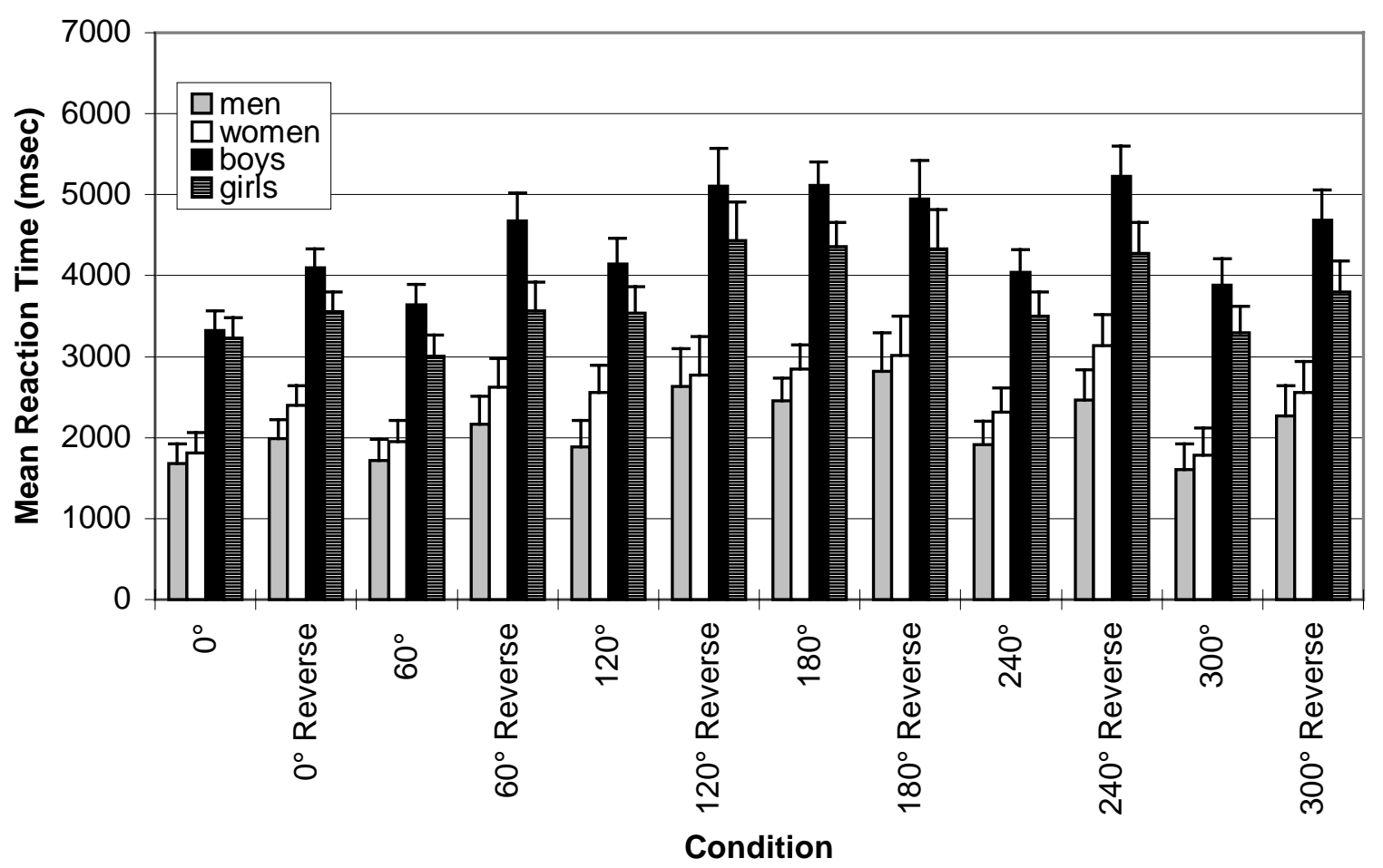

Figure 9

Mean Reaction Time on Correct Trials of the 3-D Basketball Player Mental Rotation Task 


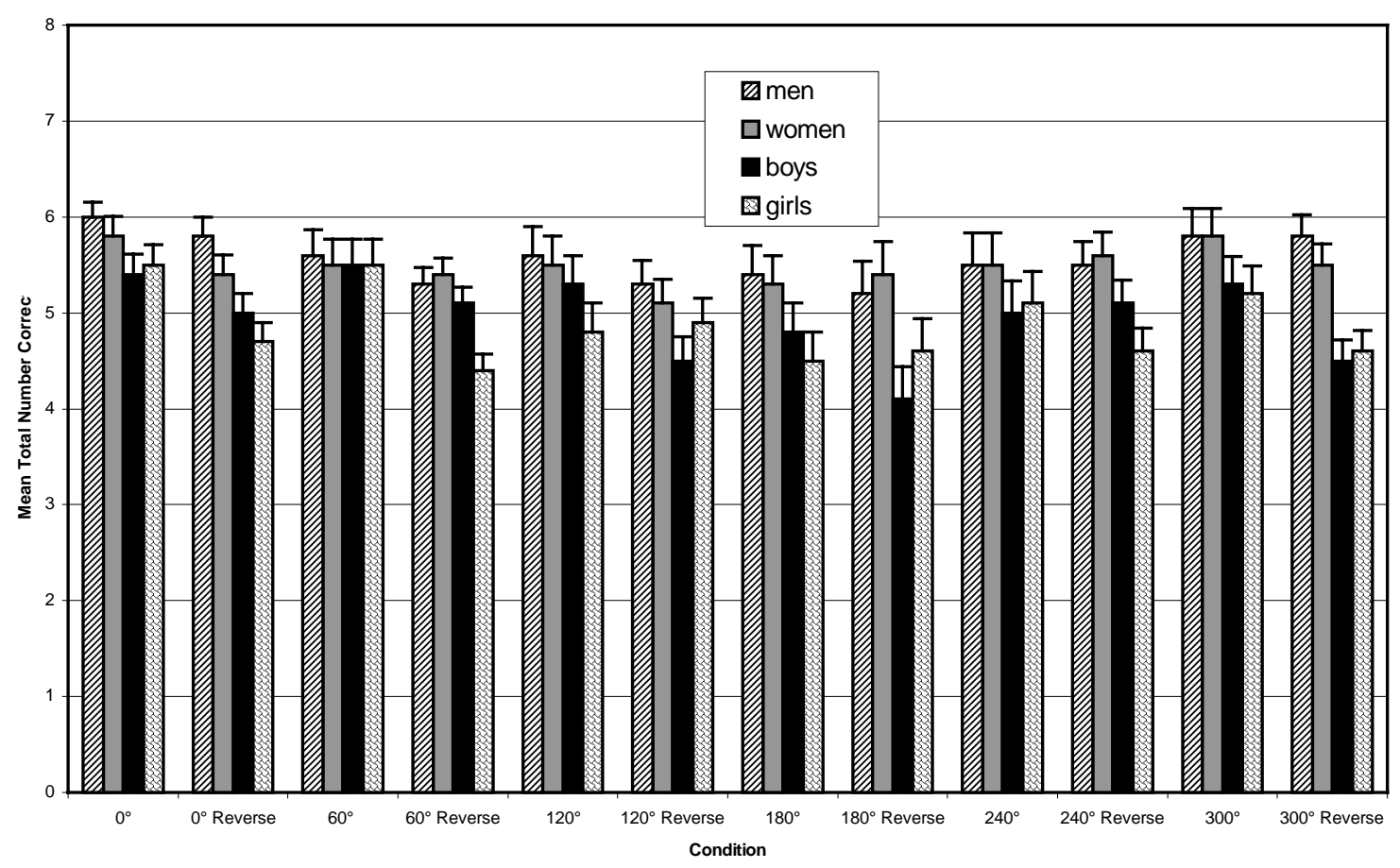

Figure 10

Total Number of Correct Responses on the 3-D Basketball Player Mental Rotation Task 


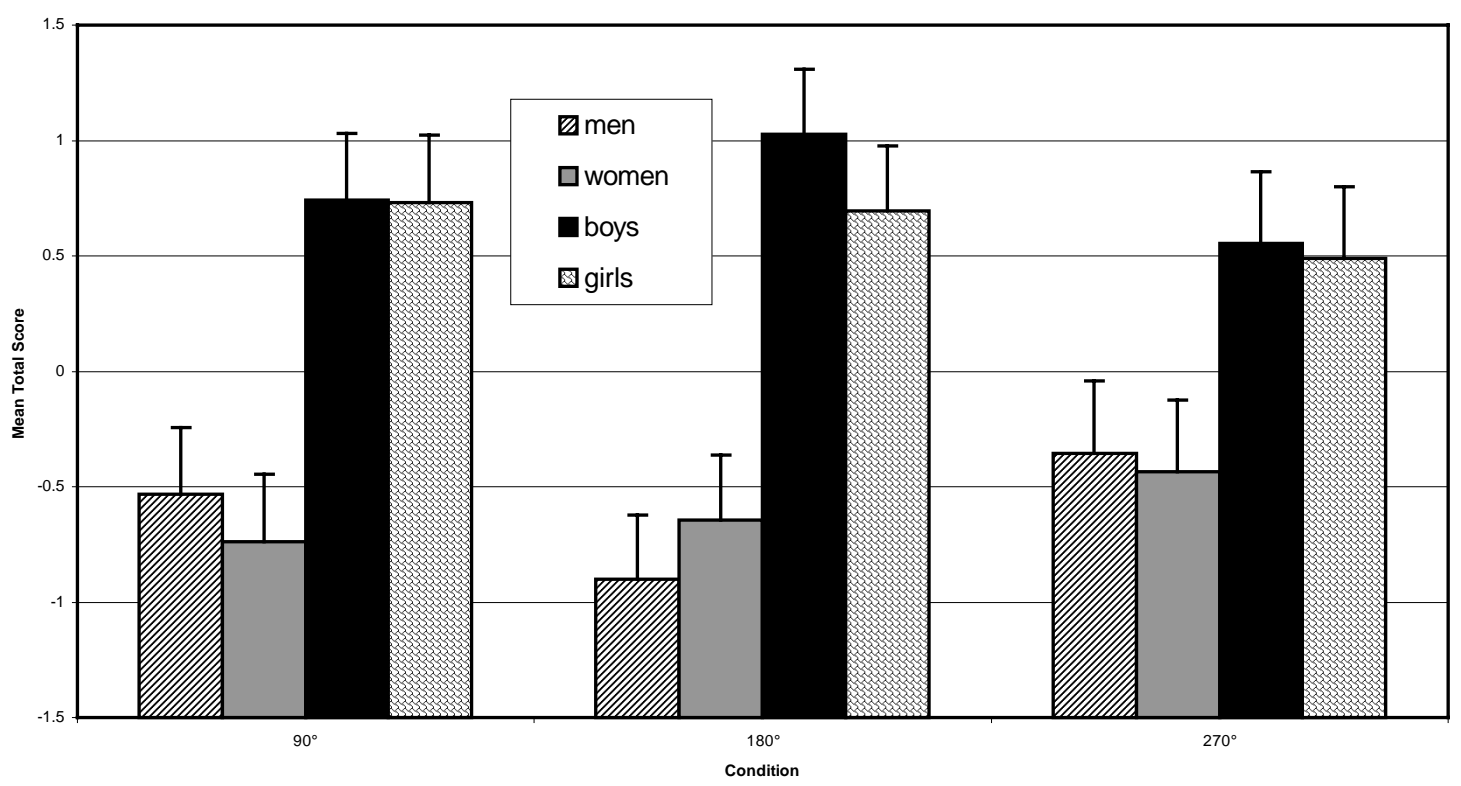

Figure 11

Total Score on the

2-D Gingerbread Man Rotation Task 


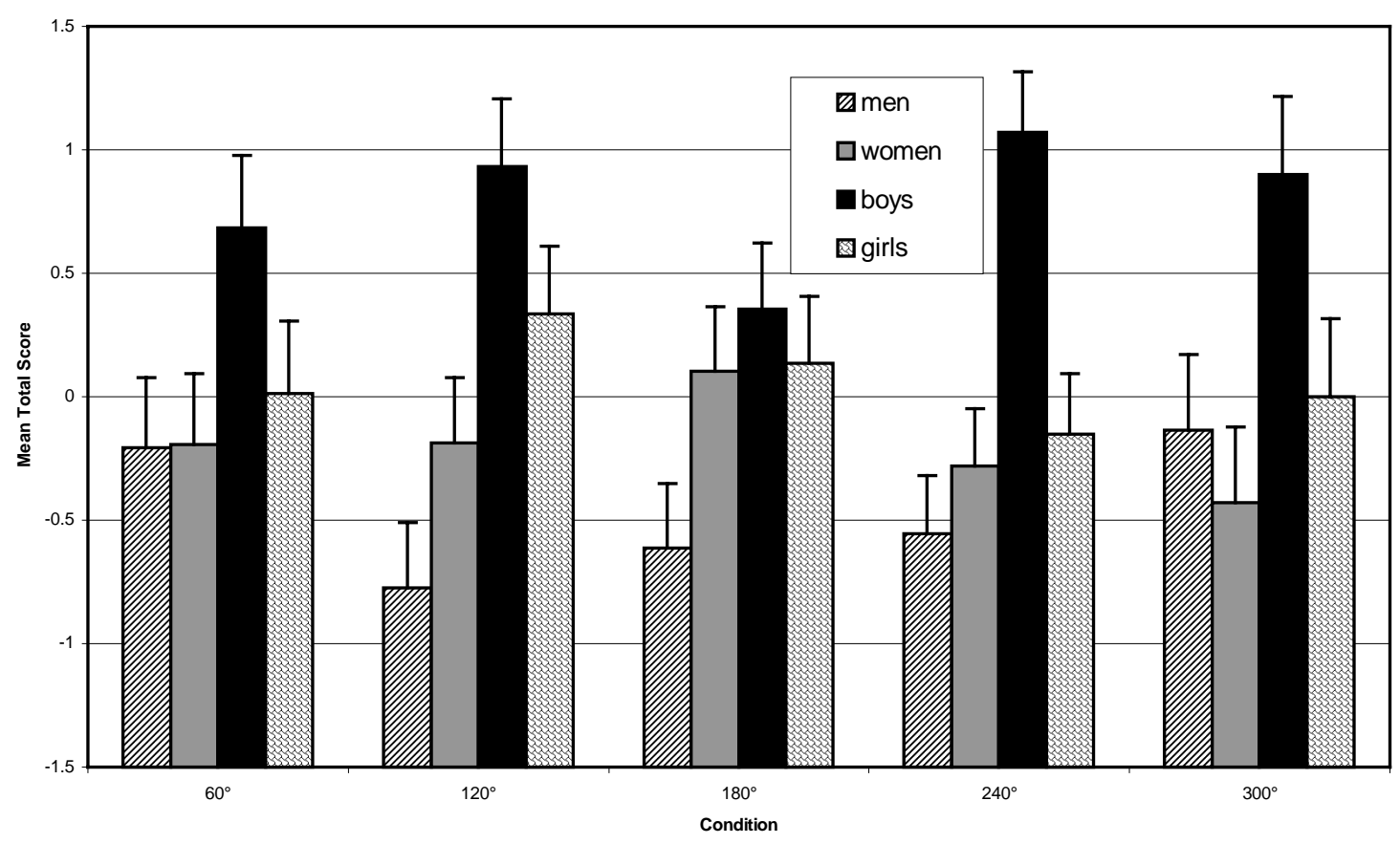

Figure 12

Total Score on the

2-D Alphanumeric Mental Rotation Task 


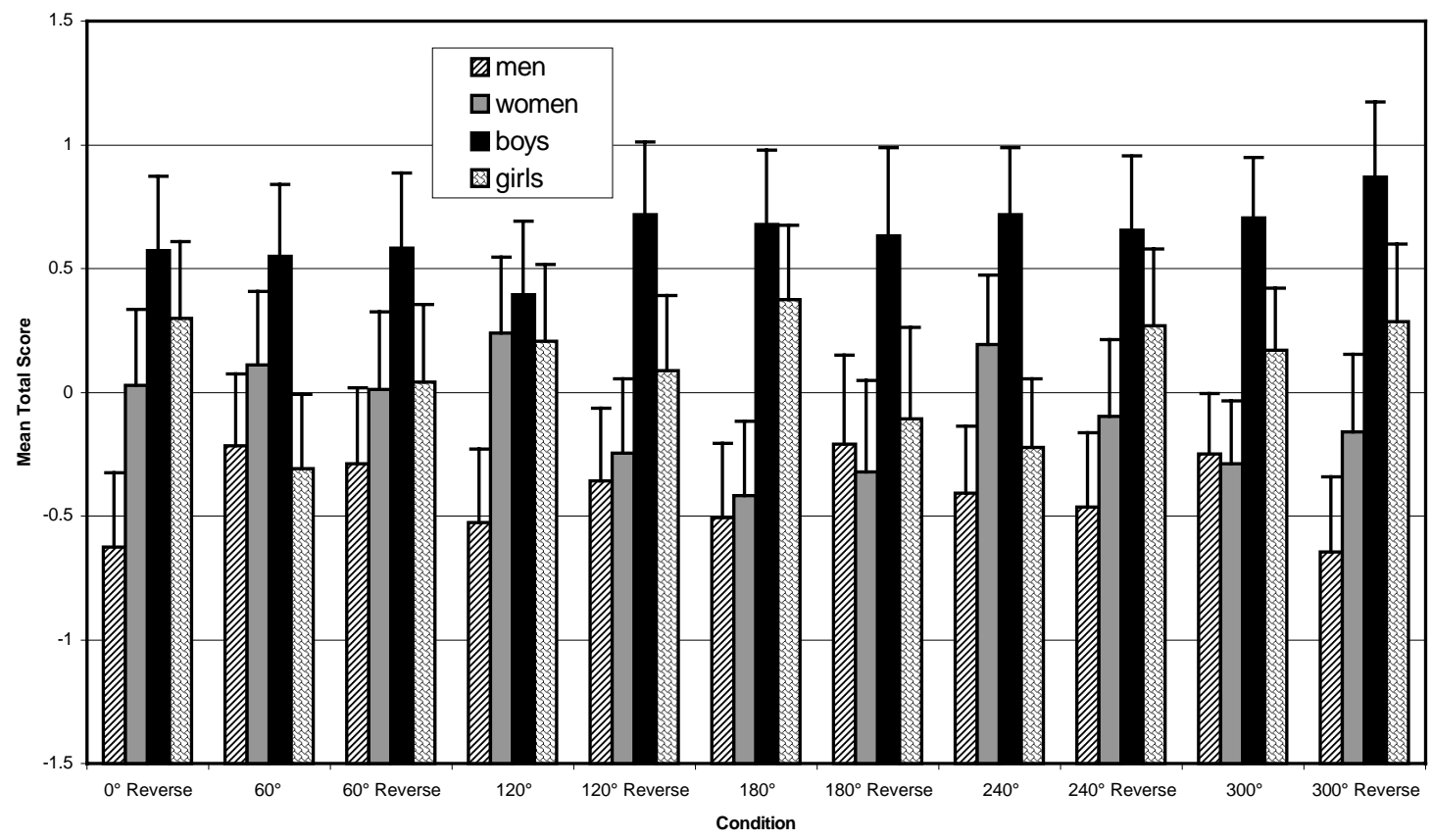

Figure 13

Total Score on the 3-D Basketball Player Mental Rotation Task 


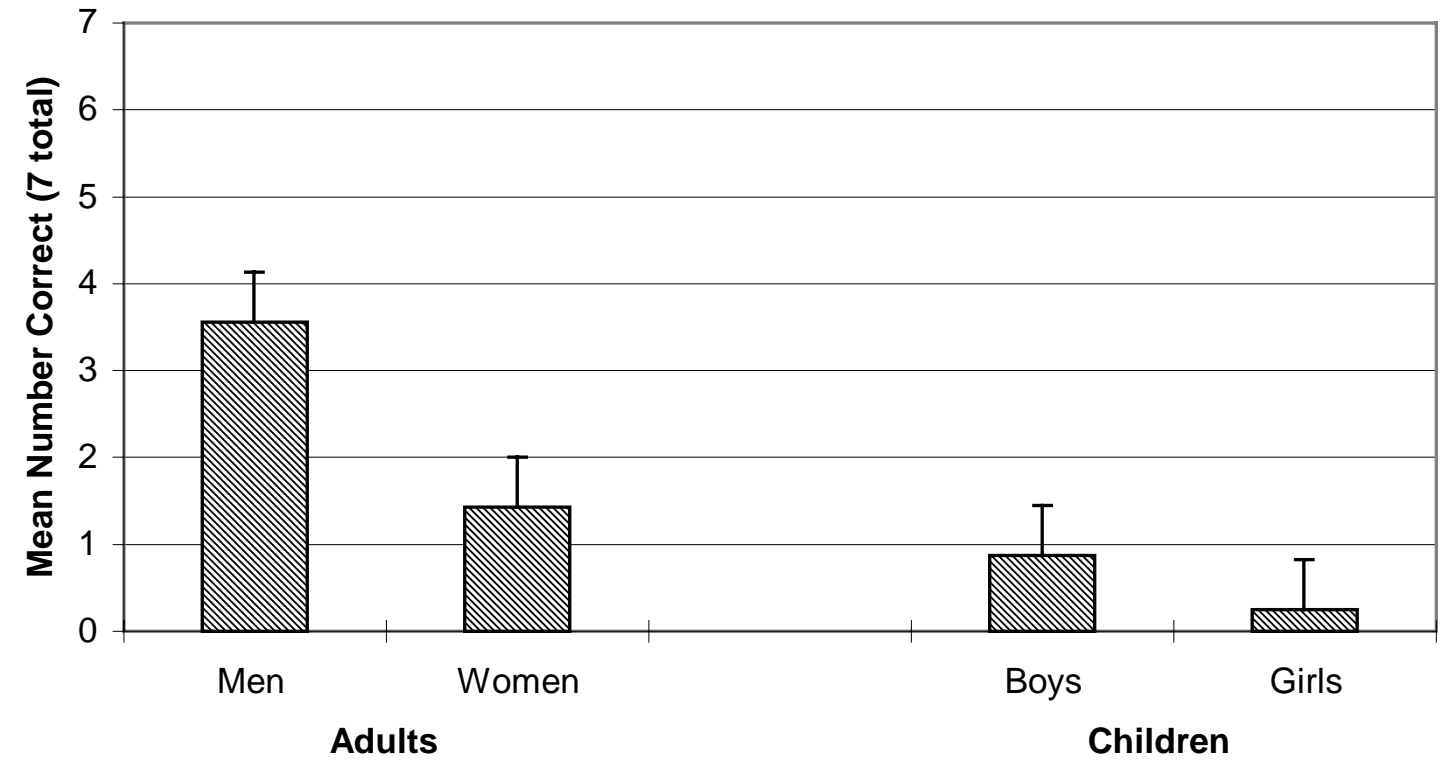

Figure 14

Mean Number of Correct Trials on the Water Level Task 


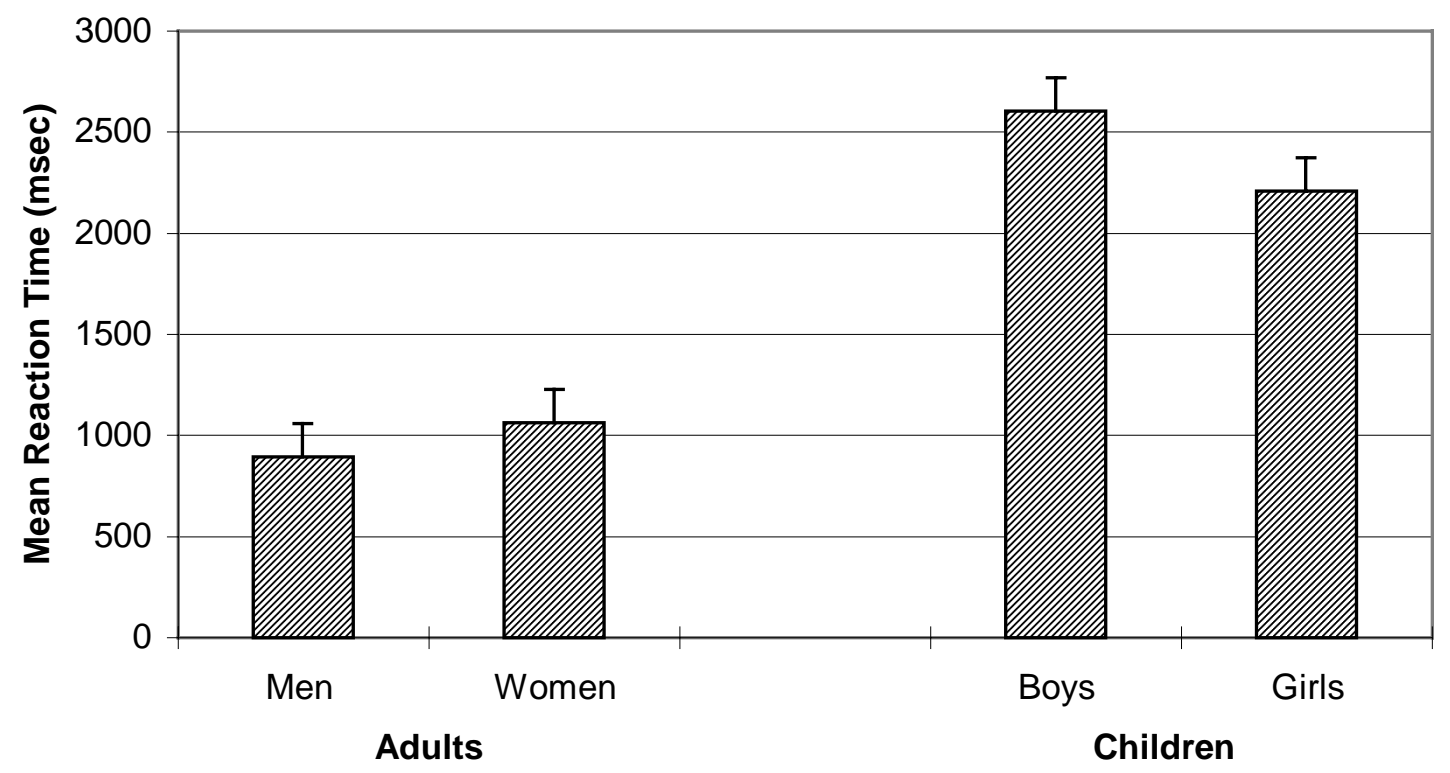

Figure 15

Mean Reaction Time on Correct Trials of the Lexical Decision-Making Task 


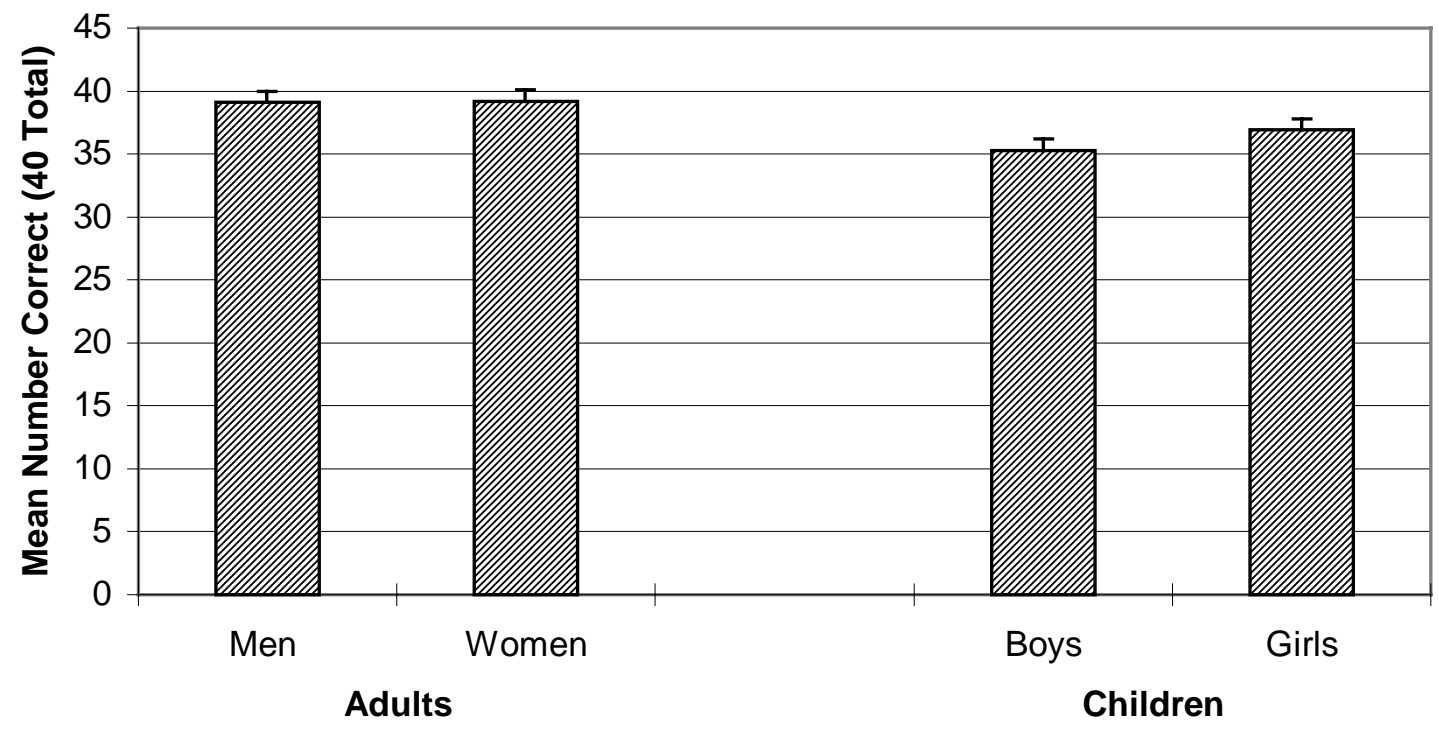

Figure 16

Mean Number of Correct Trials on

Lexical Decision-Making Task 


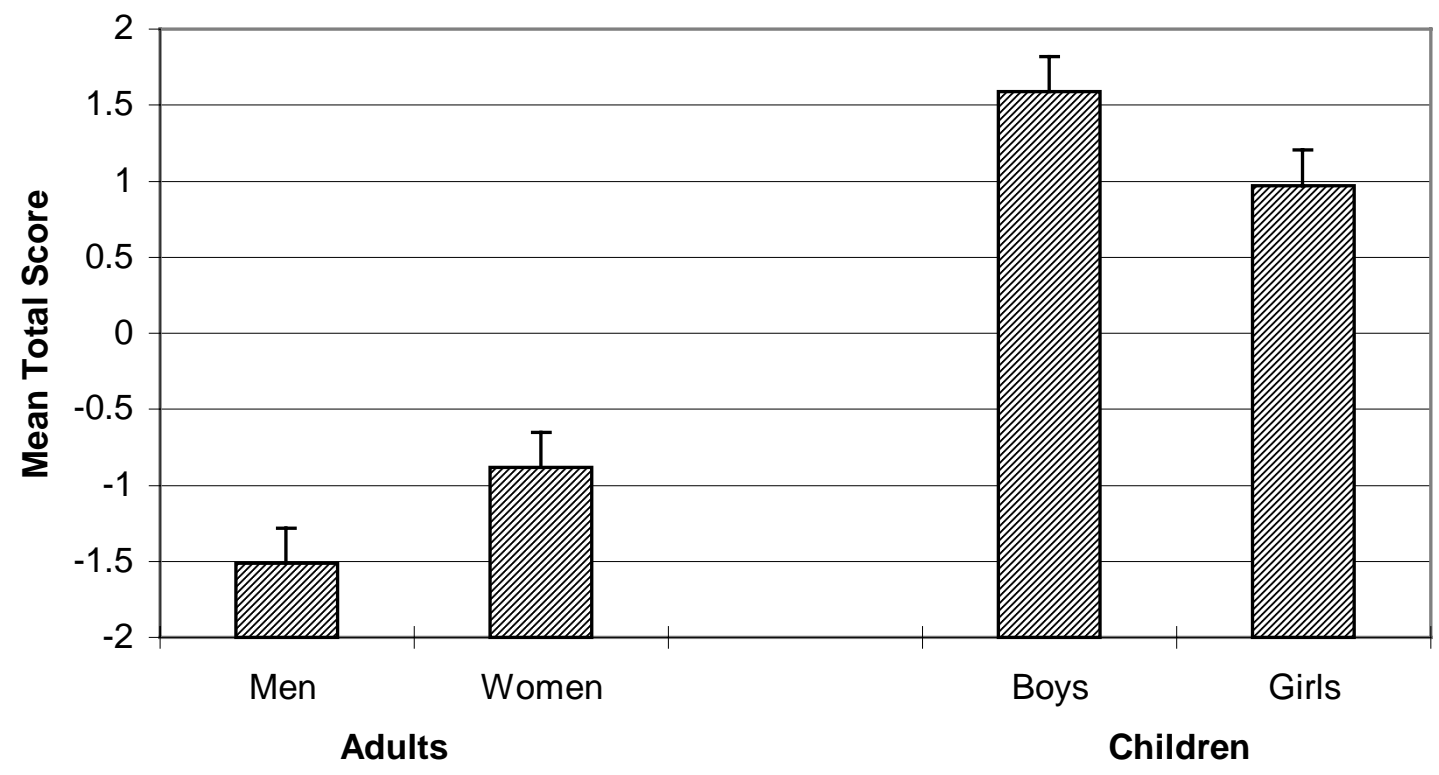

Figure 17

Total Score on the Lexical Decision-Making Task 


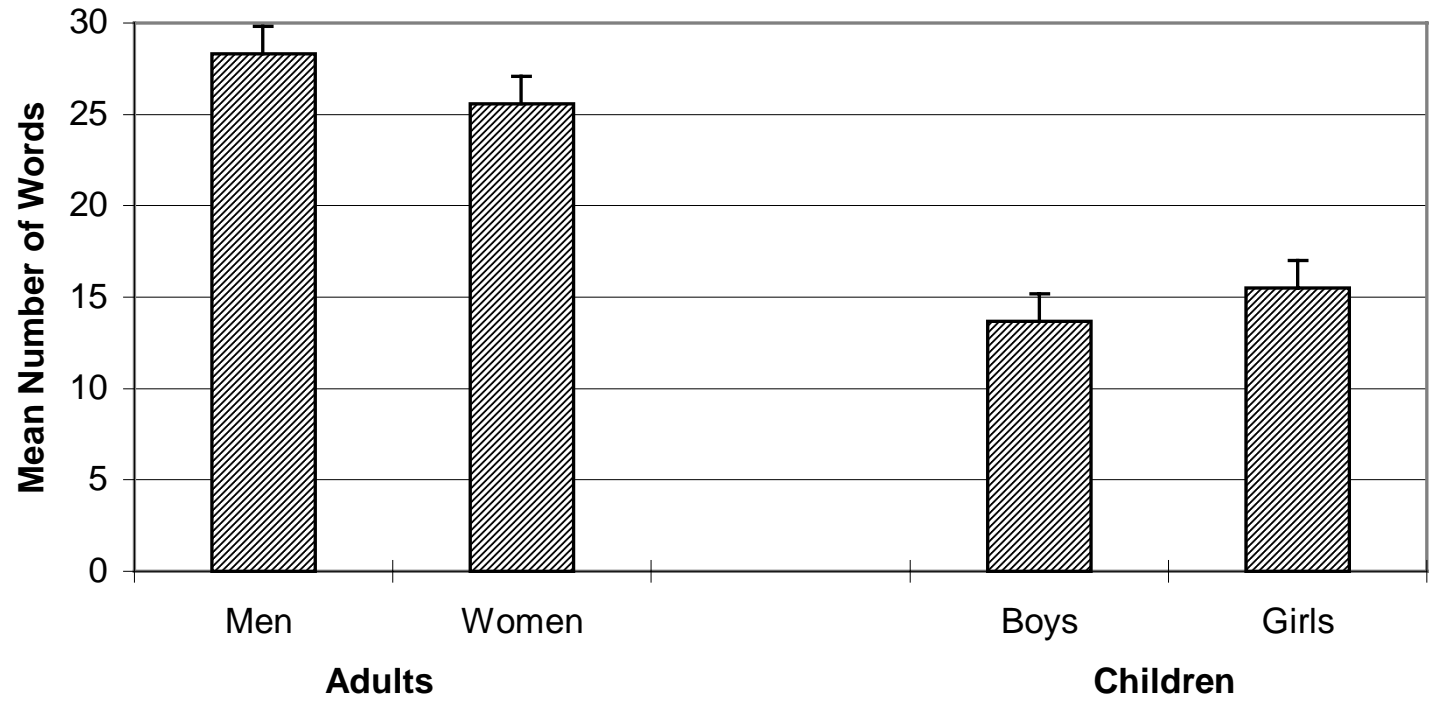

Figure 18

Mean Number of Words Produced on the Verbal Fluency Task 


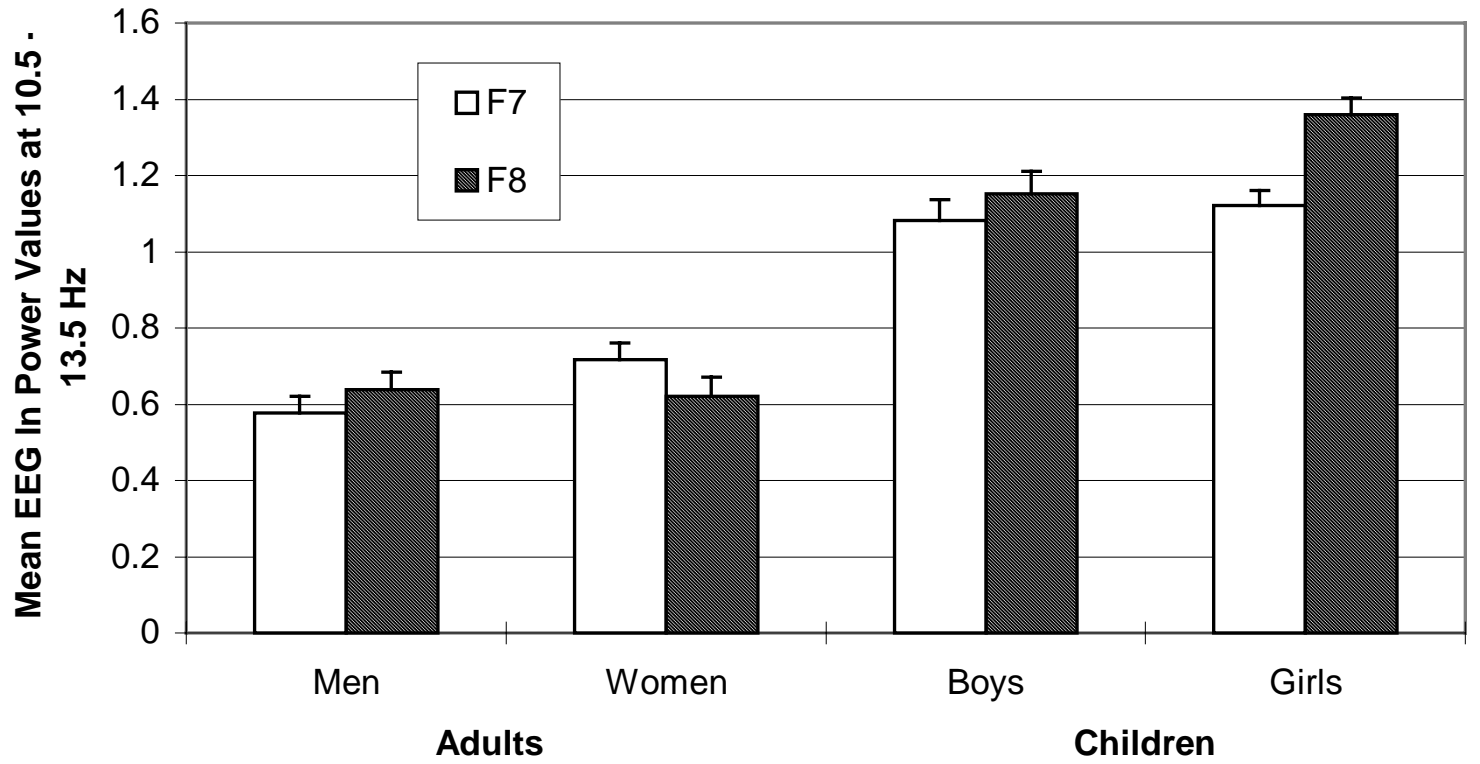

Figure 19

Baseline EEG at Lateral Frontal Region 


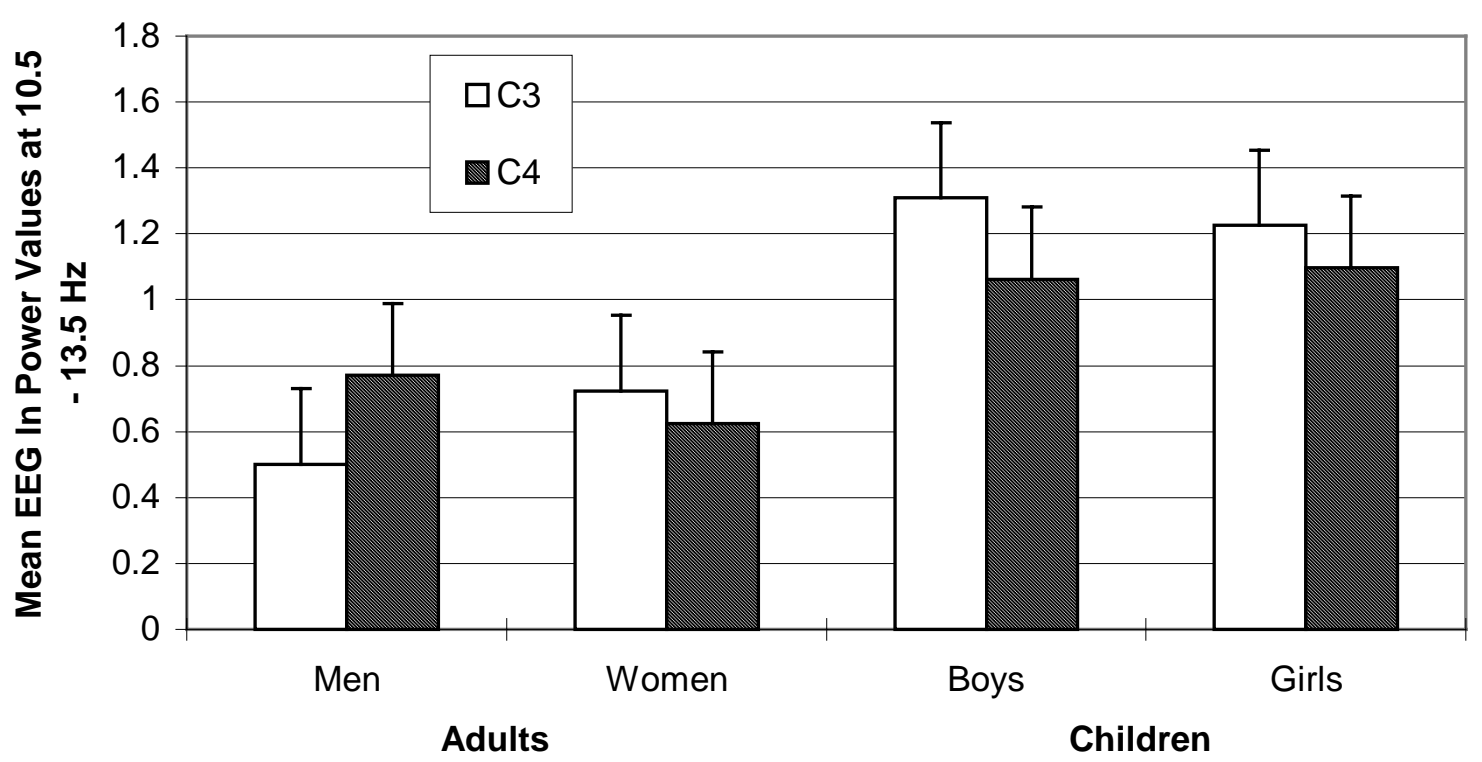

Figure 20

Baseline EEG at Central Region 
Sex Differences

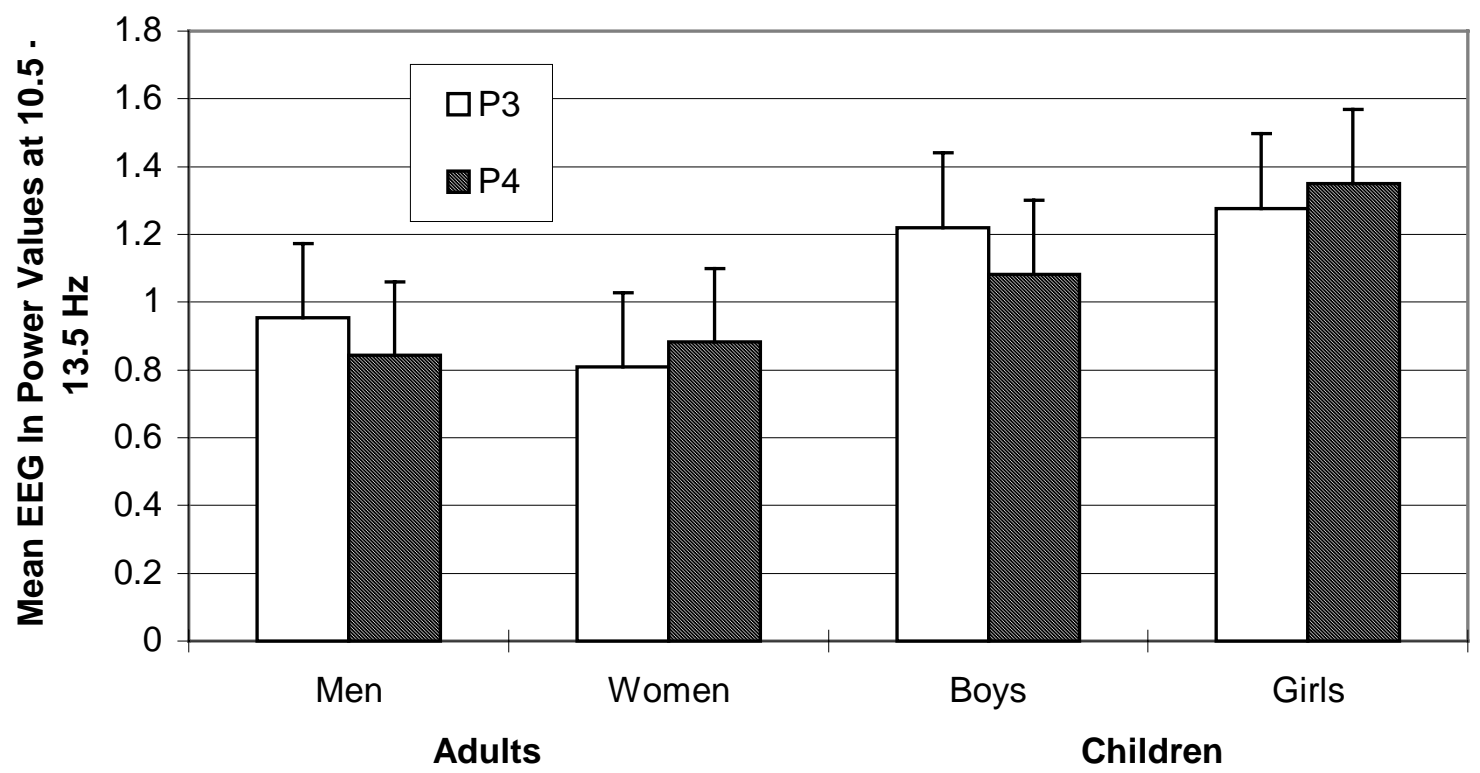

Figure 21

Baseline EEG at Parietal Region 


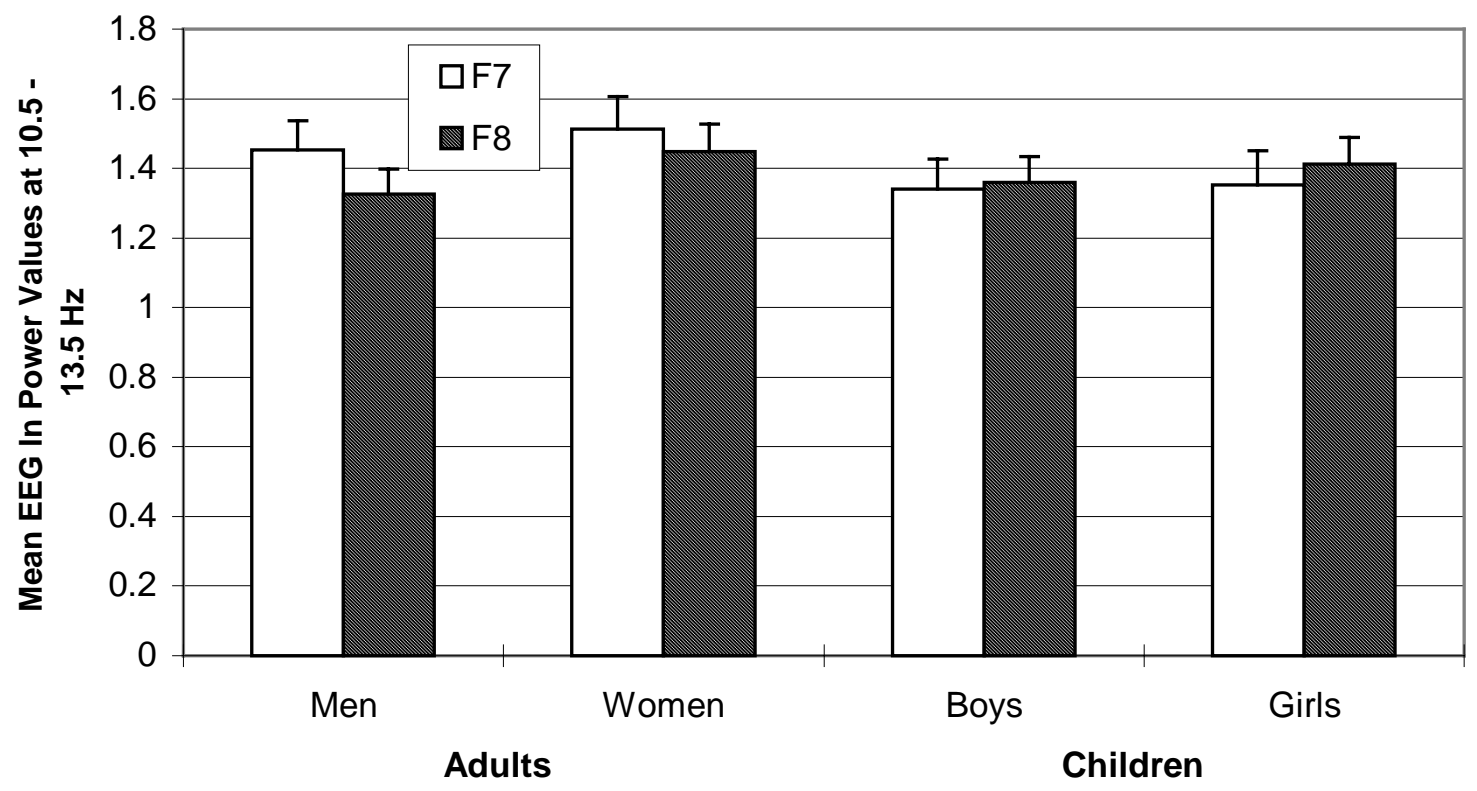

Figure 22

2-Dimensional "Gingerbread Man" Mental Rotation Task EEG Covaried with Baseline EEG at Lateral Frontal Region 


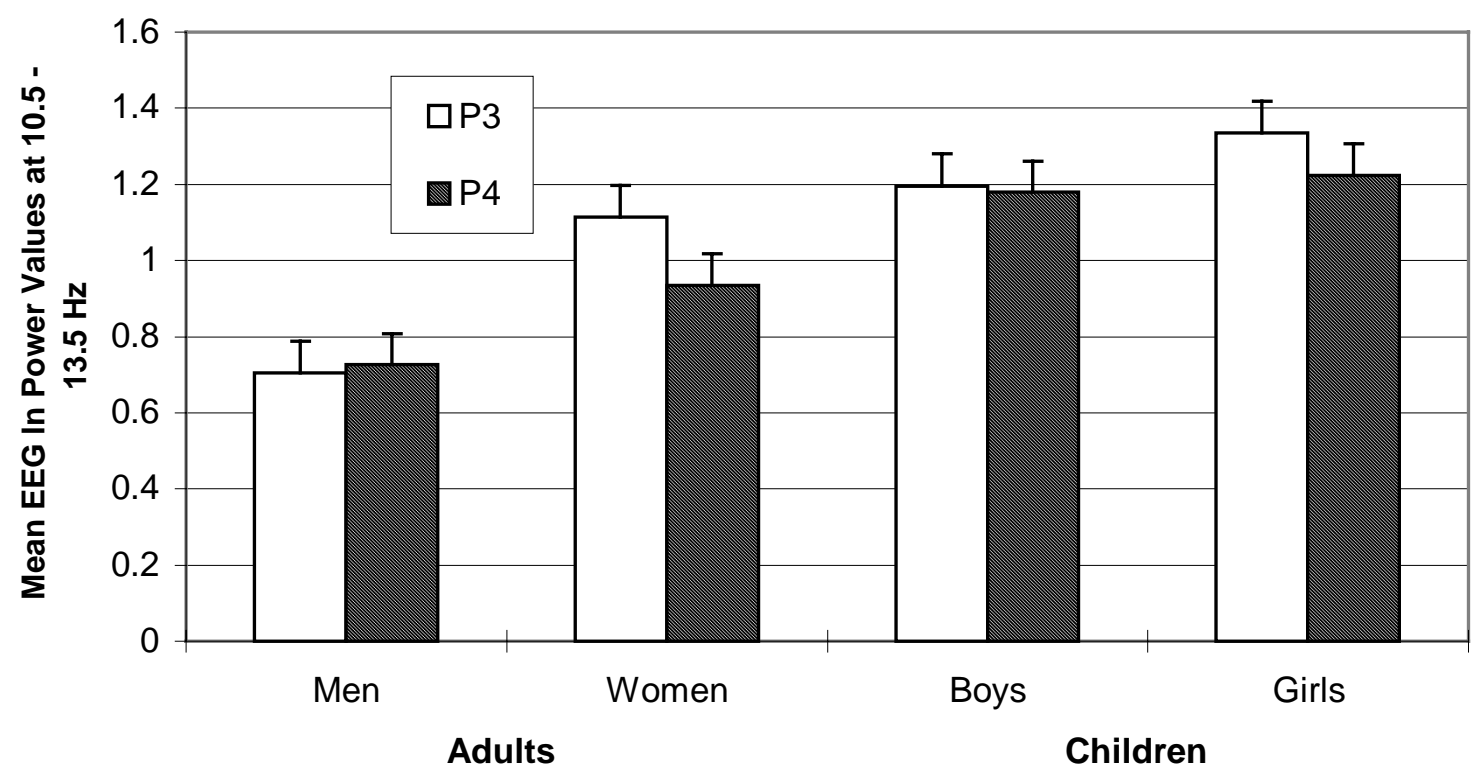

Figure 23

2-Dimensional "Gingerbread Man" Mental Rotation Task EEG Covaried with Baseline EEG at Parietal Region 


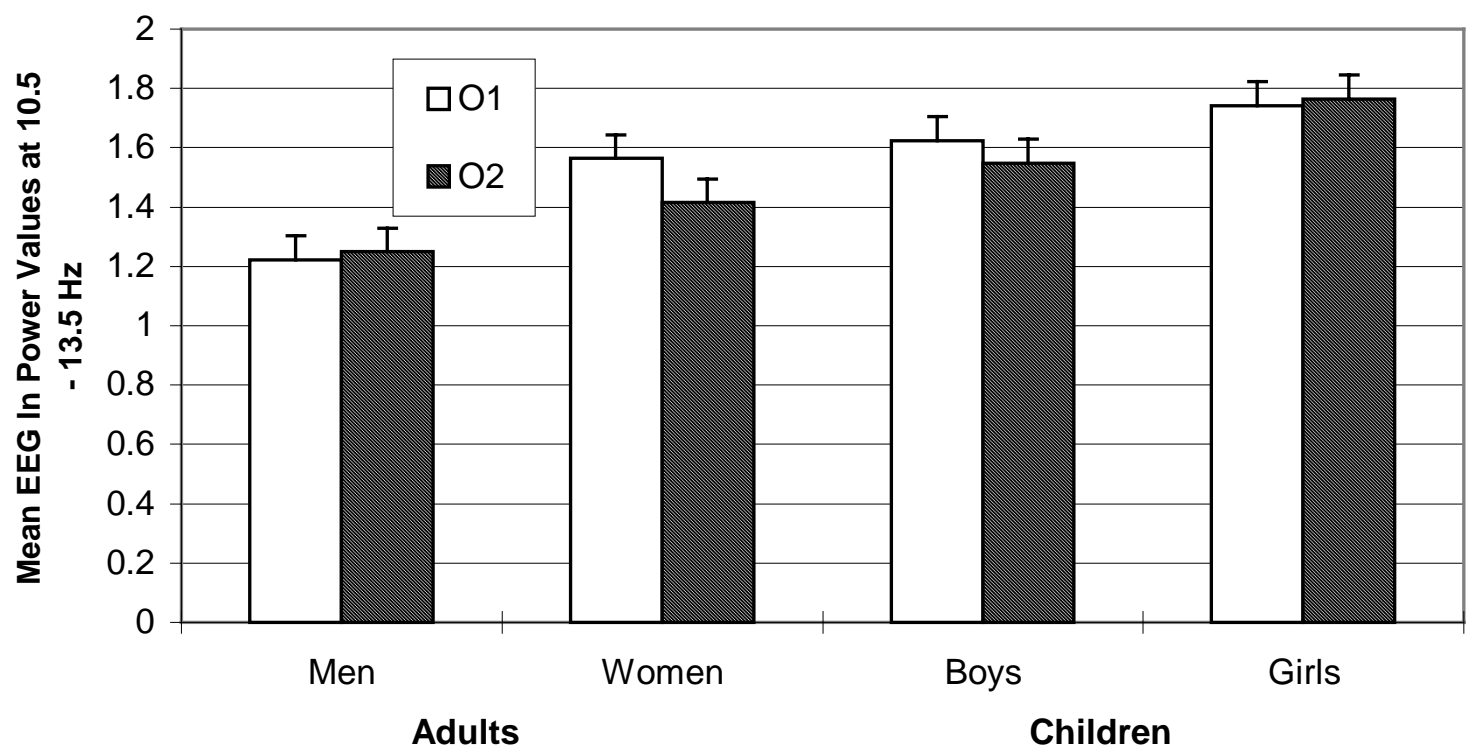

Figure 24

2-Dimensional "Gingerbread Man" Mental Rotation Task EEG Covaried with Baseline EEG at Occipital Region 


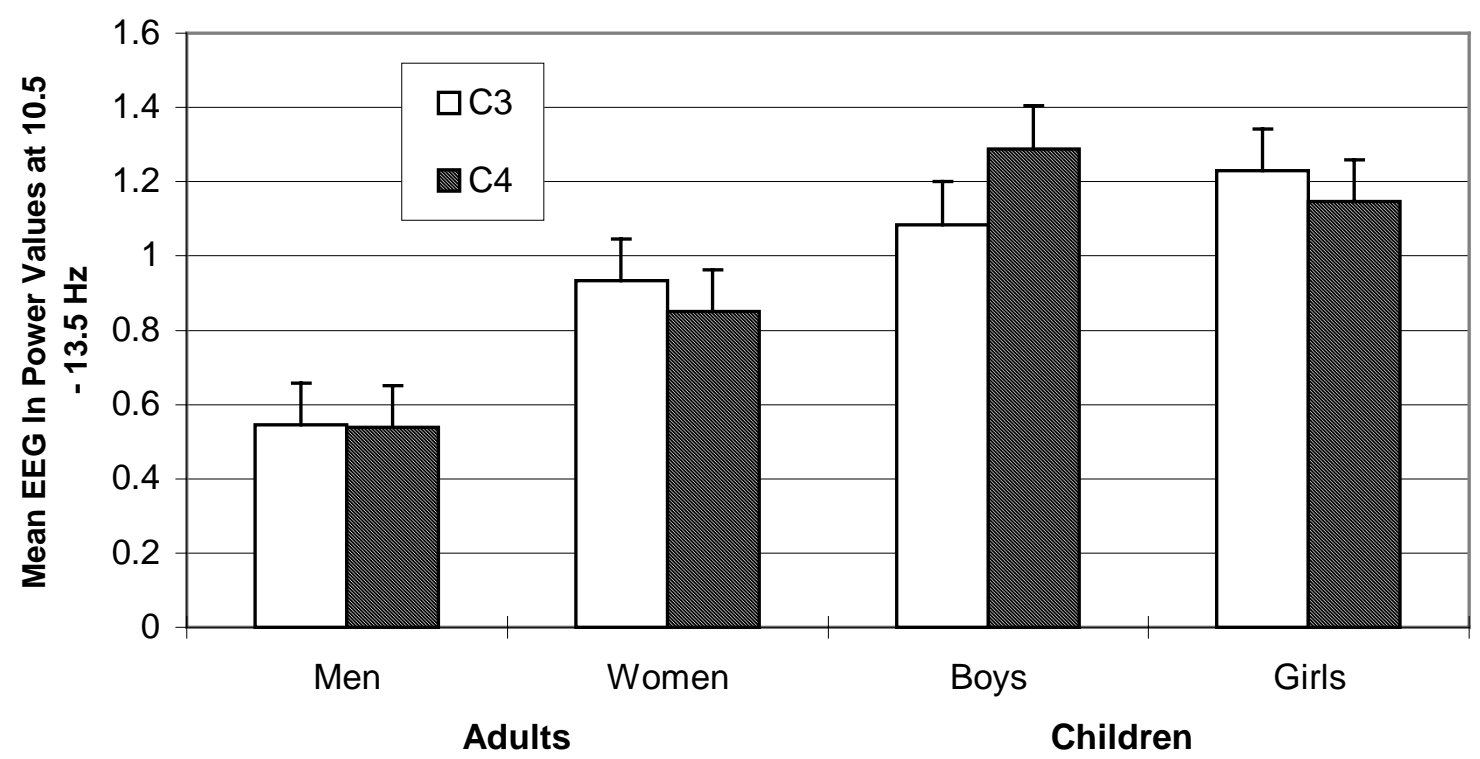

Figure 25

2-Dimensional Alphanumeric Mental Rotation Task EEG Covaried with Baseline EEG at Central Region 


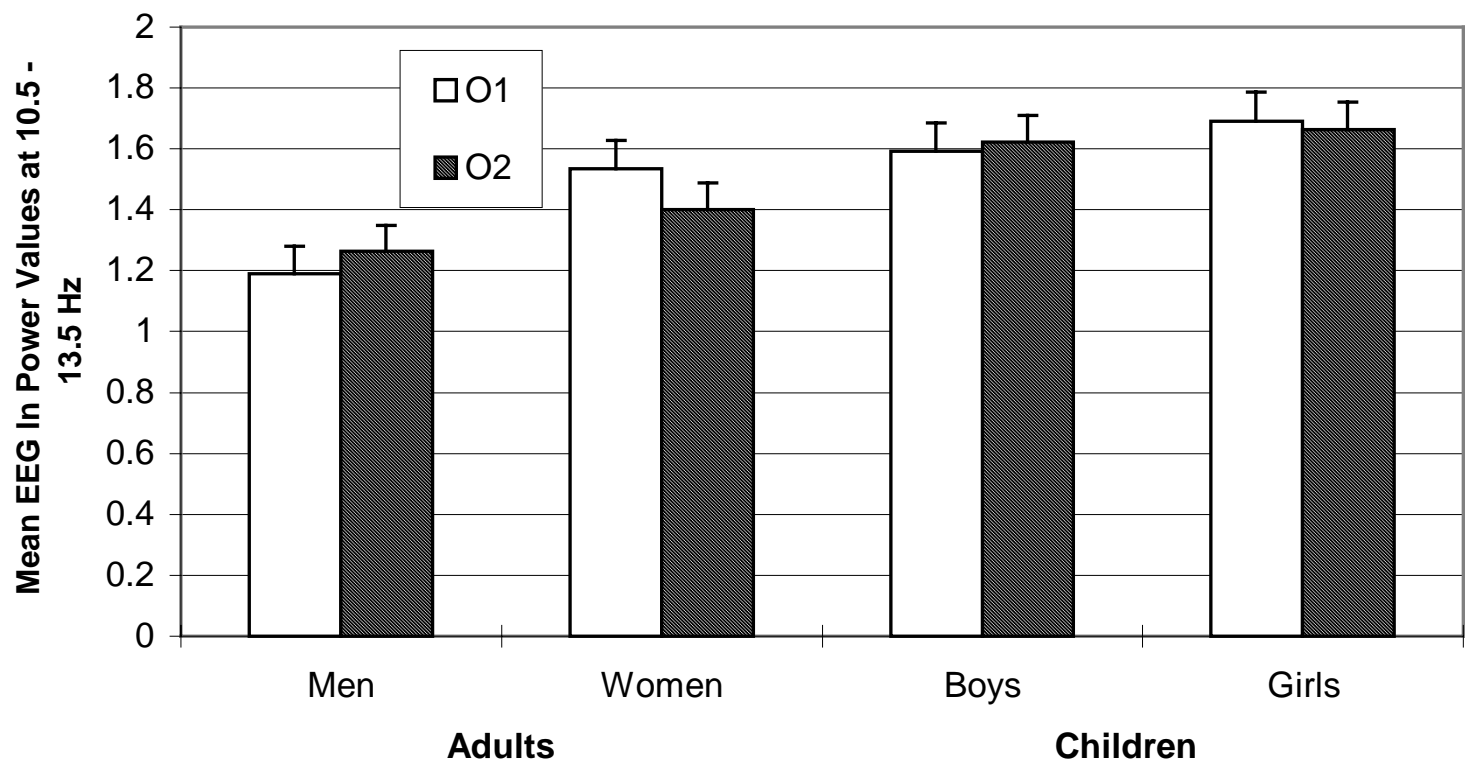

Figure 26

2-Dimensional Alphanumeric Mental Rotation Task EEG Covaried with Baseline EEG at Occipital Region 


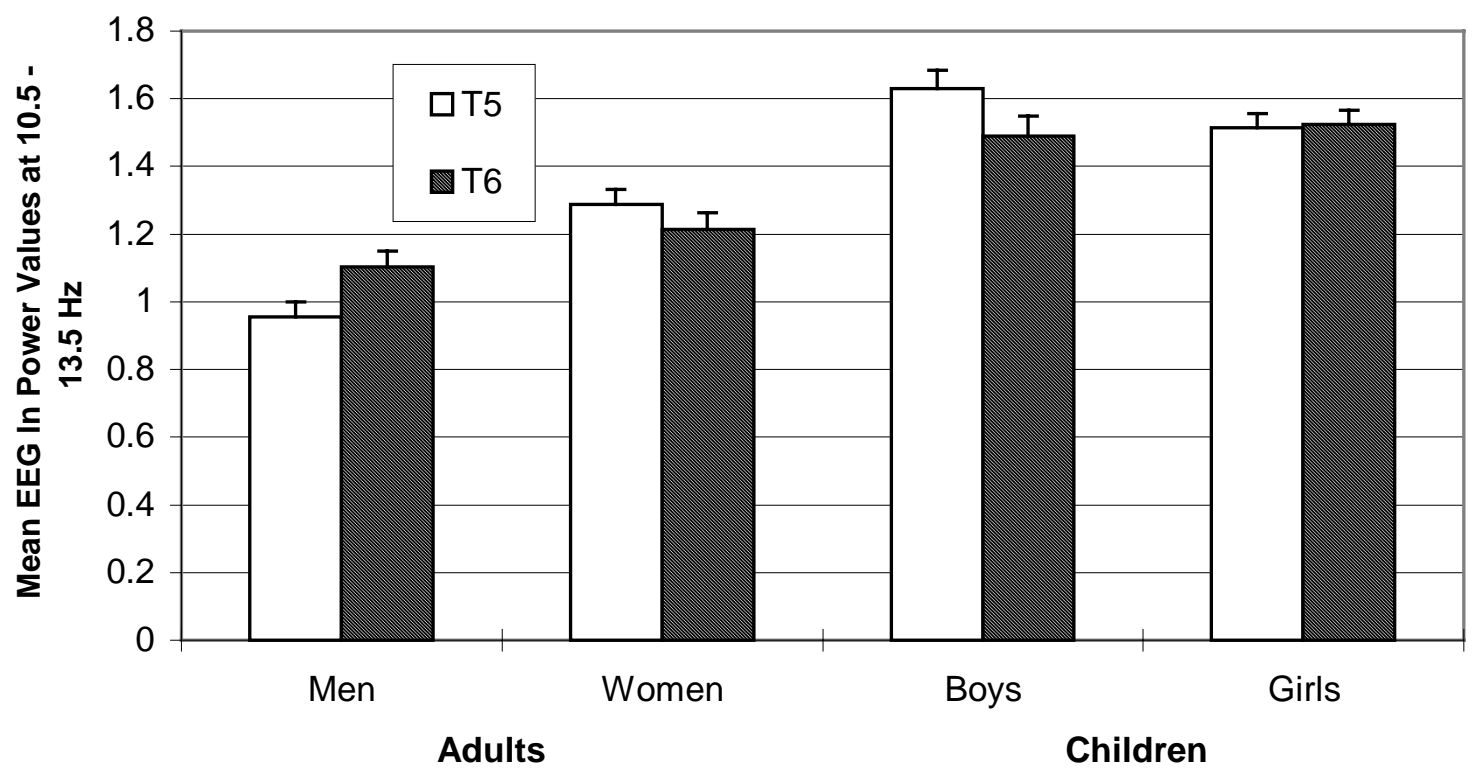

Figure 27

2-Dimensional Alphanumeric Task EEG Covaried with Baseline EEG at Posterior Temporal Region 


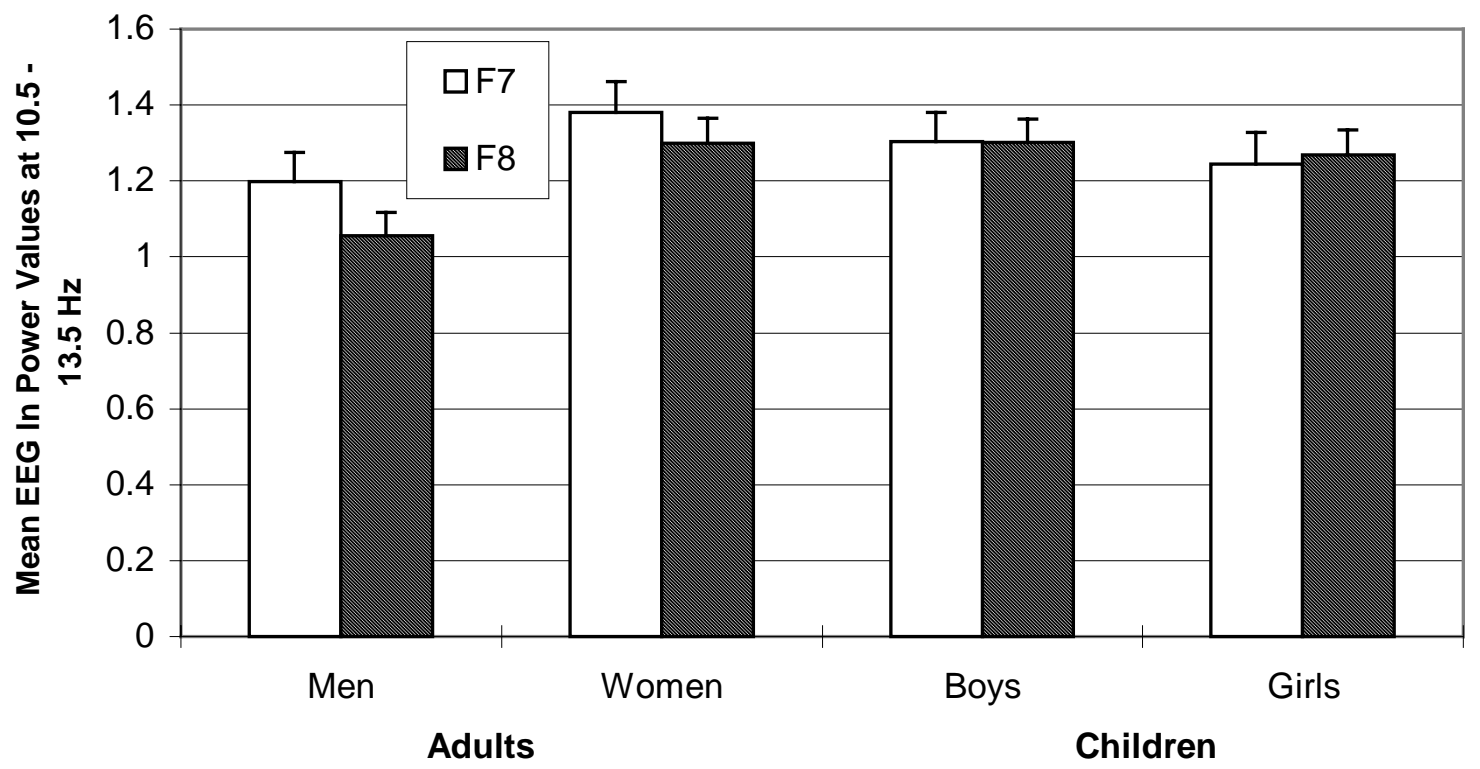

Figure 28

3-Dimensional "Basketball Player" Mental Rotation Task EEG Covaried with Baseline EEG at Lateral Frontal Region 


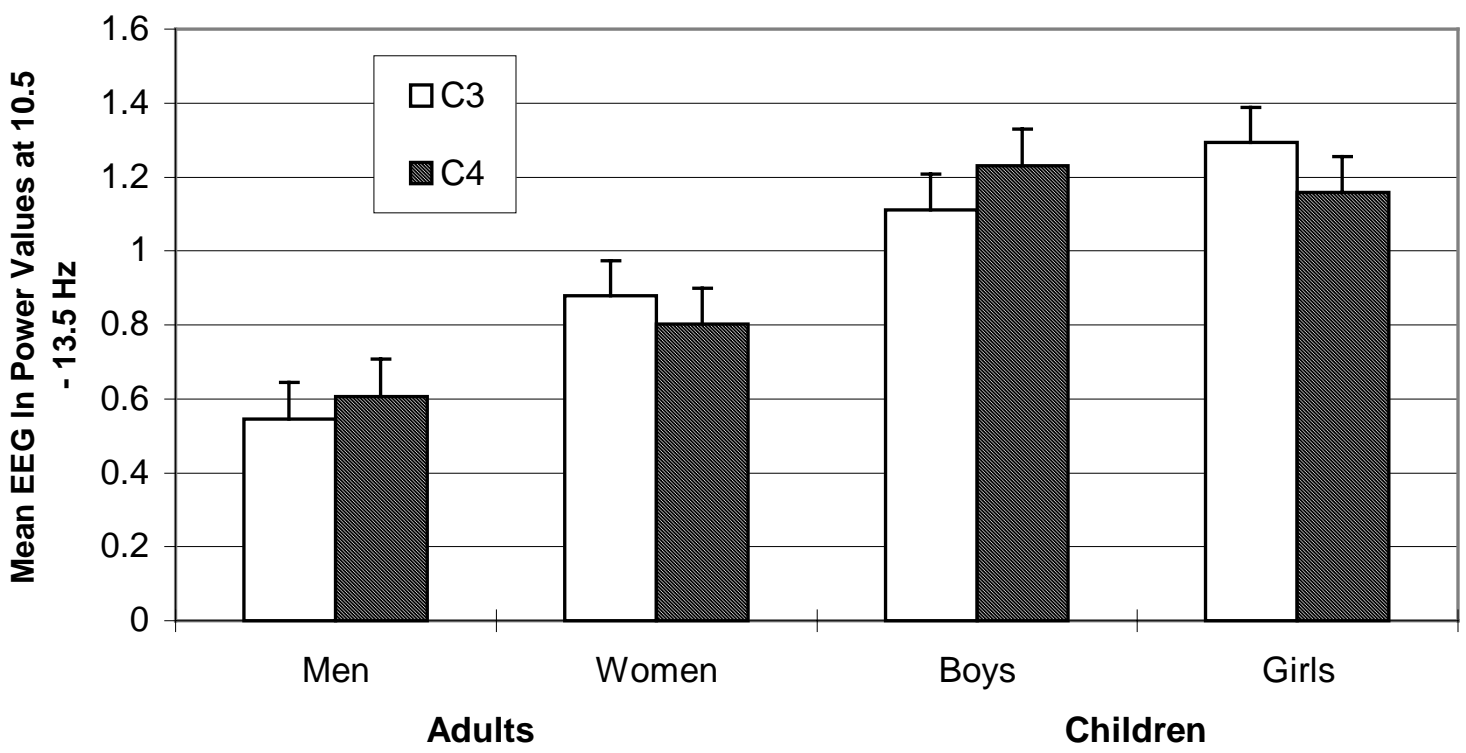

Figure 29

3-Dimensional "Basketball Player" Mental Rotation Task EEG

Covaried with Baseline EEG at Central Region 


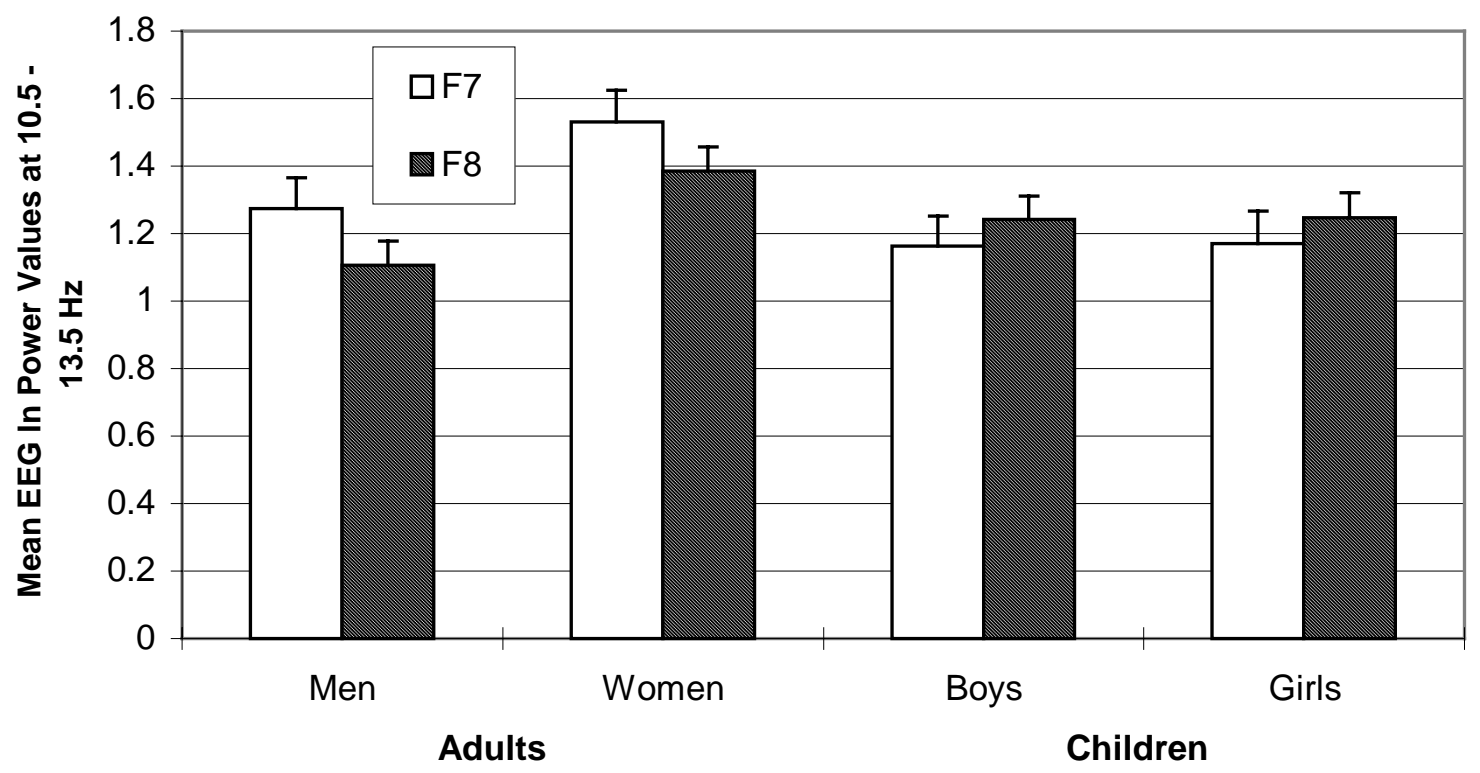

Figure 30

Reading Task EEG

Covaried with Baseline EEG at Lateral Frontal Region 
Appendix A

Discussion of Hormonal Influences on Spatial Ability

As soon as researchers began finding sex differences on mental rotation and other tests of spatial abilities, they also began searching for explanations as to how these differences might arise. Two main arguments have emerged: 1) that sex differences on spatial tasks are largely due to differential experience, and 2) that sex differences on spatial tasks are related to hormonal influx. The hormonal influx argument can be further subdivided into a "critical period" argument, stating that hormone influx at critical periods, such as the neonatal period or the timing of puberty, have a direct effect on the brain mechanisms which contribute to spatial task performance, and an "activation" argument, stating that hormone levels at the time of spatial testing contribute to the spatial task performance. The present discussion will focus on hormones and causes of the sex differences in spatial performance.

\section{Hormones: Critical Periods vs. Activation}

One argument as to why sex differences are found in mental rotation tasks is that the presence of hormones at a critical period in development may affect the development of specific brain regions and/or brain lateralization. One of the first theories addressing sex differences on spatial tasks was a "critical period" theory put forth by Waber (1977). Waber reported that late maturing females performed better on spatial ability tasks than did early maturing females. Based on this finding, she suggested that late maturing females had brains that were more laterally specialized than early maturers, meaning that there was more right hemisphere engagement in activities, and that this specialization was associated with better performance on right-hemisphere tasks. This finding is intuitive because males, who are more laterally specialized than females, are also later maturers (Waber, 1977). Thus, later maturing females' brain lateralization may look more like that of a male. However, there have been failures to replicate the finding that late maturing females perform better on spatial tasks than do early maturing females (e.g., Newcombe \& Bandura, 1983; Newcombe \& Dubas, 1989). 
Resnick, Berenbaum, Gottesman, and Bouchard (1986) made another argument for a critical period in a study of children with congenital adrenal hyperplasia (CAH), a disorder associated with elevated prenatal androgen levels. Resnick et al. (1986) found that females who had CAH performed better on tests of spatial ability than unaffected relatives, suggesting that prenatal hormones may have had an effect on spatial ability. In a different study, Jacklin, Wilcox, and Maccoby (1988) assessed umbilical cord hormone levels at birth and then tested cognitive abilities at six years of age. They reported finding that high testosterone and androstenedione levels were associated with poor performance on spatial tasks at six years of age. This is the opposite finding from the one reported by Resnick et al. (1986) and more research is needed in this area. Surprisingly, in both of these studies hormones levels were not assessed at the time of spatial testing. Particularly in the case of the females with $\mathrm{CAH}$, this leaves open the possibility that there were still hormonal effects from the disorder. Thus, information concerning hormone levels coincident with the testing situation may be more valuable than information about prenatal or birth hormone levels.

Another hormonal hypothesis regarding the sex differences in spatial ability is an activation argument, stating that hormone levels at the time of spatial testing contribute to the spatial task performance. Several different lines of reasoning support this idea. First, sex differences on spatial ability tasks are inconsistently found until after puberty (Linn \& Petersen, 1985). Until the end of the first year of life, testosterone levels are higher in males than in females, but from the end of the first year until just before the onset of puberty, testosterone levels are low among both sexes (Stahl, Gotz, Poppe, Amendt, \& Dorner, 1978). This, coupled with the inconsistent data between pre-pubescent boys and girls on mental rotation tasks, supports a hormone activation argument for the sex differences in spatial ability tasks (Linn \& Petersen, 1985; Waber, 1977).

Perhaps even more compelling evidence for hormone activation differences in spatial abilities has come from studies that directly manipulate hormone levels. In a compelling series of studies by Van Goozen and colleagues (Van Goozen, Cohen-Kettenis, Gooren, Fridja, \& Van de Poll, 1994,1995) groups 
of male-to-female and female-to-male transsexuals were studied before and after hormone therapy. The female-to-male group showed enhanced performance on spatial tests after treatment, while the male-tofemale group's performance showed deteriorated performance on tasks of spatial ability. Likewise, a study by Janowsky, Oviatt, and Orwoll (1994) found that men ages 65-70 who were supplemented with testosterone to $150 \%$ of their baseline rate performed better than a double-blind control group on spatial cognition tasks. There were no differences in non-spatial cognitive performance between treatment and control groups. Janowsky et al. (1994) suggested that testosterone's inhibiting effect on estradiol may be linked to the spatial performance enhancement. This is in agreement with other reports drawing on the level of estradiol and spatial performance across the menstrual cycle and the finding that increased levels of estradiol are related to decreased performance of spatial abilities (Hampson, 1990a, 1990b; Hampson \& Kimura, 1988; Silverman \& Phillips, 1993).

Evidence for the effects of hormones on spatial tasks are quite compelling. The evidence of the hormonal activation argument, which states that circulating hormones affect spatial performance, however, cannot be ignored. The present study, in a sense, attempted to replicate the studies that directly manipulated hormone levels by "manipulating" hormonal levels using two different age groups as participants: eight-year-olds, who should be at least two or three years away from puberty (and its hormonal influx), and college students, who should have adult-levels of male and female hormones. However, because the present study did not attempt to measure hormones directly, this manuscript does not go into a great deal of discussion about hormones and their influences on spatial ability.

\section{Appendix A References (not found in main reference list)}

Hampson, E. (1990a). Estrogen-related variations in human spatial and articulatory-motor skills. Psychoneuroendocrinology, 15, 97-111.

Hampson, E. (1990b). Variations in sex-related cognitive abilities across the menstrual cycle.

Brain and Cognition, 14, 26-43. 
Hampson, E., \& Kimura, D. (1988). Reciprocal effects of hormonal fluctuations on human motor and perceptual-spatial skills. Behavioral Neuroscience, 102, 456-459.

Jacklin, C.N., Wilcox, K.T., \& Maccoby, E.E. (1988). Neonatal sex-steroid hormones and cognitive abilities at six years. Developmental Psychobiology, 21, 567-574.

Newcombe, N., \& Dubas, J.S. (1989). Associations of timing of puberty, spatial ability, and lateralization in women. Child Development, 60, 246-254.

Resnick, S.M., Berenbaum, S.A., Gottesman, I.I., \& Bouchard, T.J. (1986). Early influences on cognitive functioning in Congenital Adrenal Hyperplasia. Developmental Psychology, 22, 191-198.

Silverman, I., \& Philips, K. (1993). Effects of Estrogen changes during the menstrual cycle on spatial performance. Ethology and Sociobiology, 14, 257-270.

Stahl, F., Gotz, F., Poppe, I., Amendt, P., \& Dorner, G. (1978). Pre- and early postnatal testosterone levels in rat and human. In G. Dorner \& M. Kawakami (Eds.) Hormones and brain development (pp. 99-109). New York: Elsevier/North-Holland Biomedical Press.

Waber, D.P. (1977). Sex differences in mental abilities, hemispheric lateralization, and rate of physical growth at adolescence. Developmental Psychology, 13, 29-38. 
Appendix B

For College Students

\section{VIRGINIA POLYTECHNIC AND STATE UNIVERSITY}

\section{Informed Consent for Participants of Investigative Projects}

Title of Project: "Task Ability Related to Age and EEG Power Values"

Investigator: $\quad$ Jonathan Roberts

Faculty Advisor: Martha Ann Bell, PhD.

\section{Purpose of this Research}

You have been invited to participate in a research project investigating the development of spatial skills. Specifically, we are examining how brain-wave activity and age are related to the ability to "mentally rotate" objects and recognize words.

\section{Procedures}

This study involves a 60-minute visit to the Developmental Cognitive Neuroscience Section (Derring 5076-F) of the Development Labs at Virginia Tech. This study involves 2

Questionnaires (Handedness Questionnaire, and Neurological Questionnaire) that will be completed in our research lab, as well as an EEG recording. It will take approximately 5 minutes to complete these 2 questionnaires.

First, we will ask you for your informed consent that details information concerning the questionnaires and the visit you will make to our research lab. Then you will fill out the three questionnaires mentioned above.

Next, you will have a cap that helps us collect brain-wave activity placed on your head. The cap looks and fits like a swim cap. In order to collect brain-wave activity, gel will be applied to your head through little holes in the cap. In addition, we will be placing two small stickers near one eye to monitor eye movements and one small sticker on the back to ensure high quality brain-wave activity recording. These procedures are similar to ones used in a doctor's office and will cause no harm. While brain-wave activity is being recorded you will be asked to sit quietly with your eyes closed for one minute and then to sit quietly with your eyes open for one minute. Brain wave activity will also be recorded while playing 5 different games on a computer. These games take about 5 minutes each. After this procedure, the cap and sticky patches will be removed and the gel will be washed from your head with warm water and a wash cloth. Finally, you will complete one paper-and-pencil task and one word task. 


\section{Risks}

There is minimal risk associated with this research project. The brain-wave procedures are similar to that done in a doctor's office and are not harmful. The researcher who will apply the brain-wave cap will wear disposable latex gloves. The EEG gel could cause an allergic reaction, but the chance of this is extremely rare. Other researchers in our laboratory have used OmniPrep over 500 infants, children, and adults and none have had a reaction to the gel. In the rare chance that a reaction does occur, the skin will be cleansed with rubbing alcohol, the company manufacturing the gel will be called immediately, and the Chair of the Virginia Tech Institutional Review Board will be notified.

\section{Benefits of this Research}

There are no tangible benefits to you. No promise or guarantee of benefits have been made to encourage you to participate in this study. In a scientific sense, however, this research study will give developmental specialists more information about the development of particular brain areas and the corresponding correlation with problem solving abilities.

\section{Extent of Confidentiality}

Information gathered for this study will be confidential and the information from each individual will be identified by code number only. We will not ask for social security numbers. Only the code number will be entered into the computer with data from your visit. Information linking name and code number will be kept in a file drawer and locked. Only Jonathan Roberts and Dr. Martha Ann Bell will have access to the card file.

\section{Compensation}

You will be given extra credit in your psychology class for participation in this study.

\section{Freedom to Withdraw}

You may withdraw from participation in this lab visit at any time without penalty. You will still receive the extra credit in your psychology class.

\section{Approval of Research}

This research has been approved, as required, by the Institutional Review Board for Research Involving Human Subjects at VPI\&SU and by the Department of Psychology at Virginia Tech.

\section{Participant's Responsibilities}

I voluntarily agree to participate in this study. I will be asked to have EEG recording equipment applied. I will also be asked to sit quietly for one minute with my eyes open and one minute with my closed. I will play the computer game to the best of my ability. 


\section{$\underline{\text { X. Participant's Permission }}$}

I have read and understand the Informed Consent and conditions of this project. I have had all my questions answered. I hereby acknowledge the above and give my voluntary consent for participation in this project.

If I participate, I may withdrawal at any time without penalty. I agree to abide by the rules of this project.

Signature

Date

Should I have any questions about this study, I may contact:

Jonathan Roberts

231-2320

Investigator

Office Phone

Martha Ann Bell, PhD

231-2546

Faculty Advisor

Office Phone

David Harrison, PhD

231-6581

Chair, Psychology Ethics Committee

Office Phone

231-5281

Tom Hurd, Chair

Phone

IRB Research Division 
Appendix C

For 8-year-Olds

\section{VIRGINIA POLYTECHNIC AND STATE UNIVERSITY}

\section{Informed Consent for Participants \\ of Investigative Projects}

Title of Project: "Task Ability Related to Age and EEG Power Values"

Investigator: Jonathan Roberts

Faculty Advisor: Martha Ann Bell, PhD.

\section{Purpose of this Research}

You are invited to help us with a research project about the way brain waves are related to the way you play games.

\section{Procedures}

First, you will have a cap that looks like a swim cap put on your head. Then, we will put some gel through some little holes that are on the cap. This allows us to measure your brain waves. After that, you will be asked to sit quietly and still for one minute with your eyes closed and one minute with your eyes open. Then, you will play some games on a computer. Finally, we will wash the gel off your head.

\section{Risks}

We are going to get some gel in your hair, but we will wash it out when you are done playing the games.

\section{Benefits of this Research}

You will get to help us understand the way that different brain waves are related to the different ways that people think.

\section{Extent of Confidentiality}

We won't use your name when we report the results of this study.

\section{Compensation}

We will give you a trip to a treasure chest of small prizes. 


\section{Freedom to Withdraw}

We don't think you will, but if you really feel like you don't want to do this anymore then you don't have to.

\section{Approval of Research}

Virginia Tech approved this project.

\section{Participant's Responsibilities}

We will ask you to sit still with your eyes open for one minute and closed for one minute. Also, we will ask you to play a game on the computer for us.

\section{$\underline{\text { X. Participant's Permission }}$}

I have read and understand this form. I have asked any questions that I have had, and I agree to participate in this experiment. I understand that I can quit at any time I want and I won't be penalized. I understand that I will get a copy of this form.

Signature

Date

Should I have any questions about this study, I may contact:

Jonathan Roberts

$\underline{231-2320}$

Investigator

Office Phone

Martha Ann Bell, PhD

$\underline{231-2546}$

Office Phone

Faculty Advisor

David Harrison, $\mathrm{PhD}$

$\underline{231-6581}$

Office Phone

Chair, Psychology Ethics Committee

Tom Hurd, Chair

$\underline{231-5281}$

Phone

IRB Research Division 
Appendix D

For Parents of 8-year-Olds

\title{
VIRGINIA POLYTECHNIC AND STATE UNIVERSITY
}

\author{
Informed Consent for Participants \\ of Investigative Projects
}

Title of Project: "Task Ability Related to Age and EEG Power Values"

Investigator: Jonathan Roberts

Faculty Advisor: Martha Ann Bell, PhD.

\section{Purpose of this Research}

You and your child have been invited to participate in a research project investigating the development of spatial skills. Specifically, we are examining how brain-wave activity and age are related to the ability to "mentally rotate" objects and recognize words.

\section{Procedures}

This study involves a 60-minute visit to the Developmental Cognitive Neuroscience Section (Derring 5076-F) of the Development Labs at Virginia Tech. This study involves 2

Questionnaires (Handedness Questionnaire and Neurological Questionnaire) that will be completed in our research lab, as well as an EEG recording. The handedness questionnaire and the neurological questionnaire will have already been given to you over the phone.

Upon arriving at the laboratory, will ask you for your informed consent that details information concerning the questionnaires and the visit you and your child will make to our research lab.

Next, your child will have a cap that helps us collect brain-wave activity placed on his/her head. The cap looks and fits like a swim cap. In order to collect brain-wave activity, gel will be applied to your child's head through little holes in the cap. In addition, we will be placing two small stickers near one eye to monitor eye movements and one small sticker on the back to ensure high quality brain-wave activity recording. These procedures are similar to ones used in a doctor's office and will cause no harm. While brain-wave activity is being recorded your child will be asked to sit quietly with his/her eyes closed for one minute and then to sit quietly with their eyes open for one minute. Brain wave activity will also be recorded while they are playing five different games on a computer. The games that your child will play are a matching game where they are asked to tell which two figures look alike. These games take about 5 minutes each to play. After the games, your child will read a paragraph and answer four questions about that paragraph. After this procedure, the cap and sticky patches will be removed and the gel will be washed from your head with warm water and a wash cloth. Finally, your child will complete one paper-and-pencil task and play another game that involves thinking of different words. 


\section{Risks}

There is minimal risk associated with this research project. The brain-wave procedures are similar to that done in a doctor's office and are not harmful. The researcher who will apply the brain-wave cap will wear disposable latex gloves. The EEG gel could cause an allergic reaction, but the chance of this is extremely rare. Other researchers in our laboratory have used OmniPrep over 500 infants, children, and adults and none have had a reaction to the gel. In the rare chance that a reaction does occur, the skin will be cleansed with rubbing alcohol, the company manufacturing the gel will be called immediately, and the Chair of the Virginia Tech Institutional Review Board will be notified.

\section{Benefits of this Research}

There are no tangible benefits to you or your child. No promise or guarantee of benefits have been made to encourage you and your child to participate in this study. In a scientific sense, however, this research study will give developmental specialists more information about the development of particular brain areas and the corresponding correlation with problem solving abilities.

\section{Extent of Confidentiality}

Information gathered for this study will be confidential and the information from each individual will be identified by code number only. We will not ask for social security numbers. Only the code number will be entered into the computer with data from your visit. Information linking name and code number will be kept in a file drawer and locked. Only Jonathan Roberts and Dr. Martha Ann Bell will have access to the card file.

\section{Compensation}

You will be not be compensated for your participation in this study. Your child, however, will receive trips to a "treasure chest" of toys.

\section{Freedom to Withdraw}

You may withdraw from participation in this lab visit at any time.

\section{Approval of Research}

This research has been approved, as required, by the Institutional Review Board for Research Involving Human Subjects at VPI\&SU and by the Department of Psychology at Virginia Tech.

\section{$\underline{\text { IX. Parent's Responsibilities }}$}

None. 


\section{Parent's Permission}

I have read and understand the Informed Consent and conditions of this project. I have had all my questions answered. I hereby acknowledge the above and give my voluntary consent for my child to participate in this project. I understand that I may withdrawal at any time without penalty. I understand that I will be given a copy of this consent form.

Signature

Date

Should I have any questions about this study, I may contact:

Jonathan Roberts

$\underline{231-2320}$

Investigator

Office Phone

Martha Ann Bell, PhD

$\underline{231-2546}$

Faculty Advisor

Office Phone

David Harrison, $\mathrm{PhD}$

231-6581

Chair, Psychology Ethics Committee

Office Phone

Tom Hurd, Chair

231-5281

IRB Research Division

Phone 
Appendix E

Edinburgh Inventory for Handedness

Please indicate which hand you use for the following activities. Leave blank activities that you have not participated in.

$\begin{array}{lcc}\text { Writing } & \text { Left } & \text { Right } \\ \text { Drawing } & \text { Left } & \text { Right } \\ \text { Throwing } & \text { Left } & \text { Right } \\ \text { Scissors } & \text { Left } & \text { Right } \\ \text { Toothbrush } & \text { Left } & \text { Right } \\ \text { Knife (without fork) } & \text { Left } & \text { Right } \\ \text { Spoon } & \text { Left } & \text { Right } \\ \text { Broom (upper hand) } & \text { Left } & \text { Right } \\ \text { Striking Match (match hand) } & \text { Left } & \text { Right } \\ \text { Opening box (lid) } & & \\ & \text { Left } & \text { Right }\end{array}$

Which foot do you use to kick a ball?

Left Right

Which eye do you use when using only one eye? Left Right 
Appendix F

Neurological Questionnaire

1) Have you ever had a concussion or lost consciousness as the result of a blow to the head?

2) Did you go under general anesthesia before one year of age?

3) Have you been diagnosed for ADD or ADHD?

4) Are you currently taking any Medications?

If so, what type?

5) Have you ever experienced a seizure?

6) How many drinks of coffee, tea, or cola have you had today? 
Appendix G

List of Word Pairs for Lexical Decision-Making Task

$\begin{array}{llll}\text { Pad } & \text { Pid } & \text { Nail } & \text { Rill } \\ \text { Jug } & \text { Jat } & \text { Boot } & \text { Bime } \\ \text { Motel } & \text { Moger } & \text { Clay } & \text { Clat } \\ \text { School } & \text { Schamb } & \text { Pants } & \text { Bealk } \\ \text { Flake } & \text { Hadis } & \text { Globe } & \text { Gloap } \\ \text { Crust } & \text { Crubs } & \text { Pirate } & \text { Chiral } \\ \text { Blade } & \text { Glush } & \text { Wallet } & \text { Grall } \\ \text { Friend } & \text { Cramb } & \text { Duck } & \text { Plut } \\ \text { Rib } & \text { Dak } & \text { Sleet } & \text { Wilm } \\ \text { Weed } & \text { Wamel } & \text { Keys } & \text { Yorn } \\ \text { Maps } & \text { Nops } & \text { Rock } & \text { Romb } \\ \text { Clown } & \text { Droad } & \text { Skates } & \text { Skanip } \\ \text { Cabin } & \text { Brool } & \text { Crater } & \text { Creash } \\ \text { Box } & \text { Dox } & \text { Bush } & \text { Fote } \\ \text { Draw } & \text { Selt } & \text { Gut } & \text { Yut } \\ \text { Steps } & \text { Shorp } & \text { Bird } & \text { Larm } \\ \text { Spot } & \text { Spean } & \text { Lake } & \text { Parm } \\ \text { Maze } & \text { Woaf } & \text { Farm } & \text { Stib } \\ \text { Jet } & \text { Jow } & \text { Bake } & \text { Crish } \\ \text { Ramp } & \text { Marp } & \text { Crib } & \text { Trib }\end{array}$


Appendix $\mathrm{H}$

Copy of the Reading Task

It was raining outside. Inside, Mother and Oliver were sitting in the big chair, having a hug.

"Tell me a secret," said Oliver.

"All right," said Mother. Mother whispered a secret into Oliver's

ear: "We are snug as three bugs in a rug."

"Me too," said Amanda.

"First I have to tell my tiger," said Oliver. Oliver whispered the secret into his tiger's ear: "Three bugs are having a hug."

"Now me," said Amanda. Oliver whispered the secret into Amanda's ear: "Three bugs are on the rug."

Was it raining outside?

Did Oliver tell the same secret to Amanda that Mother told to him?

Were Amanda and Oliver sitting in the big chair, having a hug?

Did Oliver tell the secret to his tiger before he told it to Amanda?

Note: all responses were answered with YES or NO keys 
Appendix I

Summary of all EEG Analyses

$\underline{\text { Summary of MANOVA F Values for Low Alpha (7.5 - 10.5) during the Baseline Condition }}$

\begin{tabular}{|c|c|c|c|c|c|c|c|}
\hline$\underline{\text { Region }}$ & Age & Sex & Age X Sex & Hemi & Hemi X Age & Hemi X Sex & Hemi X Age X Sex \\
\hline$d f$ & 1,60 & 1,60 & 1,60 & 1,60 & 1,60 & 1,60 & 1,60 \\
\hline Fp1, Fp2 & $6.03 *$ & & & & $6.87 *$ & & \\
\hline $\mathrm{F} 3, \mathrm{~F} 4$ & $10.09 * *$ & & & & & & \\
\hline F7, F8 & $15.69 * * *$ & & & $3.04+$ & $6.71 *$ & & \\
\hline $\mathrm{C} 3, \mathrm{C} 4$ & $18.64 * * *$ & & & & & & \\
\hline $\mathrm{T} 3, \mathrm{~T} 4$ & $22.35 * * *$ & & & $8.41 * *$ & $7.44 * *$ & $7.05 * *$ & $6.91 *$ \\
\hline T5, T6 & $8.34 * *$ & & & & & $4.53^{*}$ & \\
\hline P3, P4 & $11.06^{* *}$ & & & & & & \\
\hline $\mathrm{O} 1, \mathrm{O} 2$ & $10.47^{* *}$ & & & & & & $3.42+$ \\
\hline
\end{tabular}

Note. Only numbers that were significant at the $\mathrm{p} \leq .10$ level are presented.

$* \mathrm{p} \leq .05 . * * \mathrm{p} \leq .01 . * * * \mathrm{p} \leq .001 .+\mathrm{p} \leq .10$. 
Summary of MANCOVA F Values for Low Alpha Values $(7.5-10.5 \mathrm{~Hz})$ during the Task Conditions Covaried with Baseline

\begin{tabular}{|c|c|c|c|c|c|c|c|c|c|}
\hline Region & Age & Sex & Age X Sex & Task & Hemi & Task X Hemi & Task X Age X Hemi & Task X Sex X Hemi & Task X Age X Sex X Hemi \\
\hline$d f$ & 1,58 & 1,58 & 1,58 & 4,55 & 4,55 & 4,55 & 4,55 & 4,55 & 4,55 \\
\hline 1 (Fp1, Fp2) & $7.34 * *$ & $5.96 *$ & & $22.17 * * *$ & & $2.76^{*}$ & & & \\
\hline $2(\mathrm{~F} 3, \mathrm{~F} 4)$ & $55.93 * * *$ & $11.14 * * *$ & $6.53^{* *}$ & $6.02 * * *$ & & $3.15^{*}$ & $2.75^{*}$ & & \\
\hline $3(\mathrm{~F} 7, \mathrm{~F} 8)$ & $3.76+$ & $5.58 *$ & $5.56^{*}$ & $7.56^{* * *}$ & & & & & \\
\hline $4(\mathrm{C} 3, \mathrm{C} 4)$ & $49.21 * * *$ & $10.02 * *$ & $8.39 * *$ & $2.33+$ & & & & & \\
\hline $5(\mathrm{~T} 3, \mathrm{~T} 4)$ & $11.98 * * *$ & $3.63+$ & $4.28 *$ & & $11.96 * *$ & & & & \\
\hline $6(\mathrm{~T} 5, \mathrm{~T} 6)$ & $60.66^{* * *} *$ & $4.95^{*}$ & $5.49 *$ & $7.76^{* *}$ & & & & & \\
\hline 7 (P3, P4) & $51.68 * * *$ & $8.71 * *$ & $8.93 * *$ & $4.24 * *$ & & & & & \\
\hline $8(\mathrm{O} 1, \mathrm{O} 2)$ & $32.85 * * *$ & $6.28 *$ & $3.20+$ & $4.66 * *$ & & & & & \\
\hline
\end{tabular}

Note. Only numbers that were significant at the $\underline{\mathrm{p}} \leq .10$ level are presented.

Task = Gingerbread Man Mental Rotation. Basketball Player Mental Rotation, Alphanumeric Mental Rotation, Lexical Decision-Making, or Reading

Hemi $=$ Left or Right Hemisphere

$* \underline{p} \leq .05 . * * \underline{p} \leq .01 . * * * \underline{p} \leq .001 .+\underline{p} \leq .10$. 
$\underline{\text { Summary of MANCOVA F Values for Post-Hoc Analyses of Low Alpha (7.5 - 10.5 Hz) during Gingerbread Man Mental Rotation Task Covaried with Baseline }}$

\begin{tabular}{|c|c|c|c|c|c|c|c|}
\hline Region & Age & Sex & Age X Sex & Hemi & Hemi X Age & Hemi X Sex & Hemi X Age X Sex \\
\hline$d f$ & 1,58 & 1,58 & 1,58 & 1,58 & 1,58 & 1,58 & 1,58 \\
\hline Fp1, Fp2 & & $3.84+$ & & & & & \\
\hline F3, F4 & $40.06^{* * *}$ & $8.84 * *$ & $6.84 * *$ & $4.76^{*}$ & $2.98+$ & & \\
\hline \multicolumn{8}{|l|}{ F7, F8 } \\
\hline $\mathrm{C} 3, \mathrm{C} 4$ & $33.30 * * *$ & $11.90 * * *$ & $10.21 * *$ & & & & \\
\hline T3, T4 & $2.78+$ & & & $12.44 * * *$ & $22.93 * * *$ & & \\
\hline T5, T6 & $35.02 * * *$ & $7.19 * *$ & & $3.16+$ & & & \\
\hline P3, P4 & $34.09 * * *$ & $15.35^{* * *}$ & $7.93 * *$ & & & & \\
\hline $\mathrm{O} 1, \mathrm{O} 2$ & $26.22 * * *$ & $6.55 * *$ & & & & & \\
\hline
\end{tabular}

Note. Only numbers that were significant at the $\mathrm{p} \leq .10$ level are presented.

Hemi $=$ Left or Right Hemisphere.

$* \mathrm{p} \leq .05 . * * \mathrm{p} \leq .01 . * * * \mathrm{p} \leq .001 .+\mathrm{p} \leq .10$. 
Summary of MANCOVA F Values for Post-Hoc Analyses of Low Alpha (7.5 - 10.5 Hz) during Alphanumeric Mental Rotation Task Covaried with Baseline

\begin{tabular}{|c|c|c|c|c|c|c|c|}
\hline Region & Age & Sex & Age X Sex & Hemi & Hemi X Age & Hemi X Sex & Hemi X Age X Sex \\
\hline$\overline{d f}$ & 1,58 & 1,58 & 1,58 & 1,58 & 1,58 & 1,58 & 1,58 \\
\hline Fp1, Fp2 & & $6.03 *$ & & & & $2.77+$ & \\
\hline F3, F4 & $40.76^{* * *}$ & $8.62 * *$ & $3.99 *$ & & & & \\
\hline F7, F8 & & $4.14^{*}$ & $3.55+$ & & & & $3.14^{*}$ \\
\hline $\mathrm{C} 3, \mathrm{C} 4$ & $33.59 * * *$ & $4.56^{*}$ & $6.29 *$ & & & & \\
\hline T3, T4 & $10.78^{* *}$ & $3.47+$ & $3.61+$ & $7.98 * *$ & $20.80 * * *$ & & \\
\hline T5, T6 & $50.66 * * *$ & $2.83+$ & & & & $4.12^{*}$ & \\
\hline P3, P4 & $43.94 * * *$ & $5.11^{*}$ & $6.77 * *$ & & & & \\
\hline $\mathrm{O} 1, \mathrm{O} 2$ & $24.90 * * *$ & $5.07 *$ & & & $3.23+$ & & \\
\hline
\end{tabular}

Note. Only numbers that were significant at the $\mathrm{p} \leq .10$ level are presented.

Hemi $=$ Left or Right Hemisphere.

$* \mathrm{p} \leq .05 . * * \mathrm{p} \leq .01 . * * * \mathrm{p} \leq .001 .+\mathrm{p} \leq .10$. 
$\underline{\text { Summary of MANCOVA F Values for Post-Hoc Analyses of Low Alpha }(7.5 \text { - 10.5 Hz) during Basketball Player Mental Rotation Task Covaried with Baseline }}$

\begin{tabular}{|c|c|c|c|c|c|c|c|}
\hline Region & Age & Sex & Age X Sex & Hemi & Hemi X Age & Hemi X Sex & Hemi X Age X Sex \\
\hline$d f$ & 1,58 & 1,58 & 1,58 & 1,58 & 1,58 & 1,58 & 1,58 \\
\hline Fp1, Fp2 & & $4.31 *$ & & & & & \\
\hline $\mathrm{F} 3, \mathrm{~F} 4$ & $69.74 * * *$ & $10.35 * *$ & $4.17^{*}$ & & & & \\
\hline $\mathrm{F} 7, \mathrm{~F} 8$ & $11.77 * * *$ & $5.17^{*}$ & $5.23^{*}$ & & $6.66 * *$ & & \\
\hline $\mathrm{C} 3, \mathrm{C} 4$ & $51.79 * * *$ & $9.33 * *$ & $8.92 * *$ & & & & \\
\hline $\mathrm{T} 3, \mathrm{~T} 4$ & $7.68 * *$ & & & $5.84^{*}$ & $14.08 * * *$ & & \\
\hline $\mathrm{T} 5, \mathrm{~T} 6$ & $56.62 * * *$ & $5.01 *$ & $3.99 *$ & & & $4.25^{*}$ & \\
\hline $\mathrm{P} 3, \mathrm{P} 4$ & $38.13 * * *$ & $9.39 * *$ & $5.15^{*}$ & & & & \\
\hline $\mathrm{O} 1, \mathrm{O} 2$ & $24.56^{* * *}$ & $4.81^{*}$ & $3.73+$ & & & & \\
\hline
\end{tabular}

Note. Only numbers that were significant at the $\mathrm{p} \leq .10$ level are presented. Hemi $=$ Left or Right Hemisphere.

$* \mathrm{p} \leq .05 . * * \mathrm{p} \leq .01 . * * * \mathrm{p} \leq .001 .+\mathrm{p} \leq .10$. 
Summary of MANCOVA F Values for Post-Hoc Analyses of Low Alpha (7.5 - 13.5 Hz) during Lexical Decision-Making Task Covaried with Baseline

\begin{tabular}{|c|c|c|c|c|c|c|c|}
\hline Region & Age & Sex & Age X Sex & Hemi & Hemi X Age & Hemi X Sex & Hemi X Age X Sex \\
\hline$d f$ & 1,58 & 1,58 & 1,58 & 1,58 & 1,58 & 1,58 & 1,58 \\
\hline Fp1, Fp2 & $31.54 * * *$ & $6.59 * *$ & $4.59^{*}$ & & & & \\
\hline $\mathrm{F} 3, \mathrm{~F} 4$ & $59.84 * * *$ & $7.41 * *$ & $5.89 *$ & & & & \\
\hline F7, F8 & $12.57 * * *$ & $9.45^{* *}$ & $10.46^{* *}$ & & & & \\
\hline $\mathrm{C} 3, \mathrm{C} 4$ & $49.40 * * *$ & $5.97 *$ & $5.61 *$ & & & & \\
\hline $\mathrm{T} 3, \mathrm{~T} 4$ & $19.88 * * *$ & $3.91^{*}$ & $5.89 *$ & $5.74 *$ & $12.32^{* * *}$ & & \\
\hline T5, T6 & $61.44 * * *$ & $3.23+$ & $5.32 *$ & & & & \\
\hline P3, P4 & $54.48 * * *$ & $3.85+$ & $6.49 * *$ & & & & \\
\hline $\mathrm{O} 1, \mathrm{O} 2$ & $37.70^{* * *}$ & $6.18^{*}$ & & & & & \\
\hline
\end{tabular}

Note. Only numbers that were significant at the $\underline{p} \leq .10$ level are presented.

Hemi $=$ Left or Right Hemisphere.

$* \mathrm{p} \leq .05 . * * \mathrm{p} \leq .01 . * * * \mathrm{p} \leq .001 .+\mathrm{p} \leq .10$. 
$\underline{\text { Summary of MANCOVA F Values for Post-Hoc Analyses of Low Alpha (7.5 - 10.5 Hz) during Reading Task Covaried with Baseline }}$

\begin{tabular}{|c|c|c|c|c|c|c|c|}
\hline Region & Age & Sex & Age X Sex & Hemi & Hemi X Age & Hemi X Sex & Hemi X Age X Sex \\
\hline$d f$ & 1,58 & 1,58 & 1,58 & 1,58 & 1,58 & 1,58 & 1,58 \\
\hline Fp1, Fp2 & $7.70 * *$ & $3.69+$ & $2.96+$ & $3.74+$ & & & \\
\hline $\mathrm{F} 3, \mathrm{~F} 4$ & $30.30 * * *$ & $11.40 * * *$ & $6.40 * *$ & & & & \\
\hline $\mathrm{F} 7, \mathrm{~F} 8$ & & $3.47+$ & $3.25+$ & & $6.98 * *$ & & \\
\hline $\mathrm{C} 3, \mathrm{C} 4$ & $21.39 * * *$ & $7.68 * *$ & & & & & \\
\hline $\mathrm{T} 3, \mathrm{~T} 4$ & $12.56^{* * *}$ & $5.36^{*}$ & $10.47^{* *}$ & $6.65 * *$ & $3.29+$ & & \\
\hline $\mathrm{T} 5, \mathrm{~T} 6$ & $54.86^{* * *}$ & $3.62+$ & $11.32 * * *$ & & & & \\
\hline $\mathrm{P} 3, \mathrm{P} 4$ & $30.26 * * *$ & $4.31^{*}$ & $8.47 * *$ & $6.09 *$ & & & \\
\hline $\mathrm{O} 1, \mathrm{O} 2$ & $23.92 * * *$ & $3.98^{*}$ & $4.95^{*}$ & & & & \\
\hline
\end{tabular}

Note. Only numbers that were significant at the $\mathrm{p} \leq .10$ level are presented.

Hemi $=$ Left or Right Hemisphere.

$* \mathrm{p} \leq .05 . * * \mathrm{p} \leq .01 . * * * \mathrm{p} \leq .001 .+\mathrm{p} \leq .10$. 
$\underline{\text { Summary of MANOVA F Values for High Alpha }(10.5-13.5 \mathrm{~Hz}) \text { during the Baseline Condition }}$

\begin{tabular}{|c|c|c|c|c|c|c|c|}
\hline Region & Age & Sex & Age X Sex & Hemi & Hemi X Age & Hemi X Sex & Hemi X Age X Sex \\
\hline$d f$ & 1,60 & 1,60 & 1,60 & 1,60 & 1,60 & 1,60 & 1,60 \\
\hline Fp1, Fp2 & $3.95^{*}$ & & & & $3.19+$ & & \\
\hline F3, F4 & $8.06 * *$ & & & & & & \\
\hline F7, F8 & $11.77 * * *$ & & & $3.63+$ & $5.63 *$ & & $5.11 *$ \\
\hline $\mathrm{C} 3, \mathrm{C} 4$ & $5.91 *$ & & & & $4.21 *$ & & $3.35+$ \\
\hline $\mathrm{T} 3, \mathrm{~T} 4$ & $8.00 * *$ & & & $10.14^{* *}$ & & & $3.45+$ \\
\hline T5, T6 & $3.73+$ & & & & & & \\
\hline P3, P4 & $2.85+$ & & & & & $4.55^{*}$ & \\
\hline $\mathrm{O} 1, \mathrm{O} 2$ & & & & & & & \\
\hline
\end{tabular}

Note. Only numbers that were significant at the $\mathrm{p} \leq .10$ level are presented.

$* \mathrm{p} \leq .05 . * * \mathrm{p} \leq .01 . * * * \mathrm{p} \leq .001 .+\mathrm{p} \leq .10$. 
Summary of MANCOVA F Values for High Alpha Values $(10.5-13.5 \mathrm{~Hz})$ during the Task Conditions Covaried with Baseline

\begin{tabular}{|c|c|c|c|c|c|c|c|c|c|}
\hline$\underline{\text { Region }}$ & Age & Sex & Age X Sex & Task & Hemi & Task X Hemi & Task X Age X Hemi & Task X Sex X Hemi & Task X Age X Sex X Hemi \\
\hline$d f$ & 1,58 & 1,58 & 1,58 & 4,55 & 4,55 & 4,55 & 4,55 & 4,55 & 4,55 \\
\hline $1(\mathrm{Fp} 1, \mathrm{Fp} 2)$ & & $3.27+$ & & $14.44 * * *$ & & & & & \\
\hline $2(\mathrm{~F} 3, \mathrm{~F} 4)$ & $38.56^{* * *}$ & $6.21 *$ & $5.04 *$ & & & & & & \\
\hline $3(\mathrm{~F} 7, \mathrm{~F} 8)$ & & $2.85+$ & $2.80+$ & $10.58 * * *$ & $8.50 * *$ & & & & \\
\hline $4(\mathrm{C} 3, \mathrm{C} 4)$ & $30.77 * * *$ & $6.09 *$ & & $7.47 * * *$ & & & & & \\
\hline $5(\mathrm{~T} 3, \mathrm{~T} 4)$ & $5.07 *$ & & & $4.42 * *$ & & & & & \\
\hline $6(\mathrm{~T} 5, \mathrm{~T} 6)$ & $36.91 * * *$ & & $4.27 *$ & $2.03+$ & & $3.55^{* *}$ & & & $2.12+$ \\
\hline $7(\mathrm{P} 3, \mathrm{P} 4)$ & $36.54 * * *$ & $5.07 *$ & $4.08 *$ & $5.25 * * *$ & & & & $3.50 * *$ & \\
\hline $8(\mathrm{O} 1, \mathrm{O} 2)$ & $16.99 * * *$ & $7.35 * *$ & & $6.39 * * *$ & $2.73+$ & $2.99 *$ & & & \\
\hline
\end{tabular}

Note. Only numbers that were significant at the $\mathrm{p} \leq .10$ level are presented.

Task = Gingerbread Man Mental Rotation. Basketball Player Mental Rotation, Alphanumeric Mental Rotation, Lexical Decision-Making, or Reading

Hemi $=$ Left or Right Hemisphere

$* \underline{p} \leq .05 . * * \underline{p} \leq .01 . * * * \underline{p} \leq .001 .+\underline{p} \leq .10$. 
Summary of MANCOVA F Values for Post-Hoc Analyses of High Alpha (10.5 - 13.5 Hz) during Gingerbread Man Mental Rotation Task Covaried with Baseline

\begin{tabular}{|c|c|c|c|c|c|c|c|}
\hline Region & Age & Sex & Age X Sex & Hemi & Hemi X Age & Hemi X Sex & Hemi X Age X Sex \\
\hline$d f$ & 1,58 & 1,58 & 1,58 & 1,58 & 1,58 & 1,58 & 1,58 \\
\hline Fp1, Fp2 & & $2.75+$ & & & & & \\
\hline $\mathrm{F} 3, \mathrm{~F} 4$ & $19.55 * * *$ & $6.06^{*}$ & & & & & \\
\hline F7, F8 & & & & & $4.75^{*}$ & & \\
\hline $\mathrm{C} 3, \mathrm{C} 4$ & $15.22 * * *$ & $3.56+$ & & & & $3.29+$ & \\
\hline \multicolumn{8}{|l|}{$\mathrm{T} 3, \mathrm{~T} 4$} \\
\hline T5, T6 & $15.38 * * *$ & $2.88+$ & & & & & \\
\hline P3, P4 & $21.55^{* * *}$ & $6.37 * *$ & & & & $6.17 *$ & \\
\hline $\mathrm{O} 1, \mathrm{O} 2$ & $14.97 * * *$ & $6.96 * *$ & & $5.01 *$ & & & $6.91 * *$ \\
\hline
\end{tabular}

Note. Only numbers that were significant at the $\underline{p} \leq .10$ level are presented.

Hemi $=$ Left or Right Hemisphere.

$* \mathrm{p} \leq .05 . * \mathrm{p} \leq .01 . * * * \mathrm{p} \leq .001 .+\mathrm{p} \leq .10$. 
Summary of MANCOVA F Values for Post-Hoc Analyses of High Alpha (10.5 - 13.5 Hz) during Alphanumeric Mental Rotation Task Covaried with Baseline

\begin{tabular}{|c|c|c|c|c|c|c|c|}
\hline Region & Age & Sex & Age X Sex & Hemi & Hemi X Age & Hemi X Sex & Hemi X Age X Sex \\
\hline$d f$ & 1,58 & 1,58 & 1,58 & 1,58 & 1,58 & 1,58 & 1,58 \\
\hline Fp1, Fp2 & & $4.81 *$ & & & & & \\
\hline $\mathrm{F} 3, \mathrm{~F} 4$ & $21.60 * *$ & $4.38^{*}$ & $4.78^{*}$ & & & & $3.62+$ \\
\hline F7, F8 & $3.04+$ & & & $10.03 * *$ & & & \\
\hline $\mathrm{C} 3, \mathrm{C} 4$ & $18.95 * * *$ & $3.05+$ & $2.82+$ & & & $4.08^{*}$ & \\
\hline $\mathrm{T} 3, \mathrm{~T} 4$ & $8.27 * *$ & & & & & $3.38+$ & \\
\hline T5, T6 & $30.06 * * *$ & & $3.40+$ & & & & $6.77 * *$ \\
\hline $\mathrm{P} 3, \mathrm{P} 4$ & $24.36 * * *$ & & $4.55^{*}$ & & & & \\
\hline $\mathrm{O} 1, \mathrm{O} 2$ & $12.41 * * *$ & $3.45+$ & & & & $3.88 *$ & \\
\hline
\end{tabular}

Note. Only numbers that were significant at the $\mathrm{p} \leq .10$ level are presented.

Hemi $=$ Left or Right Hemisphere.

$* \mathrm{p} \leq .05 . * * \mathrm{p} \leq .01 . * * * \mathrm{p} \leq .001 .+\mathrm{p} \leq .10$. 
Summary of MANCOVA F Values for Post-Hoc Analyses of High Alpha (10.5 - 13.5 Hz) during Basketball Player Mental Rotation Task Covaried with Baseline

\begin{tabular}{llllllll}
\hline Region & Age & Sex & Age X Sex & Hemi & Hemi X Age & Hemi X Sex & Hemi X Age X Sex \\
\hline$d f$ & 1,58 & 1,58 & 1,58 & 1,58 & 1,58 & 1,58 & 1,58
\end{tabular}

Fp1, Fp2

F3, F4 $33.91 * * * \quad 5.18$

$3.63+\quad 5.86^{*} \quad 7.51^{* *}$

F7, F8

$3.63+$

$3.13+$

C3, C4

$26.51^{* * * *}$

$3.19+$

$8.23 * *$

T3, T4

T5, T6

$24.29 * * *$

$3.54+$

$3.30+$

$4.67 *$

P3, P4

$21.21^{* * *}$

4.24*

O1, O2

$9.93 * *$

$4.32 *$

Note. Only numbers that were significant at the $\underline{p} \leq .10$ level are presented.

Hemi $=$ Left or Right Hemisphere.

$* \mathrm{p} \leq .05 . * * \mathrm{p} \leq .01 . * * * \mathrm{p} \leq .001 .+\mathrm{p} \leq .10$. 
$\underline{\text { Summary of MANCOVA F Values for Post-Hoc Analyses of High Alpha (10.5 - 13.5 Hz) during Lexical Decision-Making Task Covaried with Baseline }}$

\begin{tabular}{|c|c|c|c|c|c|c|c|}
\hline Region & Age & Sex & Age X Sex & Hemi & Hemi X Age & Hemi X Sex & Hemi X Age X Sex \\
\hline$d f$ & 1,58 & 1,58 & 1,58 & 1,58 & 1,58 & 1,58 & 1,58 \\
\hline Fp1, Fp2 & $11.16^{* * *}$ & $4.45^{*}$ & & & & & \\
\hline F3, F4 & $43.47 * * *$ & $2.73+$ & $3.94 *$ & & & & \\
\hline F7, F8 & & $4.94 *$ & $5.03 *$ & $4.64 *$ & & & \\
\hline $\mathrm{C} 3, \mathrm{C} 4$ & $41.04 * * *$ & $3.63+$ & & & & & \\
\hline T3, T4 & $8.17 * *$ & & & & & & \\
\hline T5, T6 & $38.49 * * *$ & & $5.93 *$ & $3.24+$ & & & \\
\hline P3, P4 & $49.30^{* * *}$ & & $3.32+$ & & & & $3.12+$ \\
\hline $\mathrm{O} 1, \mathrm{O} 2$ & $19.57 * * *$ & $6.34 *$ & & & & & \\
\hline
\end{tabular}

Note. Only numbers that were significant at the $\mathrm{p} \leq .10$ level are presented.

Hemi $=$ Left or Right Hemisphere.

$* \mathrm{p} \leq .05 . * * \mathrm{p} \leq .01 . * * * \mathrm{p} \leq .001 .+\mathrm{p} \leq .10$. 
Summary of MANCOVA F Values for Post-Hoc Analyses of High Alpha (10.5 - 13.5 Hz) during Reading Task Covaried with Baseline

\begin{tabular}{|c|c|c|c|c|c|c|c|}
\hline Region & Age & Sex & Age X Sex & Hemi & Hemi X Age & Hemi X Sex & Hemi X Age X Sex \\
\hline$d f$ & 1,58 & 1,58 & 1,58 & 1,58 & 1,58 & 1,58 & 1,58 \\
\hline Fp1, Fp2 & $4.40^{*}$ & & & & & & \\
\hline $\mathrm{F} 3, \mathrm{~F} 4$ & $36.96 * * *$ & $6.54 * *$ & $7.53^{* *}$ & & & & \\
\hline F7, F8 & & $3.60+$ & $3.05+$ & $3.52+$ & $9.66 * *$ & & \\
\hline $\mathrm{C} 3, \mathrm{C} 4$ & $16.86^{* * *}$ & $10.03 * *$ & & & & & \\
\hline $\mathrm{T} 3, \mathrm{~T} 4$ & $3.50+$ & $4.09 *$ & & & $2.96+$ & & \\
\hline T5, T6 & $43.83 * * *$ & $2.90+$ & $2.90+$ & & & & \\
\hline P3, P4 & $27.09 * * *$ & $5.49 *$ & $3.46+$ & & & & \\
\hline $\mathrm{O} 1, \mathrm{O} 2$ & $12.96 * * *$ & $9.67 * *$ & & $5.93 *$ & & & $2.94+$ \\
\hline
\end{tabular}

Note. Only numbers that were significant at the $\underline{p} \leq .10$ level are presented.

Hemi $=$ Left or Right Hemisphere.

$* \mathrm{p} \leq .05 . * \mathrm{p} \leq .01 . * * * \mathrm{p} \leq .001 .+\mathrm{p} \leq .10$. 
$\underline{\text { Summary of MANOVA F Values for Alpha }(7.5-13.5 \mathrm{~Hz}) \text { during the Baseline Condition }}$

\begin{tabular}{|c|c|c|c|c|c|c|c|}
\hline Region & Age & Sex & Age X Sex & Hemi & Hemi X Age & Hemi X Sex & Hemi X Age X Sex \\
\hline$d f$ & 1,60 & 1,60 & 1,60 & 1,60 & 1,60 & 1,60 & 1,60 \\
\hline Fp1, Fp2 & $4.63^{*}$ & & & & $6.80 * *$ & & \\
\hline F3, F4 & $8.81 * *$ & & & & & & \\
\hline F7, F8 & $14.04 * * *$ & & & $3.60+$ & $8.49 * *$ & & \\
\hline $\mathrm{C} 3, \mathrm{C} 4$ & $13.99 * * *$ & & & & $4.02 *$ & & \\
\hline $\mathrm{T} 3, \mathrm{~T} 4$ & $17.23 * * *$ & & & $13.50 * * *$ & $5.55^{*}$ & $6.79 * *$ & $6.42 * *$ \\
\hline T5, T6 & $5.94 *$ & & & & & & \\
\hline P3, P4 & $7.91 * *$ & & & & & & \\
\hline $\mathrm{O} 1, \mathrm{O} 2$ & $7.92 * *$ & & & & & & $3.18+$ \\
\hline
\end{tabular}

Note. Only numbers that were significant at the $\mathrm{p} \leq .10$ level are presented.

$* \mathrm{p} \leq .05 . * * \mathrm{p} \leq .01 . * * * \mathrm{p} \leq .001 .+\mathrm{p} \leq .10$. 
$\underline{\text { Summary of MANCOVA F Values for Alpha Values }(7.5-13.5 \mathrm{~Hz}) \text { during the Task Conditions Covaried with Baseline }}$

\begin{tabular}{|c|c|c|c|c|c|c|c|c|c|}
\hline$\underline{\text { Region }}$ & Age & Sex & Age X Sex & Task & Hemi & Task X Hemi & Task X Age X Hemi & Task X Sex X Hemi & Task X Age X Sex X Hemi \\
\hline$d f$ & 1,58 & 1,58 & 1,58 & 4,55 & 4,55 & 4,55 & 4,55 & 4,55 & 4,55 \\
\hline $1(\mathrm{Fp} 1, \mathrm{Fp} 2)$ & $6.30 *$ & $6.11 *$ & & $12.98 * * *$ & & & & & \\
\hline $2(\mathrm{~F} 3, \mathrm{~F} 4)$ & $54.96 * * *$ & $10.40 * *$ & $6.14^{*}$ & $4.29 * *$ & & $3.06^{*}$ & & & \\
\hline $3(\mathrm{~F} 7, \mathrm{~F} 8)$ & & $5.48 *$ & $4.60^{*}$ & $4.82 * *$ & & & & & \\
\hline $4(\mathrm{C} 3, \mathrm{C} 4)$ & $45.13 * * *$ & $9.94 * *$ & $6.84 * *$ & $2.27+$ & & & $2.25+$ & & \\
\hline $5(\mathrm{~T} 3, \mathrm{~T} 4)$ & $9.49 * *$ & & & $2.13+$ & $4.12 *$ & & & & \\
\hline $6(\mathrm{~T} 5, \mathrm{~T} 6)$ & $52.44 * * *$ & $5.17 *$ & $4.61 *$ & $5.30 * * *$ & & $2.71 *$ & & & \\
\hline $7(\mathrm{P} 3, \mathrm{P} 4)$ & $47.72 * * *$ & $8.94 * *$ & $7.21 * *$ & $3.95 * *$ & & & & & \\
\hline $8(\mathrm{O} 1, \mathrm{O} 2)$ & $29.53 * * *$ & $6.78 * *$ & & $4.42 * *$ & & $4.40 * *$ & & & \\
\hline
\end{tabular}

Note. Only numbers that were significant at the $\mathrm{p} \leq .10$ level are presented.

Task = Gingerbread Man Mental Rotation. Basketball Player Mental Rotation, Alphanumeric Mental Rotation, Lexical Decision-Making, or Reading

Hemi $=$ Left or Right Hemisphere

$* \underline{p} \leq .05 . * * \underline{p} \leq .01 . * * * \underline{p} \leq .001 .+\underline{p} \leq .10$. 
$\underline{\text { Summary of MANCOVA F Values for Post-Hoc Analyses of Alpha }(7.5-13.5 \mathrm{~Hz}) \text { during Gingerbread Man Mental Rotation Task Covaried with Baseline }}$

\begin{tabular}{|c|c|c|c|c|c|c|c|}
\hline Region & Age & Sex & Age X Sex & Hemi & Hemi X Age & Hemi X Sex & Hemi X Age X Sex \\
\hline$d f$ & 1,58 & 1,58 & 1,58 & 1,58 & 1,58 & 1,58 & 1,58 \\
\hline Fp1, Fp2 & & $4.26^{*}$ & & & & & \\
\hline $\mathrm{F} 3, \mathrm{~F} 4$ & $34.79 * * *$ & $8.49 * *$ & $5.31 *$ & & & & \\
\hline F7, F8 & & & & & $3.14+$ & & \\
\hline $\mathrm{C} 3, \mathrm{C} 4$ & $27.29 * * *$ & $9.78 * *$ & $6.94 * *$ & & & & \\
\hline $\mathrm{T} 3, \mathrm{~T} 4$ & & & & $5.93 *$ & $9.10 * *$ & & \\
\hline T5, T6 & $28.07 * * *$ & $6.97 * *$ & & $3.26+$ & & & \\
\hline P3, P4 & $31.02 * * *$ & $14.11 * * *$ & $5.47^{*}$ & & & & \\
\hline $\mathrm{O} 1, \mathrm{O} 2$ & $24.46^{* * * *}$ & $7.28 * *$ & & & & & $3.96^{*}$ \\
\hline
\end{tabular}

Note. Only numbers that were significant at the $\mathrm{p} \leq .10$ level are presented. Hemi $=$ Left or Right Hemisphere.

$* \mathrm{p} \leq .05 . * * \mathrm{p} \leq .01 . * * * \mathrm{p} \leq .001 .+\mathrm{p} \leq .10$. 
Summary of MANCOVA F Values for Post-Hoc Analyses of Alpha $(7.5-13.5 \mathrm{~Hz})$ during Alphanumeric Mental Rotation Task Covaried with Baseline

\begin{tabular}{|c|c|c|c|c|c|c|c|}
\hline Region & Age & Sex & Age X Sex & Hemi & Hemi X Age & Hemi X Sex & Hemi X Age X Sex \\
\hline$d f$ & 1,58 & 1,58 & 1,58 & 1,58 & 1,58 & 1,58 & 1,58 \\
\hline Fp1, Fp2 & & $6.88 * *$ & & & & & \\
\hline $\mathrm{F} 3, \mathrm{~F} 4$ & $36.80 * * *$ & $8.18 * *$ & $4.26^{*}$ & & & & \\
\hline F7, F8 & & $4.12 *$ & $2.98+$ & $2.97+$ & & & \\
\hline $\mathrm{C} 3, \mathrm{C} 4$ & $28.16 * * *$ & $4.44 *$ & $5.40 *$ & & & & \\
\hline $\mathrm{T} 3, \mathrm{~T} 4$ & $9.69 * *$ & & & $4.34 *$ & $10.63 * *$ & & \\
\hline T5, T6 & $43.42 * * *$ & $3.27+$ & & & & & $4.53^{*}$ \\
\hline P3, P4 & $37.47 * * *$ & $5.29 *$ & $5.66^{*}$ & & & & \\
\hline $\mathrm{O} 1, \mathrm{O} 2$ & $21.88 * * *$ & $4.92 *$ & & $7.50 * *$ & & & \\
\hline
\end{tabular}

Note. Only numbers that were significant at the $\mathrm{p} \leq .10$ level are presented.

Hemi $=$ Left or Right Hemisphere.

$* \mathrm{p} \leq .05 . * * \mathrm{p} \leq .01 . * * * \mathrm{p} \leq .001 .+\mathrm{p} \leq .10$. 
$\underline{\text { Summary of MANCOVA F Values for Post-Hoc Analyses of Alpha }(7.5-13.5 \mathrm{~Hz}) \text { during Basketball Player Mental Rotation Task Covaried with Baseline }}$

\begin{tabular}{|c|c|c|c|c|c|c|c|}
\hline Region & Age & Sex & Age X Sex & Hemi & Hemi X Age & Hemi X Sex & Hemi X Age X Sex \\
\hline$d f$ & 1,58 & 1,58 & 1,58 & 1,58 & 1,58 & 1,58 & 1,58 \\
\hline Fp1, Fp2 & & $3.86^{*}$ & & & & & \\
\hline $\mathrm{F} 3, \mathrm{~F} 4$ & $63.15^{* * *}$ & $9.32 * *$ & $3.17+$ & & & & \\
\hline F7, F8 & $8.74 * *$ & $4.61^{*}$ & $4.34^{*}$ & & $7.29 * *$ & & \\
\hline $\mathrm{C} 3, \mathrm{C} 4$ & $45.65^{* * *}$ & $8.25 * *$ & $6.40 * *$ & & & & \\
\hline $\mathrm{T} 3, \mathrm{~T} 4$ & $4.17^{*}$ & & & & $4.62 *$ & & \\
\hline T5, T6 & $44.43^{* * *}$ & $5.51^{*}$ & $3.05+$ & & & & \\
\hline $\mathrm{P} 3, \mathrm{P} 4$ & $34.32 * * *$ & $9.38 * *$ & $3.85+$ & & & & \\
\hline $\mathrm{O} 1, \mathrm{O} 2$ & $20.69 * * *$ & $5.06^{*}$ & & & & & \\
\hline
\end{tabular}

Note. Only numbers that were significant at the $\mathrm{p} \leq .10$ level are presented.

Hemi $=$ Left or Right Hemisphere.

$* \mathrm{p} \leq .05 . * * \mathrm{p} \leq .01 . * * * \mathrm{p} \leq .001 .+\mathrm{p} \leq .10$. 
Summary of MANCOVA F Values for Post-Hoc Analyses of Alpha (7.5 - 13.5 Hz) during Lexical Decision-Making Task Covaried with Baseline

\begin{tabular}{|c|c|c|c|c|c|c|c|}
\hline Region & Age & Sex & Age X Sex & Hemi & Hemi X Age & Hemi X Sex & Hemi X Age X Sex \\
\hline$d f$ & 1,58 & 1,58 & 1,58 & 1,58 & 1,58 & 1,58 & 1,58 \\
\hline Fp1, Fp2 & $27.85 * * *$ & $7.08 * *$ & $4.62 *$ & & $3.74+$ & & \\
\hline $\mathrm{F} 3, \mathrm{~F} 4$ & $61.86 * * *$ & $6.56^{* *}$ & $5.56^{*}$ & & & & \\
\hline F7, F8 & $11.06^{* *}$ & $9.20 * *$ & $8.72 * *$ & & & & \\
\hline $\mathrm{C} 3, \mathrm{C} 4$ & $49.99 * * *$ & $6.24 *$ & $5.27 *$ & & & & \\
\hline $\mathrm{T} 3, \mathrm{~T} 4$ & $17.09 * * *$ & $2.97+$ & $4.75^{*}$ & & & & \\
\hline T5, T6 & $54.71 * * *$ & $2.84+$ & $4.97 *$ & & & & \\
\hline P3, P4 & $54.66^{* * * *}$ & $4.31 *$ & $5.84 *$ & & & & \\
\hline $\mathrm{O} 1, \mathrm{O} 2$ & $35.54 * * *$ & $6.08^{*}$ & & & & & \\
\hline
\end{tabular}

Note. Only numbers that were significant at the $\underline{p} \leq .10$ level are presented.

Hemi $=$ Left or Right Hemisphere.

$* \mathrm{p} \leq .05 . * \mathrm{p} \leq .01 . * * * \mathrm{p} \leq .001 .+\mathrm{p} \leq .10$. 
$\underline{\text { Summary of MANCOVA F Values for Post-Hoc Analyses of Alpha }(7.5 \text { - 13.5 Hz) during Reading Task Covaried with Baseline }}$

\begin{tabular}{|c|c|c|c|c|c|c|c|}
\hline Region & Age & Sex & Age X Sex & Hemi & Hemi X Age & Hemi X Sex & Hemi X Age X Sex \\
\hline$d f$ & 1,58 & 1,58 & 1,58 & 1,58 & 1,58 & 1,58 & 1,58 \\
\hline Fp1, Fp2 & $9.09 * *$ & $3.22+$ & $3.70+$ & & & & \\
\hline $\mathrm{F} 3, \mathrm{~F} 4$ & $40.74 * * *$ & $11.76 * * *$ & $7.84 * *$ & & & & \\
\hline $\mathrm{F} 7, \mathrm{~F} 8$ & & $4.02 *$ & $3.49+$ & & $8.57 * *$ & & \\
\hline $\mathrm{C} 3, \mathrm{C} 4$ & $22.15 * * *$ & $9.67 * *$ & & & & & \\
\hline $\mathrm{T} 3, \mathrm{~T} 4$ & $9.78 * *$ & $5.84^{*}$ & $7.17 * *$ & & $3.11+$ & & \\
\hline $\mathrm{T} 5, \mathrm{~T} 6$ & $56.23 * * *$ & $4.37^{*}$ & $9.14 * *$ & & & & \\
\hline $\mathrm{P} 3, \mathrm{P} 4$ & $32.60 * * *$ & $5.46^{*}$ & $7.87 * *$ & $4.40^{*}$ & & & \\
\hline $\mathrm{O} 1, \mathrm{O} 2$ & $23.40 * * *$ & $5.84^{*}$ & $3.73+$ & & & & \\
\hline
\end{tabular}

Note. Only numbers that were significant at the $\mathrm{p} \leq .10$ level are presented. Hemi $=$ Left or Right Hemisphere.

$* \mathrm{p} \leq .05 . * * \mathrm{p} \leq .01 . * * * \mathrm{p} \leq .001 .+\mathrm{p} \leq .10$. 
Representations of two-way interactions using only variables included in the interaction.

Figure 20j. Baseline EEG at Central Region: Hemisphere by Age Interaction

Figure 21j. Baseline EEG at Parietal Region: Hemisphere by Sex Interaction

Figure 22j. 2-Dimensional "Gingerbread Man" Mental Rotation Task EEG Covaried with Baseline EEG at Lateral Frontal Region: Hemisphere by Age Interaction

Figure 23j. 2-Dimensional "Gingerbread Man" Mental Rotation Task EEG Covaried with Baseline EEG at Parietal Region: Hemisphere by Sex Interaction

Figure 25j. 2-Dimensional Alphanumeric Mental Rotation Task EEG Covaried with Baseline EEG at Central Region: Hemisphere by Sex Interaction

Figure 26j. 2-Dimensional Alphanumeric Mental Rotation Task EEG Covaried with Baseline EEG at Occipital Region: Hemisphere by Sex Interaction

Figure 28j. 3-Dimensional "Basketball Player" Mental Rotation Task EEG Covaried with Baseline EEG at Lateral Frontal Region: Hemisphere by Age Interaction

Figure 29j. 3-Dimensional "Basketball Player" Mental Rotation Task EEG Covaried with Baseline EEG at Central Region: Hemisphere by Sex Interaction

Figure 30j. Reading Task EEG Covaried with Baseline EEG at Lateral Frontal Region: Hemisphere by Age Interaction 


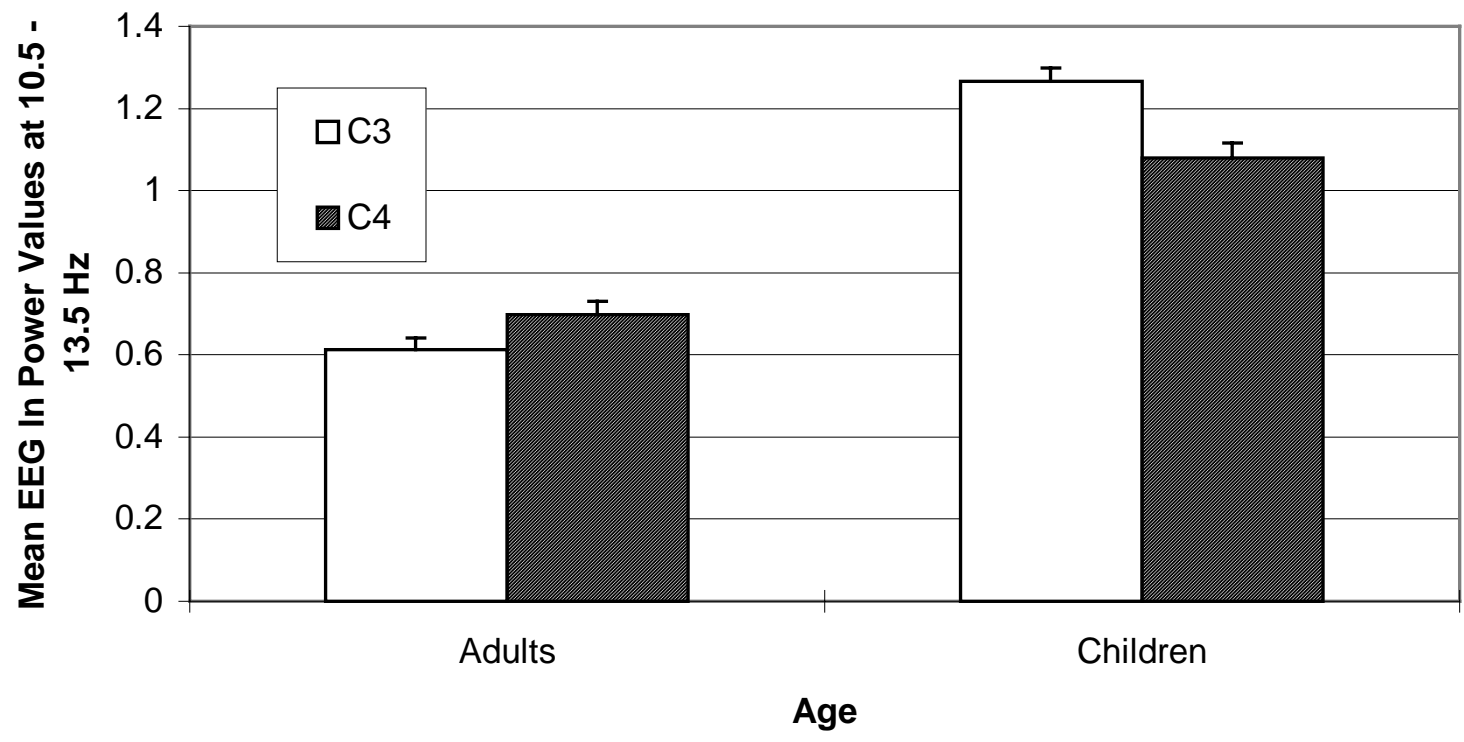

Figure 20j

Baseline EEG at Central Region:

Hemisphere by Age Interaction 


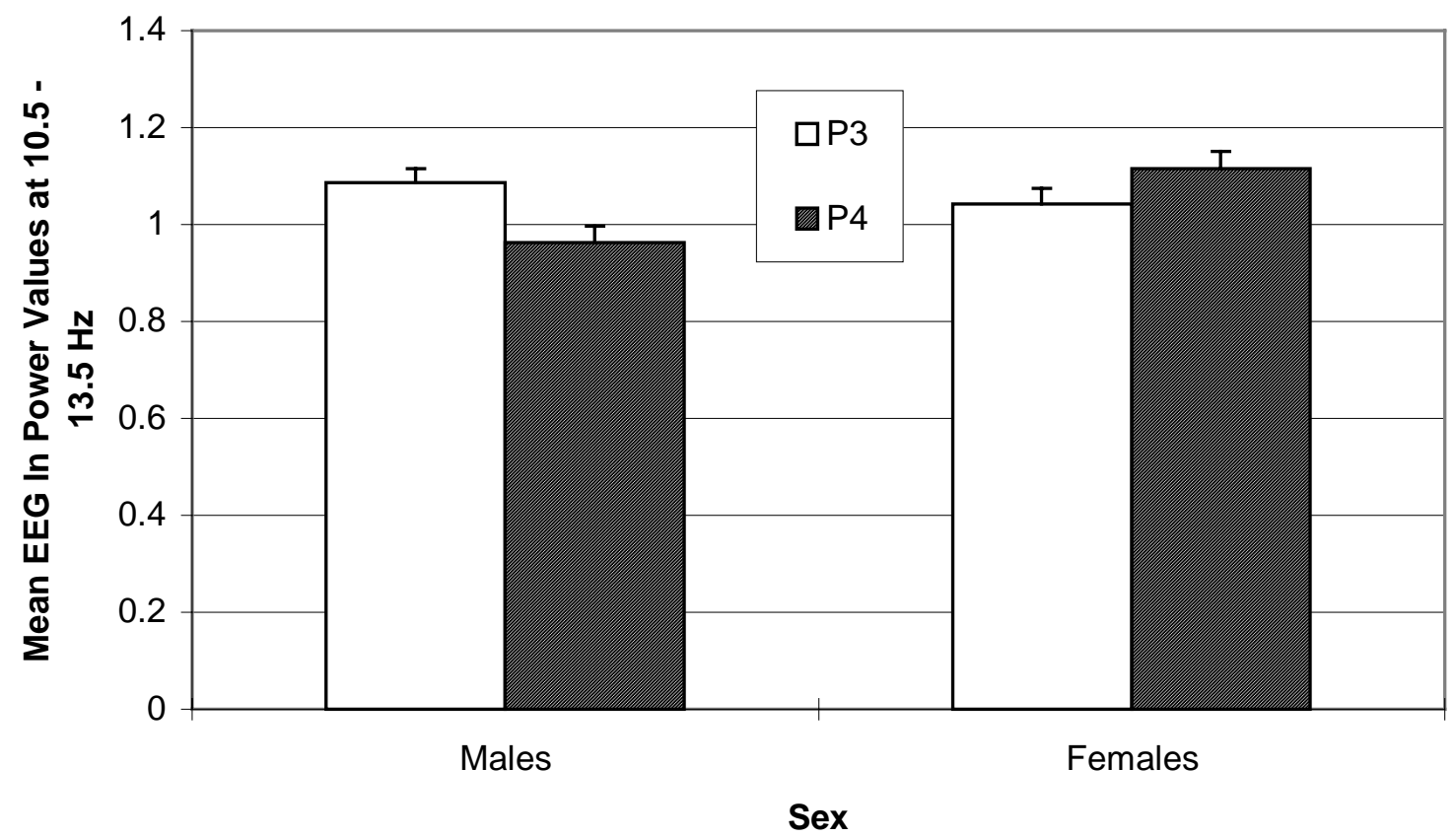

Figure 21j

Baseline EEG at Parietal Region:

Hemisphere by Sex Interaction 


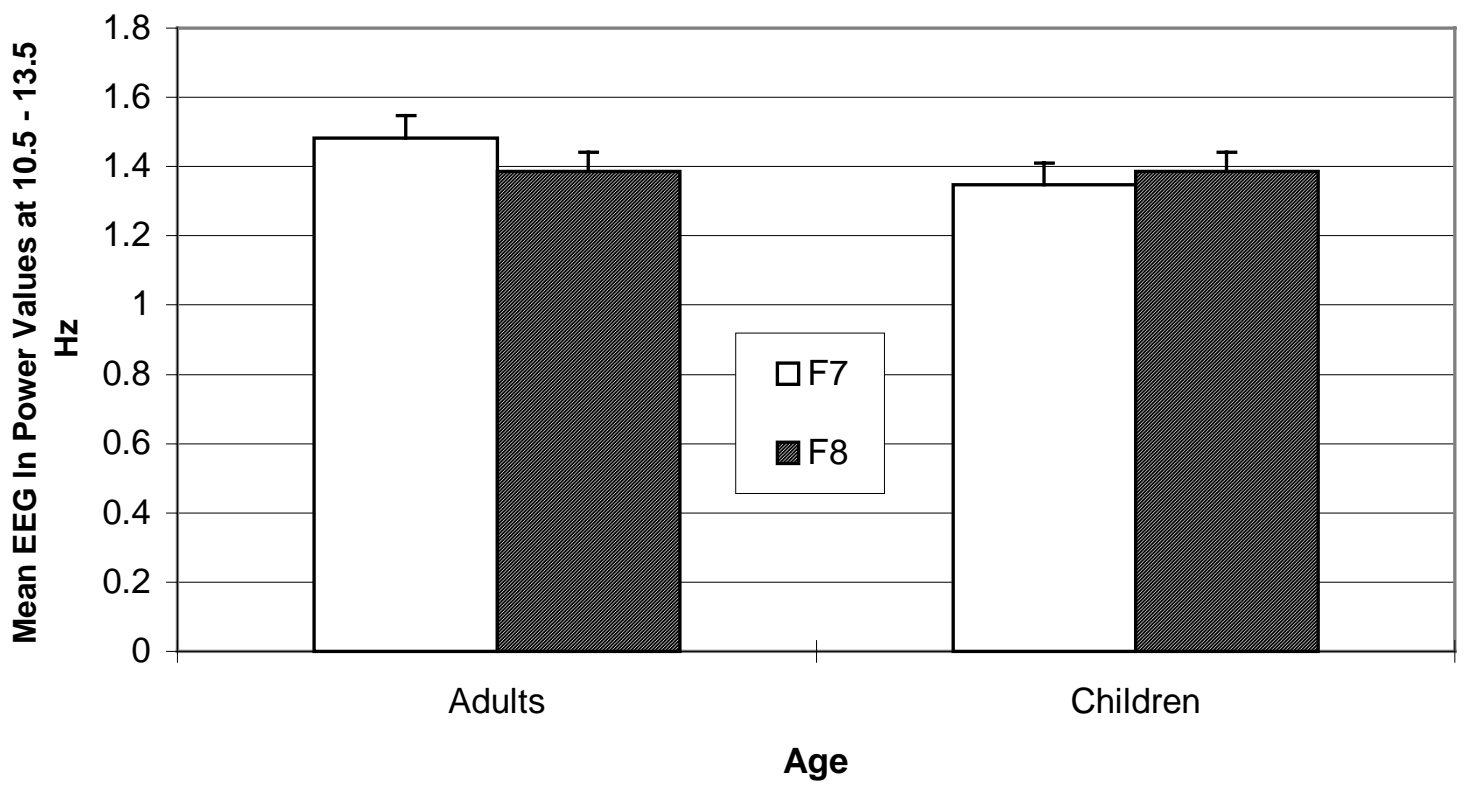

Figure 22j

2-Dimensional "Gingerbread Man" Mental Rotation Task EEG Covaried with Baseline EEG at Lateral Frontal Region: Hemisphere by Age Interaction 


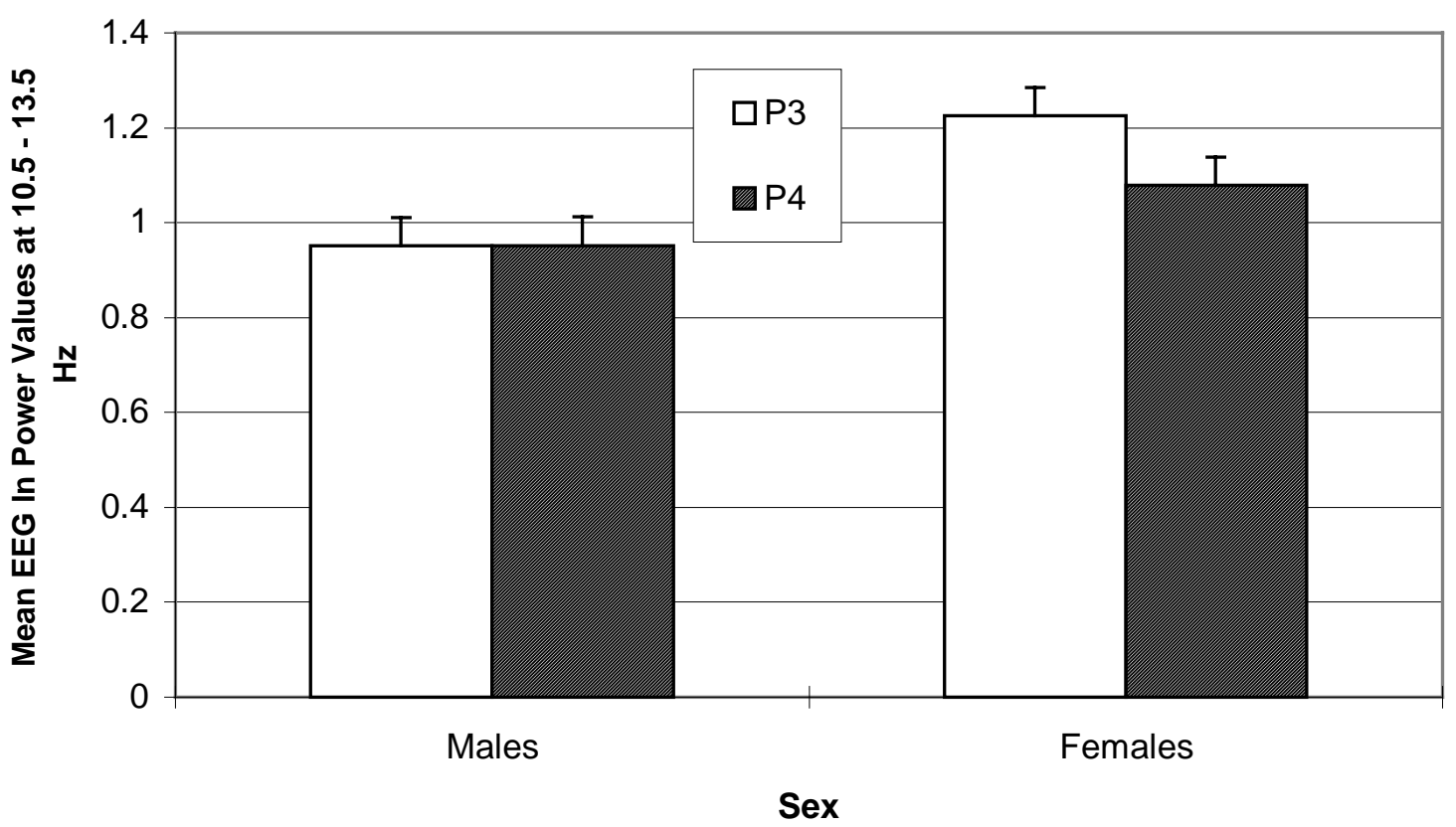

Figure 23j

2-Dimensional "Gingerbread Man" Mental Rotation Task EEG

Covaried with Baseline EEG at Parietal Region:

Hemisphere by Sex Interaction 


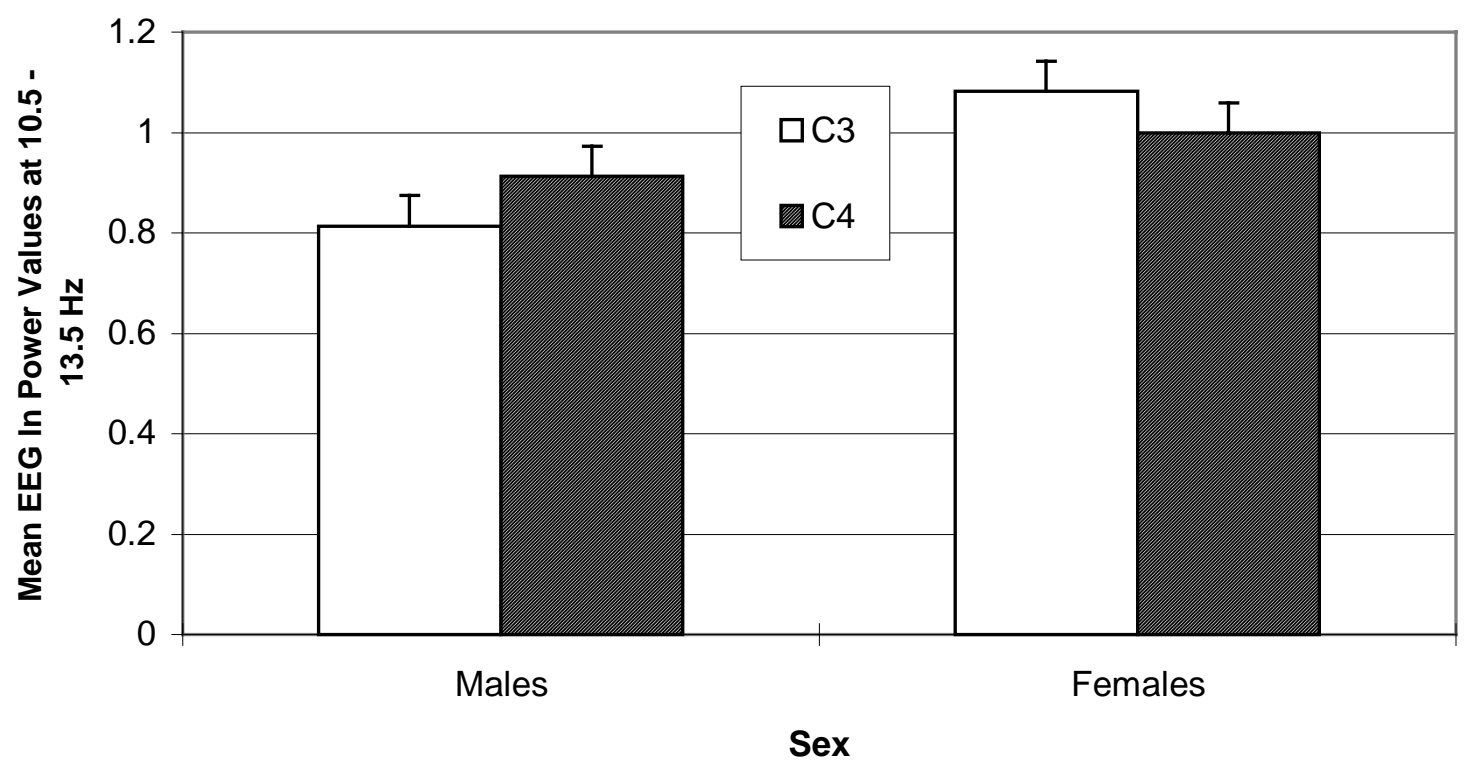

Figure 25j

2-Dimensional Alphanumeric Mental Rotation Task EEG Covaried with Baseline EEG at Central Region:

Hemisphere by Sex Interaction 


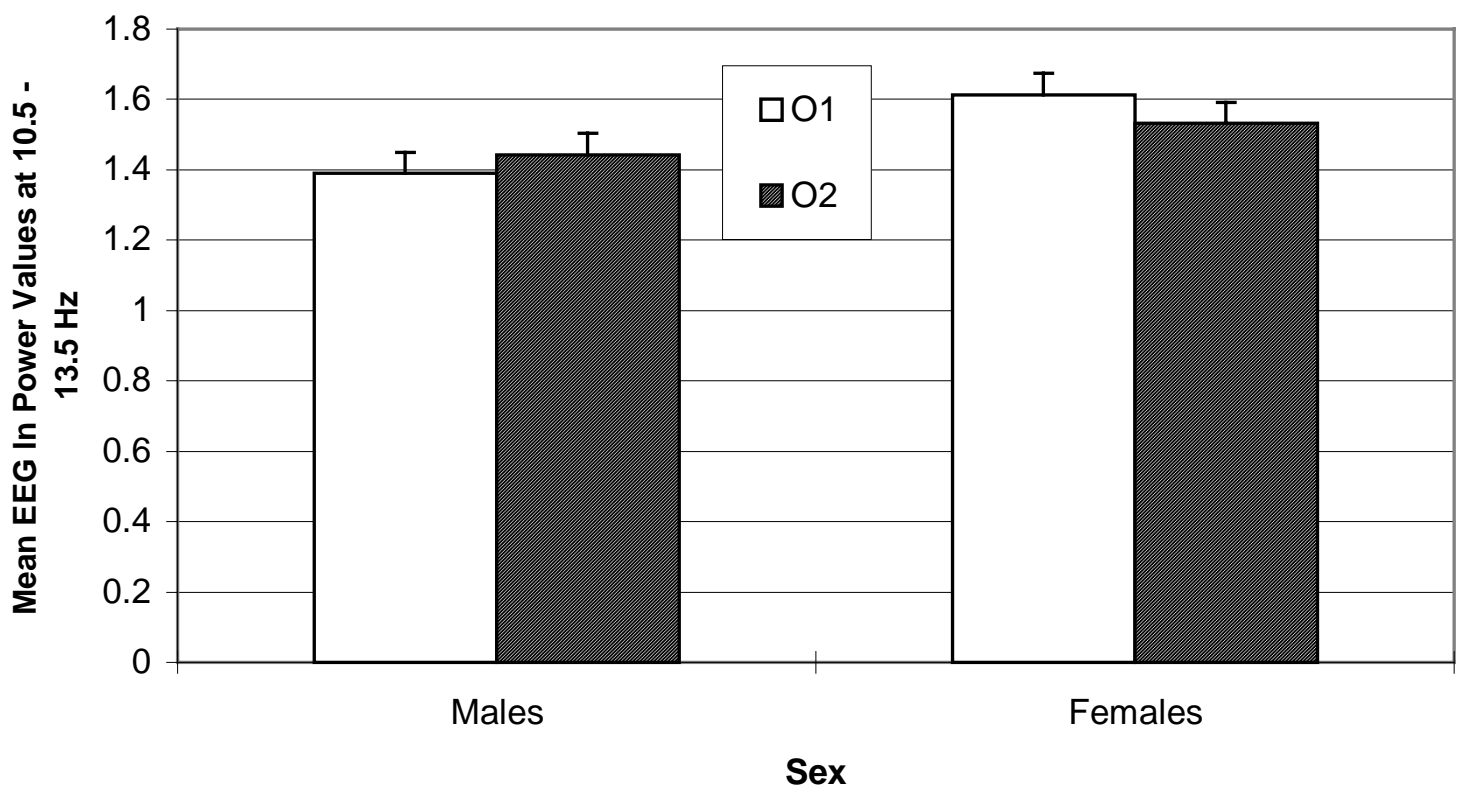

Figure 26j

2-Dimensional Alphanumeric Mental Rotation Task EEG

Covaried with Baseline EEG at Occipital Region:

Hemisphere by Sex Interaction 


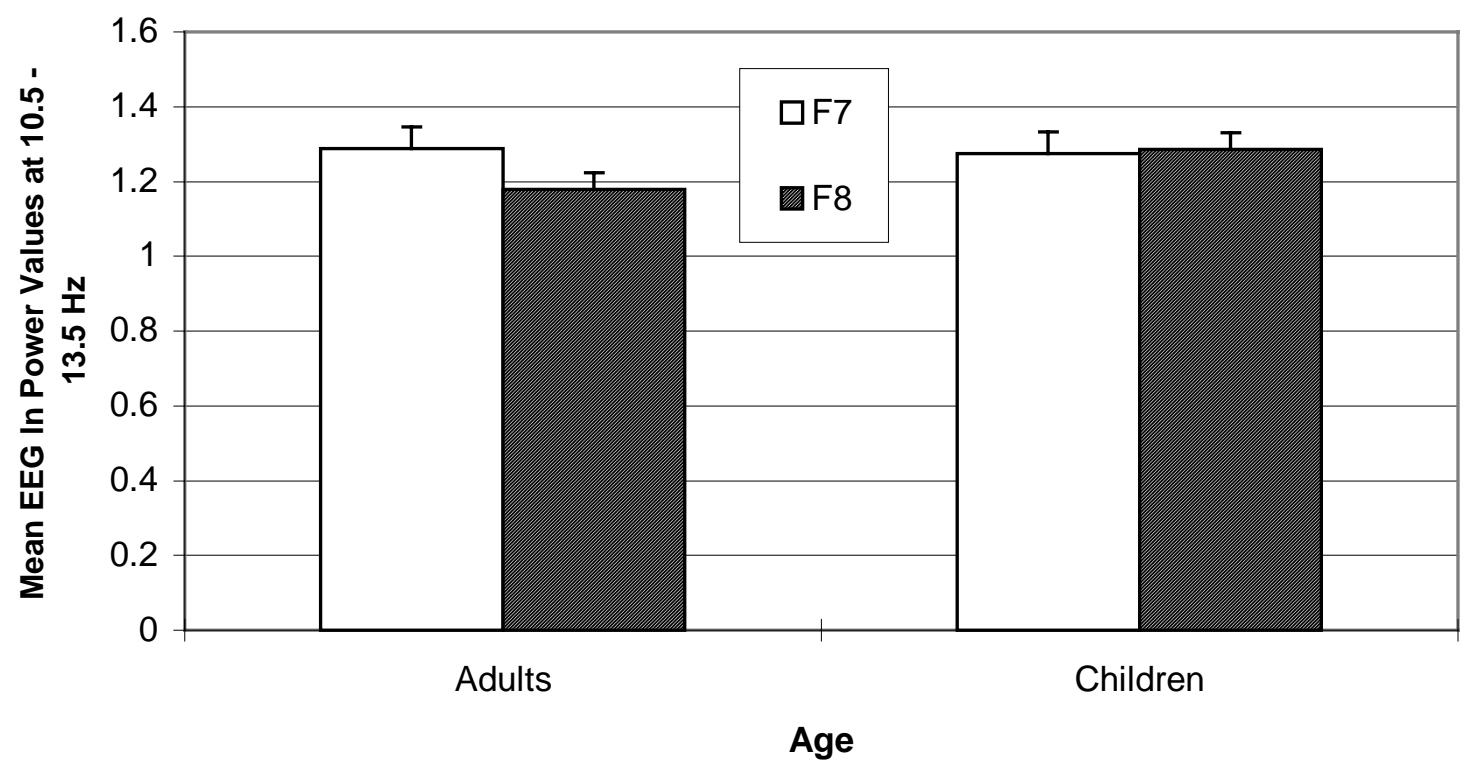

Figure 28j

3-Dimensional "Basketball Player" Mental Rotation Task EEG Covaried with Baseline EEG at Lateral Frontal Region: Hemisphere by Age Interaction 


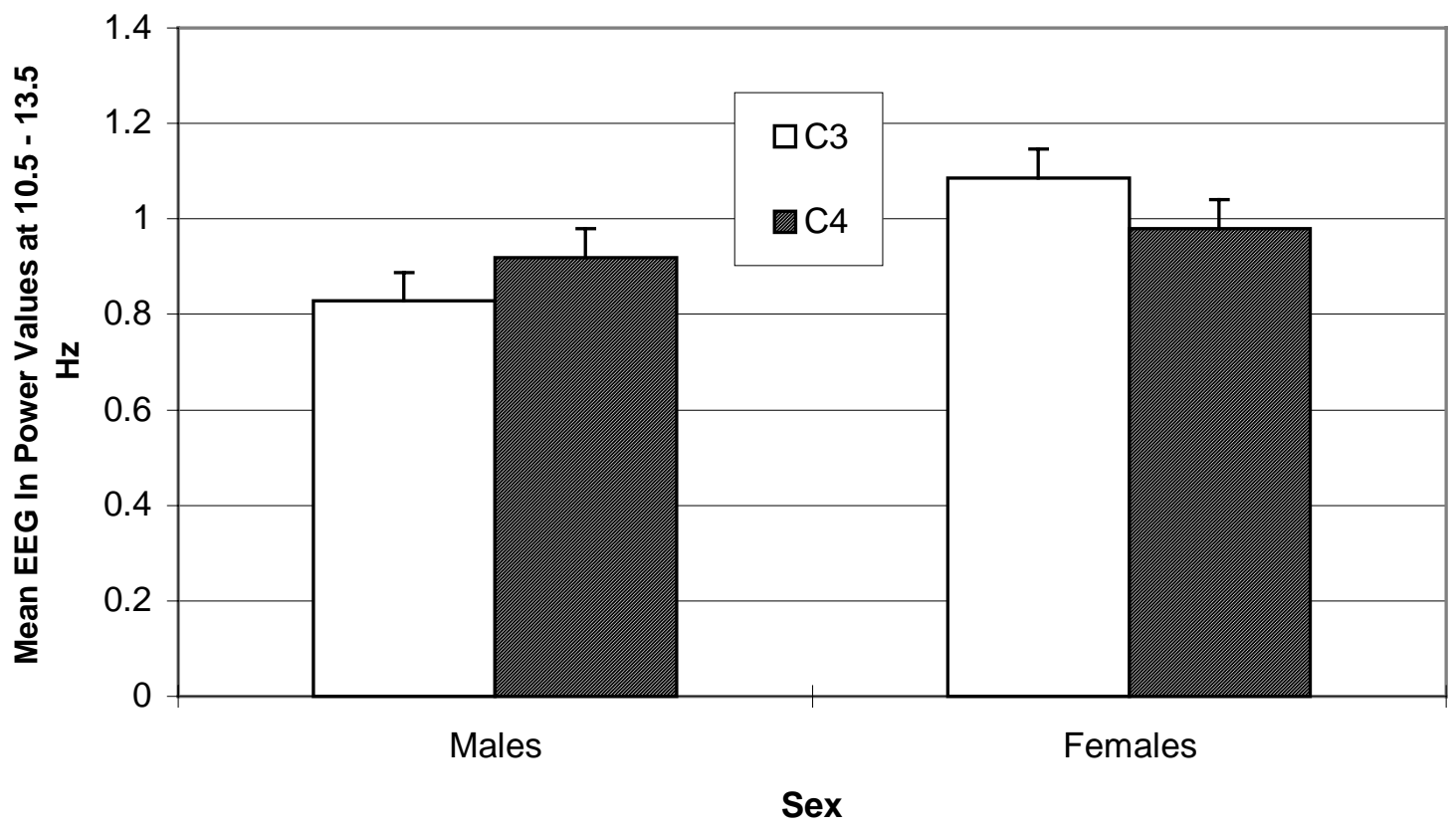

Figure 29j

3-Dimensional "Basketball Player" Mental Rotation Task EEG Covaried with Baseline EEG at Central Region:

Hemisphere by Sex Interaction 


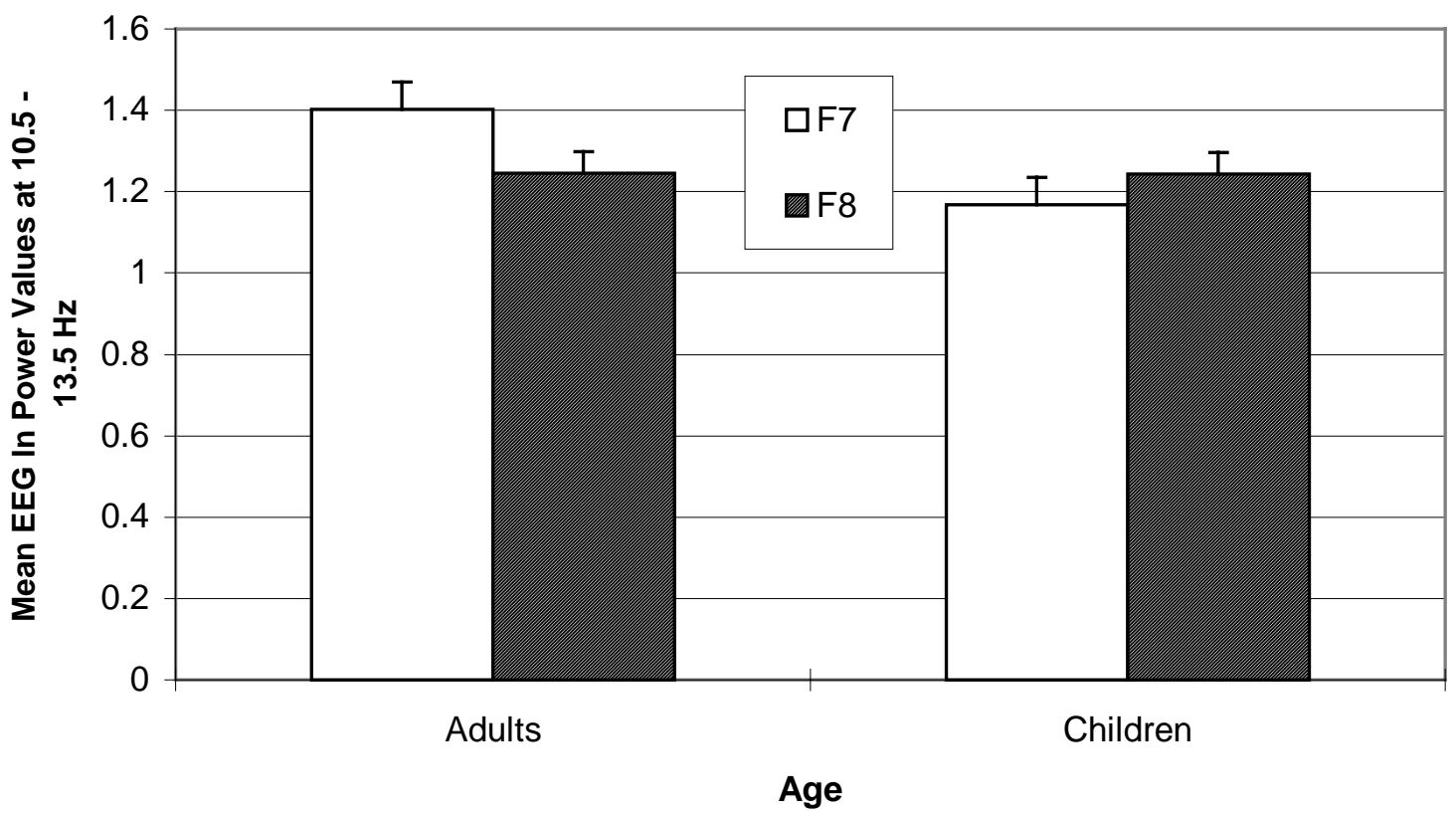

Figure 30j

Reading Task EEG Covaried with Baseline EEG at Lateral Frontal Region:

Hemisphere by Age Interaction 


\section{JONATHAN E. ROBERTS}

Office: Department of Psychology

Virginia Polytechnic Institute and State University

Blacksburg, VA 24061-0436

(540) 231-2320

jorober5@vt.edu
Home: 310 Shenandoah Circle

Blacksburg, VA 24060

\section{EDUCATION}

Ph.D. Psychology, Anticipated May, 2001

Virginia Polytechnic Institute and State University

Dissertation Title:

The Effects of Age and Sex on Mental Rotation Performance, Verbal Performance, and Brain Electrical Activity

Committee Chair: Martha Ann Bell, Ph.D.

M.S. Psychology, May 1999

Virginia Polytechnic Institute and State University

Thesis Title:

Sex Differences on a Mental Rotation Task: Variations in Hemispheric Activation

Between Children and College Students

Committee Chair: Martha Ann Bell, Ph.D.

University of South Carolina

Completed 1995-1996 year of experimental psychology program

Supervisor: Martha Ann Bell, Ph.D.

\section{B.A. Psychology, May 1995}

University of North Carolina, Wilmington

Wilmington, $\mathrm{NC}$

\section{TEACHING EXPERIENCE}

Instructor:

Sensation and Perception

Randolph-Macon Woman's College, Lynchburg, VA

Course and Laboratory Section

Fall, 2000

\section{Developmental Psychology}

Virginia Tech

Spring, 2000 
Cognitive Psychology

Virginia Tech

Fall, 1999

Advanced Social Psychology

Virginia Tech

Summer II, 1999; Summer II 2000

Psychology of Learning

Virginia Tech

Spring, 1999

Cognitive Psychology Laboratory

Virginia Tech

Fall, 1997 (2 sections); Fall 1998 (2 sections)

Social Psychology Laboratory

Virginia Tech

Summer, 1998

Introductory Psychology Laboratory

Virginia Tech

Fall 1996 (2 sections), Spring 1997 (3 sections), Spring 1998 (2 sections)

\section{EXPERIENCE TRAINING AND SUPERVISING UNDERGRADUATE RESEARCH ASSISTANTS}

\section{Graduate Research Assistant/Laboratory Manager}

Virginia Tech

- Trained and supervised a team of undergraduate research assistants for a project based in an infant cognitive development laboratory

- Assisted in setting up new psychophysiological laboratory

Supervisor: Martha Ann Bell, Ph.D.

1996-present

\section{Graduate Research Assistant}

University of South Carolina

- Participated in collecting object permanence and electrophysiological data from infants ages 5-11 months

- Received training in editing and analyzing EEG data

- Trained undergraduate research assistants

Supervisor: Martha Ann Bell, Ph.D.

1995-1996 
Undergraduate Research Assistant

University of North Carolina at Wilmington

- Conducted delayed non-matching to sample (DNMS) task with children

- Assisted with construction of materials used in task

- Assisted training others to conduct task

Supervisor: William Overman, Ph.D.

1994-1995

\section{HONORS}

"Showcase Poster" for Cognitive Psychology: Sex differences on a mental rotation task disappear with computer familiarization. Presented at the American Psychological Society $10^{\text {th }}$ Annual Convention, Washington, DC, May 1998

\section{PUBLICATIONS}

Roberts, J.E., \& Bell, M.A. (2000). Sex differences on a mental rotation task: Variations in EEG hemispheric activation between children and college students. Developmental Neuropsychology, 17, 199-224.

Roberts, J.E, Bell, M.A. (2000). Sex differences on a computerized mental rotation task disappear with computer familiarization. Perceptual and Motor Skills, 91, 1027-1034.

\section{PRESENTATIONS AT SCIENTIFIC MEETINGS}

Roberts, J.E, Bell, M.A. (2000, July). Focused attention in 8-month-old infants: Sex differences and context differences in examination and mouthing. Poster presented at the International Conference on Infant Studies, Brighton, England.

Roberts, J.E. (1999, April). Sex differences on a mental rotation task: Variations in hemispheric activation between children and college students. Poster presented at the Society for Research in Child Development, Albuquerque.

Roberts, J.E., Bell, M.A., \& Carlsen, R.M. (1998, May). Sex differences on a mental rotation task disappear with computer familiarization. Poster presented at the American Psychological Society $10^{\text {th }}$ Annual Convention, Washington, DC.

Roberts, J.E., Bell, M.A., Pope, S. (1998, April). Infant displacement and table displacement object search skills in infants $8 \& 10$ months of age. Poster presented at the International Conference on Infant Studies, Atlanta, GA. 
Roberts, J.E. (1997, April). Attention and mood are related to 8- and 10-month olds' performance on the A-not-B task. Poster presented at the Society for Research in Child Development, Washington, DC.

\section{ACCEPTED PRESENTATIONS}

Roberts, J.E (2001, April). Sex differences on spatial and verbal tasks: Variations in EEG activation between children and college students. Poster accepted for presentation at the Society for Research in Child Development, Minneapolis, MN.

Reed, L.I., Roberts, J.E, \& Bell, M.A. (2001, April). Heart period variability during cognitive processing in 8-year-old children. Poster accepted for presentation at the Society for Research in Child Development, Minneapolis, MN.

\section{PROFESSIONAL MEMBERSHIPS}

Student Member of:

American Psychological Society

International Society on Infant Studies

Society for Research in Child Development 